Key Words:

Hazardous Waste

Retention:

Permanent

\title{
2002 HYPERSPECTRAL ANALYSIS OF HAZARDOUS WASTE SITES ON THE SAVANNAH RIVER SITE
}

\author{
University of South Carolina \\ Westinghouse Savannah River Company \\ Texas A\&M University \\ SMP Enterprises
}

AUGUST 2003

Westinghouse Savannah River Company

Savannah River Site

Aiken, SC 29808

Prepared for the U.S. Department of Energy Under

Contract Number DE-AC09-96SR18500

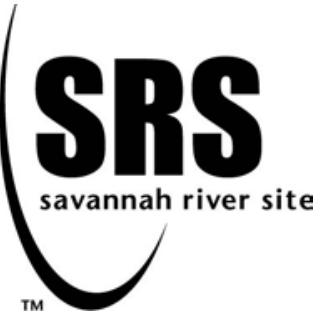


This document was prepared in conjunction with work accomplished under Contract No. DE-AC09-96SR18500 with the U. S. Department of Energy.

\section{DISCLAIMER}

This report was prepared as an account of work sponsored by an agency of the United States Government. Neither the United States Government nor any agency thereof, nor any of their employees, makes any warranty, express or implied, or assumes any legal liability or responsibility for the accuracy, completeness, or usefulness of any information, apparatus, product or process disclosed, or represents that its use would not infringe privately owned rights. Reference herein to any specific commercial product, process or service by trade name, trademark, manufacturer, or otherwise does not necessarily constitute or imply its endorsement, recommendation, or favoring by the United States Government or any agency thereof. The views and opinions of authors expressed herein do not necessarily state or reflect those of the United States Government or any agency thereof.

This report has been reproduced directly from the best available copy.

Available for sale to the public, in paper, from: U.S. Department of Commerce, National Technical Information Service, 5285 Port Royal Road, Springfield, VA 22161, phone: (800) 553-6847, fax: (703) 605-6900

email: orders@ntis.fedworld.gov

online ordering: http://www.ntis.gov/help/index.asp

Available electronically at http://www.osti.gov/bridge

Available for a processing fee to U.S. Department of Energy and its contractors, in paper, from: U.S. Department of Energy, Office of Scientific and Technical Information, P.O. Box 62, Oak Ridge, TN 37831-0062,

phone: (865)576-8401,

fax: (865)576-5728

email: $\underline{\text { reports@ adonis.osti.gov }}$ 
Key Words:

Hazardous Waste

Retention:

Permanent

\title{
2002 HYPERSPECTRAL ANALYSIS OF HAZARDOUS WASTE SITES
} ON THE SAVANNAH RIVER SITE

\author{
University of South Carolina \\ Westinghouse Savannah River Company \\ Texas A\&M University \\ SMP Enterprises
}

AUGUST 2003

Westinghouse Savannah River Company

Savannah River Site

Aiken, SC 29808

Prepared for the U.S. Department of Energy Under

Contract Number DE-AC09-96SR18500

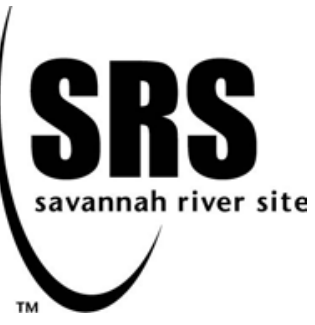




\section{RESEARCHERS AND AUTHORS}

John R. Jensen, Ph.D.

Brian C. Hadley

Jason A. Tullis

Center for GIS and Remote Sensing

Department of Geography

University of South Carolina

Columbia, SC 29208

jrjensen@sc.edu

hadleyb@mailbox.sc.edu

tullis@gwm.sc.edu

John Gladden, Ph.D.

Eric Nelson, Ph.D.

Steve Riley

Westinghouse Savannah River Company

Aiken, SC 29808

john.gladden@srs.gov

eric.nelson@srs.gov

rodney.riley@srs.gov

Tony Filippi, Ph.D.

Department of Geography

Texas A\&M University

College Station, Texas

filippi@tamu.edu

Malcolm Pendergast, Ph.D.

SMP Enterprises

Augusta, GA

mpendergast3@comcast.net 
WSRC-TR-2003-00275, REVISION 0

\section{TABLE OF CONTENTS}

1. Introduction

2. Multispectral versus Hyperspectral Data Collection at the Savannah River Site

2.1 Airborne Visible/Infrared Imaging Spectrometer (AVIRIS)

2.2 GER DAIS 3715 Remote Sensing System

2.2.1 Characteristics of the DAIS 3715 Data

2.2.2 Conversion of DAIS 3715 Hyperspectral Data to Radiance

3. In Situ Data Collection

3.1 Data Collection on the Clay Caps

3.2 Meteorological Conditions July 29-31, 2002

4. Hyperspectral Data Analysis to Extract Thematic Information on Hazardous Waste Sites

4.1 Initial Image Quality Assessment

4.1.1 Visual Examination of Color Composite Images Consisting of Three Bands

4.1.2 Visual Individual Band Examination

4.1.3 Animation

4.1.4 Statistical Individual Band Examination

5. Radiometric Preprocessing of GER DAIS 3715 Hyperspectral Data

5.1 Correcting for Remote Sensing System Induced Error

5.1.1. Line Drop-outs

5.1.2 N-line Striping Caused by Miscalibrated Detectors

5.1.2.1 De-striping Using Band and Line Mean and Standard Deviation Statistics

5.1.2.2 De-striping Using Fast Fourier Transform (FFT)

5.2 Correcting for Atmospheric Attenuation

5.2.1 ATmosphere REMoval Program - ATREM

5.2.2 Empirical Line Calibration - ELC

5.2.3 Atmospheric CORrection Now - ACORN

5.2.3.1 Single Spectrum Enhancement

5.2.4 Assessment of Empirical Line Calibration and ACORN Atmospheric Corrections

6. Geometric Preprocessing of GER Hyperspectral Data

6.1 Datum, Map Projection, Ellipsoid and the Selection of Ground Control Points

6.2 Nearest-neighbor Resampling

7. Reducing the Dimensionality of Hyperspectral Data While Retaining Its Information Content

7.1 Minimum Noise Fraction (MNF) Transformation

8. Endmember Determination - Finding Pixels with Relatively Pure Spectral Characteristics

8.1 Pixel Purity Index (PPI) Mapping

8.2 N-dimensional Endmember Visualization

9. Methods of Spectral Matching and Mapping Using Hyperspectral Data

9.1 Spectral Angle Mapper

10. Derivative Spectroscopy

9.1.1 Aaccuracy of the SAM-derived Thematic Map

10.1 First, Second, and Higher-order Derivative Images Derived from AVIRIS Data

11. Traditional and Hyperspectral Vegetation Indices

11.1 Normalized Difference Vegetation Indices

11.2 Narrow-band Derivative-based Vegetation Indices

11.2.1 Physiological Reflectance Index (PRI)

11.2.2 Normalized Difference Water Index (NDWI)

12. Summary

11.2.3 Red-edge Position (REP) Determination

13. References 
WSRC-TR-2003-00275, REVISION 0

This page intentionally left blank. 
WSRC-TR-2003-00275, REVISION 0

\section{Introduction}

Hazardous waste site inspection is a labor intensive, time consuming job, performed primarily on the ground using visual inspection and instrumentation. It is an expensive process to continually monitor hazardous waste and/or landfill sites to determine if they are maintaining their integrity. In certain instances, it may be possible to monitor aspects of the hazardous waste sites and landfills remotely. For instance, Vincent (1993) suggested the use of digital photogrammetry for surface water run-off prediction, estimation of water volume stored in landfill depressions, and other volumetric measurements. The utilization of multispectral data were suggested for the mapping of clays and iron oxides associated with contaminated groundwater, vegetation stress, and methane gas emissions (which require longer wavelength detectors). Irvine et al. (1997) examined the use of thermal imagery for the detection of buried waste trenches.

The Savannah River Site (SRS) near Aiken, S.C. is a United States Department of Energy facility operated by the Westinghouse Savannah River Company. For decades the SRS was responsible for developing weapons grade plutonium and other materials for the nation's nuclear defense. Hazardous waste was generated during this process. Waste storage site inspection is a particularly important issue at the SRS because there are over 100 hazardous waste sites scattered throughout the 300 mile $^{2}$ complex making it difficult to continually monitor all of the facilities. The goal is to use remote sensing technology to identify surface anomalies on the hazardous waste sites as early as possible so that remedial work can take place rapidly to maintain the integrity of the storage sites (Kelch et al., 2001). The anomalous areas are then targeted for intensive in situ human examination and measurement. During the 1990s, many of the hazardous waste sites were capped with protective layers of polyethelene sheeting and soil, and planted with bahia grass and/or centipede grass.

This research investigated hyperspectral remote sensing technology to determine if it can be used to measure accurately and monitor possible indicators of change on vegetated hazardous waste sites. Specifically, it evaluated the usefulness of hyperspectral remote sensing to assess the condition of vegetation on clay-caps on the Mixed Waste Management Facility (MWMF). This report first describes the principles of hyperspectral remote sensing. In situ measurement and hyperspectral remote sensing methods used to analyze hazardous waste sites on the Savannah River Site are then presented.

\section{Multispectral versus Hyperspectral Data Collection at the Savannah River Site}

Imaging spectrometry is "the simultaneous acquisition of images in many relatively narrow, contiguous and/or non-contiguous spectral bands throughout the ultraviolet, visible and infrared portions of the electromagnetic spectrum" (Jensen, 2000). The value of using an imaging spectrometer lies in its ability to provide a highresolution reflectance spectrum for each picture element in the image (Rubin, 1993; Kruse, 1994). For example, hundreds of bands in the spectral region from $0.4-2.5 \mu \mathrm{m}$ may be used to identify a large range of surface cover materials that cannot be identified with broadband, low-spectral-resolution imaging systems such as the Landsat Multispectral Scanner (MSS), Landsat Thematic Mapper (TM), or SPOT High Resolution Visible (HRV) sensors (Vane and Goetz, 1993; Jensen, 2000). Many surface materials, although not all, have diagnostic absorption features that are often only $20-40 \mathrm{~nm}$ wide. Therefore, imaging systems that acquire data in contiguous $10-30 \mathrm{~nm}$ bands may sometimes capture spectral data with sufficient resolution for the direct identification of those materials with diagnostic spectral features.

It has been possible to obtain relatively coarse multispectral remote sensor data using multiband aerial photography since the 1940s (Figure 1a). Multiband photography can now be obtained using digital frame cameras based on area array detectors (Figure 1b). More complex multispectral remote sensing instruments have traditionally been based on the use of a scanning mirror that focuses the radiant flux onto just a few detectors that are sensitive to relatively broad portions of the electromagnetic spectrum (Figure 1c), e.g., the Landsat 4 and 5 TM and the Landsat 7 Enhanced Thematic Mapper Plus (ETM+). To improve image geometry, some multispectral remote sensing systems utilize linear array technology (Figure 1d) to obtain data in relatively few bands (e.g., the SPOT HRV sensor system). 

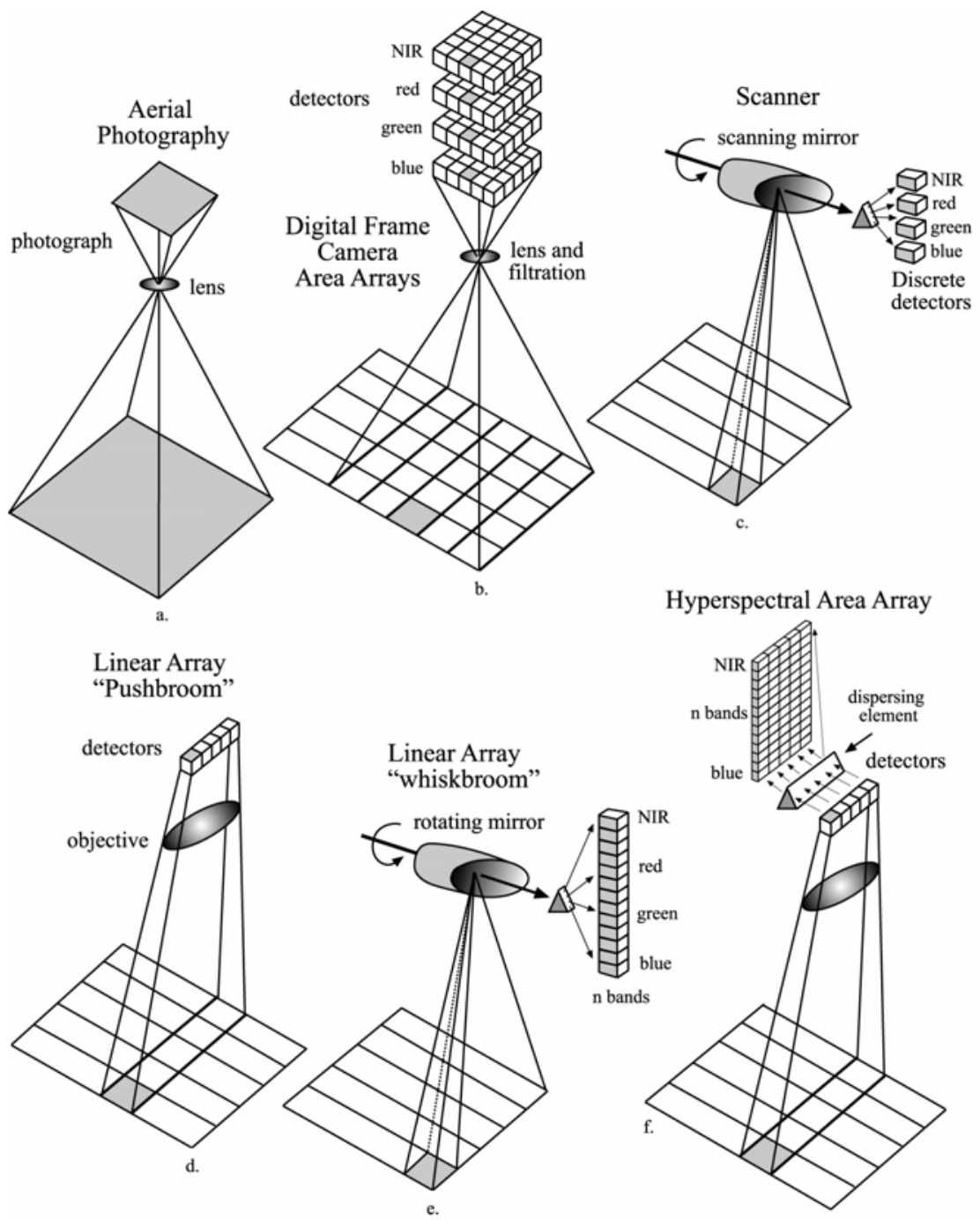

Figure 1. The GER DAIS 3715 hyperspectral remote sensing system used to collect the Savannah River Site imagery uses the linear array whiskbroom technology shown in "e".

The collection of spectral reflectance and/or emittance data in hundreds of spectral bands requires different approaches to remote sensor system design. Two approaches to imaging spectrometry are shown in Figures 1e and 1f. The "whiskbroom" scanner linear array approach is analogous to the scanner approach used for the Landsat $7 \mathrm{ETM}+$, except that radiant flux from within the instantaneous-field-of-view (IFOV) is passed onto a spectrometer, where it is dispersed and focused onto a linear array of detectors (Figure 1e). Thus, each pixel is simultaneously sensed in as many spectral bands as there are detector elements in the linear array. For high spatial resolution imaging (e.g., ground IFOVs of $10 \times 10$ to $30 \times 30 \mathrm{~m}$ ), this approach is suited only to airborne sensors that fly relatively slowly and the readout time of the detector array is a small fraction of the integration time. Ideally, an imaging spectrometer makes use of two-dimensional area arrays of detectors at the focal plane of the spectrometer. This eliminates the need for the optical scanning mechanism. In this situation, there is a dedicated column of spectral detector elements for each cross-track pixel in the scene (Figure 1f). 
WSRC-TR-2003-00275, REVISION 0

Broadband remote sensing systems such as the Landsat MSS or SPOT HRV under-sample the information content available from a reflectance spectrum by making only a few measurements in spectral bands sometimes several hundred nanometers wide. Conversely, imaging spectrometers may sample in hundreds of bands that are typically only tens of nanometers wide. Analysis of imaging spectrometer data allows extraction of a detailed spectrum for each picture element in the image. Such spectra can facilitate identification of specific materials within the IFOV of the sensor based upon their reflectance characteristics, such as minerals, atmospheric gases, vegetation, snow and ice, and dissolved matter in water bodies (Kruse, 1994).

\subsection{Airborne Visible/Infrared Imaging Spectrometer (AVIRIS)}

The first airborne imaging spectrometer was built to test the imaging spectrometer concept with infrared area arrays (Goetz et al., 1985; Vane and Goetz, 1993). The Airborne Visible/Infrared Imaging Spectrometer (AVIRIS) was developed by engineers at NASA's Jet Propulsion Laboratory to acquire data with greater spectral and spatial coverage. Previous research at the Savannah River Site used AVIRIS high spectral (224 bands) and spatial $(3.5 \times 3.5 \mathrm{~m})$ resolution imagery. Please consult Kelch et al. (2001) for a summary of the analysis of the Savannah River Site Mixed Waste Management Facility (MWMF) and H-Area using AVIRIS hyperspectral data obtained in July, 1999.

\subsection{GER DAIS 3715 Remote Sensing System}

The Digital Airborne Imaging Spectrometer (DAIS) 3715 was developed by the Geophysical and Environmental Research Corporation (GER). Its characteristics are summarized in Table 1. The hyperspectral sensor acquires images in 35 bands in the 488 to 2,094 nm region using a whiskbroom scanning mirror and linear arrays of silicon $(\mathrm{Si})$, germanium $(\mathrm{Ge})$, and indium-antimonide $(\mathrm{In}: \mathrm{Sb})$ detectors. The sensor system was flown onboard an aircraft at several altitudes above-ground-level (AGL) over the clay-capped hazardous waste sites at the Savannah River Site on July 31, 2002. One dataset was obtained at $730 \mathrm{~m}$ AGL (Figure 2) resulting in a nominal spatial resolution of $2.4 \times 2.4 \mathrm{~m}$ per pixel based on the 3.3 milliradian (mrad) IFOV of the sensor system (SpectraTech, 2002). DAIS 3715 data were recorded in 15 bits.

Table 1. Characteristics of the GER DAIS 3715 Hyperspectral remote sensing system.

\begin{tabular}{|c|c|c|c|c|c|c|c|}
\hline Sensor & Technology & $\begin{array}{c}\text { Spectral } \\
\text { Ranges } \\
(\mathrm{nm}) \\
\end{array}$ & Detector & $\begin{array}{c}\text { Nominal } \\
\text { Channel } \\
\text { Bandwidth }(\mathrm{nm})\end{array}$ & $\begin{array}{c}\text { Number of } \\
\text { Channels } \\
\text { (out of } 37 \text { total) }\end{array}$ & $\begin{array}{c}\text { IFOV } \\
\text { (mrad) }\end{array}$ & $\begin{array}{c}\text { Radiometric } \\
\text { Resolution } \\
\text { (bits) } \\
\end{array}$ \\
\hline DAIS 3715 & $\begin{array}{c}\text { Linear Array } \\
\text { (Whiskbroom) }\end{array}$ & $\begin{array}{c}488-928 \\
1248-1648 \\
2048-2094 \\
3017-4107 \\
9187-9477\end{array}$ & $\begin{array}{c}\mathrm{Si} \\
\mathrm{Ge} \\
\mathrm{In}: \mathrm{Sb} \\
\mathrm{In}: \mathrm{Sb} \\
\mathrm{Hg}: \mathrm{Cd}: \mathrm{Te}\end{array}$ & $\begin{array}{c}31 \\
400 \\
52 \\
1090 \\
290\end{array}$ & $\begin{array}{c}24 \\
1 \\
10 \\
1 \\
1\end{array}$ & 3.3 & 15 \\
\hline
\end{tabular}




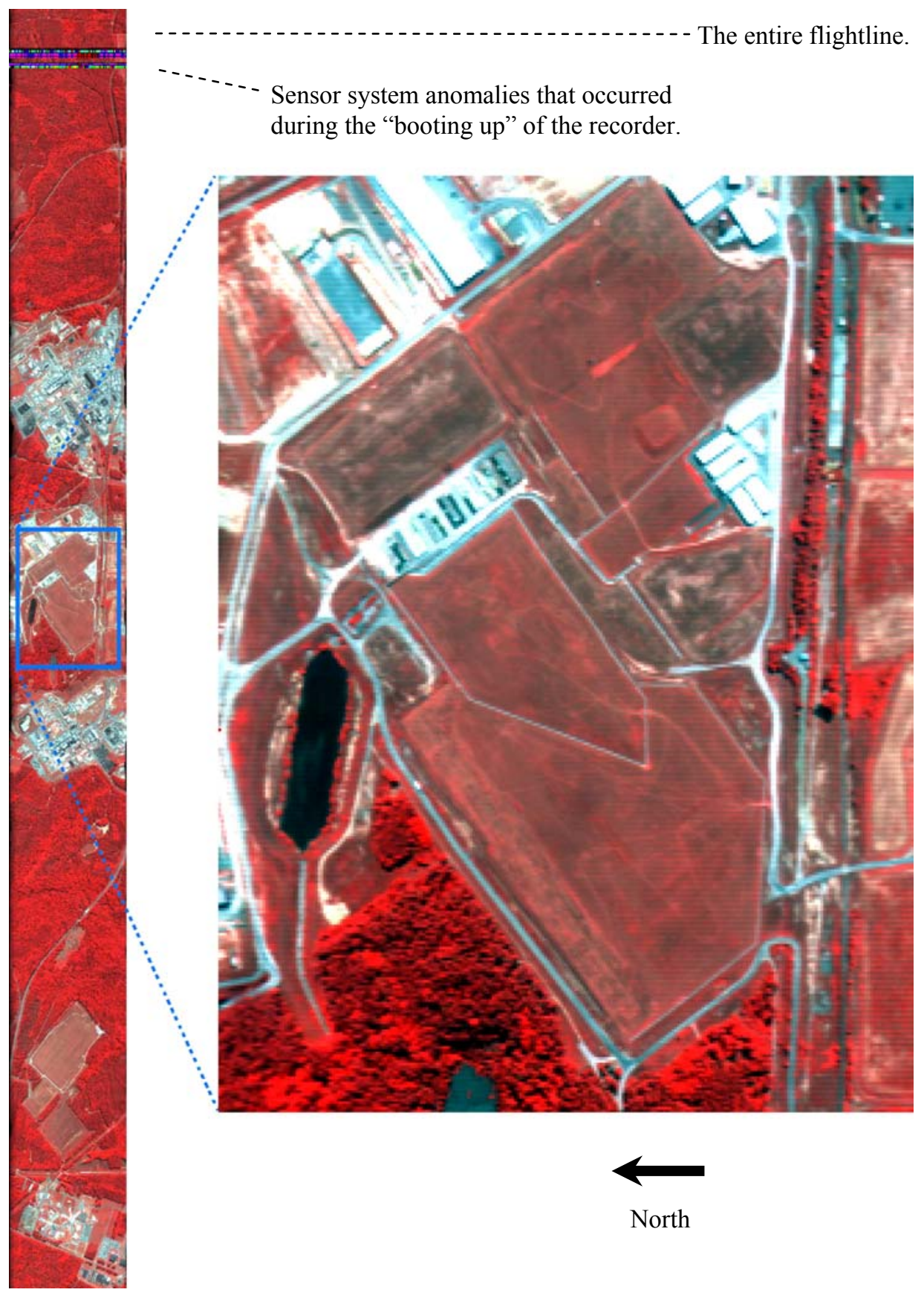

Figure 2. GER DAIS 3715 Flight line \# 05 with an enlargement of the Mixed Waste Management Facility on the Savannah River Site. Images are displayed with RGB = bands 20 (near-infrared), 10 (red), 5 (green). The images are not geometrically rectified. 


\subsubsection{Characteristics of the DAIS 3715 Data}

The DAIS 3715 hyperspectral data were subjected to minimal pre-processing using GER software prior to delivery to the University of South Carolina. This initial pre-processing on the data included gyro, baseline, and panoramic corrections (GER, 1998). The gyro correction removed the effects of aircraft motion (yaw, pitch, and roll). Baseline correction normalized each individual line and channel of the data using on-board reference panels. Panoramic correction adjusted for geometric distortions caused by variation in viewing geometry accross each scanline.

The raw brightness values in the DAIS 3715 flight-line were in units of $c t$ (abbreviation for "count"). The signed 16-bit integers ranged from $-32,768$ to 32,767 . Forty (40) channels were included in the data file. Channels 36 and 37 included thermal measurements and channels (bands) 38 through 40 contained "no-data". These channels were removed from further consideration. Only the first 35 channels were analyzed (Table 2).

Table 2. Characteristics of the DAIS 3715 channels (bands). The min, max, mean, and standard deviation summarize pixel values found within a relatively small study area in the original flight line. FWHM stands for full-width-at-half-maximum.

\begin{tabular}{|c|c|c|c|c|c|c|c|}
\hline Channel & Detector & $\begin{array}{c}\text { Center } \\
\text { Wavelength } \\
(\mathrm{nm})\end{array}$ & $\begin{array}{c}\text { FWHM } \\
(\mathrm{nm})\end{array}$ & Min & Max & Mean & $\begin{array}{l}\text { Standard } \\
\text { Deviation }\end{array}$ \\
\hline 1 & \multirow{24}{*}{$\mathrm{Si}$} & 509.3 & 43 & 141 & 6847 & 775.602 & 581.488 \\
\hline 2 & & 519.7 & 45.2 & 170 & 8697 & 991.2229 & 733.8801 \\
\hline 3 & & 532.9 & 44 & 214 & 10256 & 1189.487 & 865.2638 \\
\hline 4 & & 549.6 & 34.8 & 232 & 11736 & 1382.37 & 992.798 \\
\hline 5 & & 566 & 35.9 & 238 & 12540 & 1500.839 & 1074.251 \\
\hline 6 & & 585.5 & 29.6 & 239 & 13407 & 1619.731 & 1161.159 \\
\hline 7 & & 604.8 & 32.3 & 233 & 13634 & 1665.663 & 1197.197 \\
\hline 8 & & 627.6 & 28.4 & 210 & 13570 & 1676.878 & 1202.301 \\
\hline 9 & & 644.3 & 26.2 & 199 & 13068 & 1651.265 & 1170.296 \\
\hline 10 & & 663.4 & 31.1 & 192 & 11894 & 1567.327 & 1064.035 \\
\hline 11 & & 682.4 & 28.6 & 184 & 9889 & 1408.548 & 875.0672 \\
\hline 12 & & 701.1 & 28.4 & 232 & 8518 & 1354.903 & 724.8893 \\
\hline 13 & & 714.8 & 29 & 288 & 8000 & 1421.297 & 649.1845 \\
\hline 14 & & 732.1 & 29.8 & 317 & 7123 & 1410.074 & 551.6079 \\
\hline 15 & & 749.9 & 32 & 267 & 6453 & 1401.931 & 484.7782 \\
\hline 16 & & 772.5 & 27.9 & 240 & 5854 & 1359.693 & 431.9986 \\
\hline 17 & & 787.6 & 29.3 & 220 & 5260 & 1286.181 & 384.7054 \\
\hline 18 & & 806.6 & 29.9 & 185 & 4804 & 1217.818 & 346.7756 \\
\hline 19 & & 826.6 & 28.8 & 156 & 4416 & 1148.154 & 314.4437 \\
\hline 20 & & 847.5 & 26.7 & 131 & 4190 & 1116.107 & 296.5812 \\
\hline 21 & & 864.1 & 27.2 & 117 & 4043 & 1101.459 & 286.0367 \\
\hline 22 & & 882.2 & 27.3 & 98 & 3679 & 1015.511 & 259.595 \\
\hline 23 & & 899.7 & 25.6 & 75 & 3215 & 900.4928 & 227.0394 \\
\hline 24 & & 916.4 & 24 & 44 & 2572 & 730.8312 & 182.7046 \\
\hline 25 & $\mathrm{Ge}$ & 1447.8 & 400 & -812 & 15531 & 8234.117 & 2092.295 \\
\hline 26 & \multirow{10}{*}{$\mathrm{In}: \mathrm{Sb}$} & 2070.6 & 45.8 & -23 & 527 & 146.023 & 73.89188 \\
\hline 27 & & 2097.1 & 43.8 & -21 & 566 & 167.6695 & 82.58671 \\
\hline 28 & & 2125.9 & 59.7 & -23 & 526 & 163.3018 & 78.11213 \\
\hline 29 & & 2161.6 & 48 & -16 & 442 & 139.2517 & 64.02139 \\
\hline 30 & & 2191.1 & 53.2 & -17 & 346 & 112.651 & 50.91118 \\
\hline 31 & & 2217.4 & 56.8 & -25 & 315 & 97.50239 & 44.48464 \\
\hline 32 & & 2241.8 & 49.2 & -54 & 1426 & 407.3536 & 187.9201 \\
\hline 33 & & 2271.2 & 58 & -18 & 271 & 74.89639 & 35.95628 \\
\hline 34 & & 2302.5 & 62.7 & -8 & 104 & 30.1528 & 14.76763 \\
\hline 35 & & 2364.7 & 42.7 & -15 & 123 & 32.28723 & 16.64128 \\
\hline
\end{tabular}


WSRC-TR-2003-00275, REVISION 0

Negative values in channels 1 through 24 were associated with areas of "no-data" along the periphery and at the beginning of the flightline. "No-data" along the periphery of the flightline was the result of aircraft motion and panoramic correction performed by SpectraTech using GER software. "No-data" lines at the beginning of the flightline were the result of sensor system anomalies during the "booting-up" of the recorder (Terry, 2002). Table 2 summarizes the statistical characteristics of the hyperspectral data in a relatively small study area. Channels 25-35 contained some negative values primarily for pixels associated with waterbodies and areas in dark shadows. GER (2002) indicated that the onboard baseline correction sometimes resulted in the recording of negative values over very dark areas with a low signal-to-noise ratio. All negative values were recoded to zero. No negative values were recorded over the hazardous waste sites.

\subsubsection{Conversion of DAIS 3715 Hyperspectral Data to Radiance}

Hyperspectral imagery must be in units of radiance, $L$, prior to atmospheric correction. The radiance units required are watts per meter squared per steradian per micrometer:

$$
\frac{W}{m^{2} \cdot s r \cdot \mu m}
$$

The DAIS 3715 imagery was provided in units of count $(c t)$. Therefore, additional calibration was required beyond the on-board, baseline calibration previously discussed. To accomplish this, a conversion factor for each channel was applied to the imagery. Conversion factors provided by GER are typically in units of microwatts per centimeter squared per steradian per nanometer per count:

$$
\frac{10^{-6} W}{\mathrm{~cm}^{2} \cdot \mathrm{sr} \cdot \mathrm{nm} \cdot \mathrm{ct}}
$$

Unfortunately, the table of conversion factors for the DAIS 3715 sensor (3.3 mrad) used to record the SRS hazardous waste site data on July 31, 2002 was lost (Chang, 2002). Therefore, GER personnel provided an aperture correction term that was used in lieu of the actual calibration information. A 6 mrad aperature correction table was modified using the aperture correction term for each band which approximated the DAIS $3.3 \mathrm{mrad}$ aperature used to collect SRS data. Chang (2002) indicated that this approximation of radiance would be very close to what would be obtained using the actual conversion factors.

Radiance (in the required units) for a given channel was calculated using the following logic given the known units of the original hyperspectral imagery, the conversion factors, and the aperture correction factor:

$$
[\text { radiance in required units }]=[\text { raw pixels }] \times[\text { conversion factor }] \times[\text { units conversion }] \times[\text { aperture correction }]
$$

Corresponding to the above logic, Equation 1 was used to convert the data from raw pixels, in $c t$, to radiance in the required units:

$$
\begin{aligned}
& {\left[\frac{W}{m^{2} \cdot s r \cdot \mu m}\right]=[c t] \times\left[\frac{10^{-6} W}{c m^{2} \cdot s r \cdot n m \cdot c t}\right] \times\left[\left(\frac{10^{4} \mathrm{~cm}^{2}}{\mathrm{~m}^{2}}\right) \times\left(\frac{10^{3} \mathrm{~nm}}{\mu m}\right)\right] \times[0.3025]}
\end{aligned}
$$

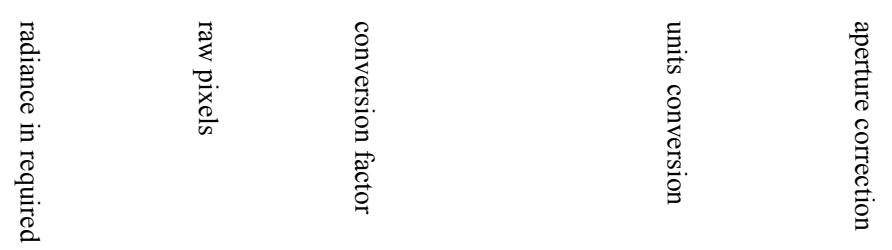


WSRC-TR-2003-00275, REVISION 0

\section{In situ Data Collection}

\subsection{Data Collection on the Clay Caps}

In situ data were collected at the Mixed Waste Management Facility and the H-Area clay cap to determine the effectiveness of remote sensing for documenting changes in the vegetation characterisitcs of hazardous waste sites on the SRS. Personnel from the SRS and from the Center for GIS and Remote Sensing Laboratory at the University of South Carolina, Columbia collected the field data over a period between July 29-30, 2002. The locations of the in situ sample points obtained on the MWMF are shown in Figure 3. The type of information collected is summarized in Table 3.

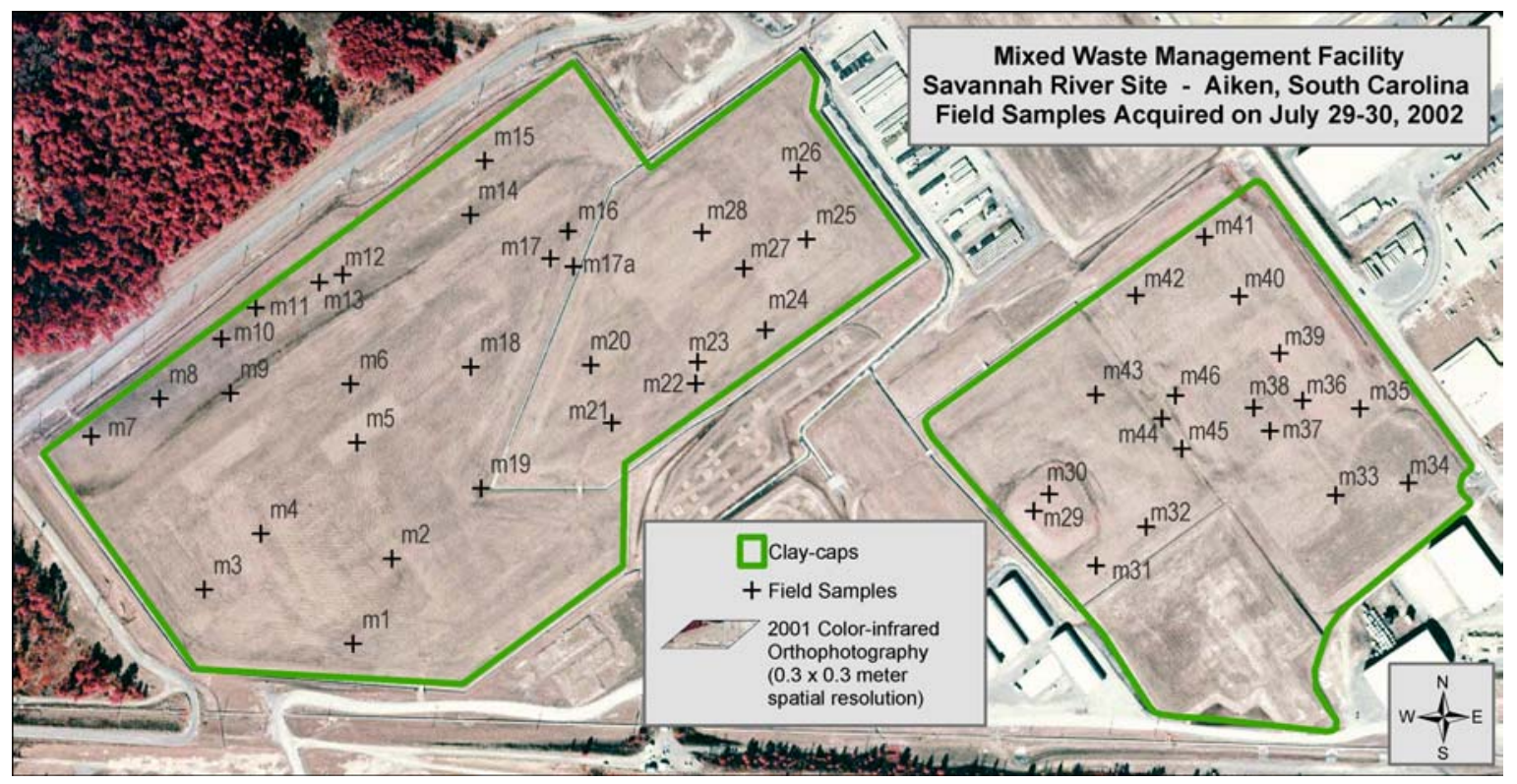

Figure 3. The location of in situ sample points on the Mixed Waste Management Facility measured July 29-30, 2002 overlaid on $0.3 \times 0.3 \mathrm{~m}$ digitized color-infrared orthophotography. 
WSRC-TR-2003-00275, REVISION 0

Table 3. In situ measurements obtained to calibrate the remote sensor data and determine the condition of vegetation on the Mixed Waste Management Facility July 29-30, 2002.

\begin{tabular}{|c|c|c|}
\hline In situ Measurement & Date & Domain / Classes \\
\hline Vegetation & July 29-30, 2002 & $\begin{array}{cl}\text { - } & \text { Primary Species: } \\
0 & \text { Bahiagrass (1) } \\
0 & \text { Centipede (2) } \\
0 & \text { Other (3) } \\
\text { - } & \text { Secondary Species } \\
\text { - } & \text { Percent Primary Species } \\
\text { - } & \text { Percent Secondary Species }\end{array}$ \\
\hline $\begin{array}{l}\text { Geographic location }(x, y) \text { of site locations using } \\
\text { global positioning systems (GPS) }\end{array}$ & July 29-30, 2002 & $\begin{array}{lccc}\text { Universal } & \text { Transverse } & \text { Mercator } & \text { NAD27 } \\
\text { Easting, Northing } & & \\
\end{array}$ \\
\hline $\begin{array}{l}\text { Stomatal conductance of bahiagrass and/or } \\
\text { centipede }\end{array}$ & July 29-30, 2002 & Mmol $\cdot m^{-2} \cdot s^{-1}$ \\
\hline $\begin{array}{l}\text { Biomass (dry above-ground) of bahiagrass and/or } \\
\text { centipede }\end{array}$ & July 29-30, 2002 & $g \cdot m^{-2} \quad($ dry grams $)$ \\
\hline $\begin{array}{l}\text { Vegetation stress (subjective assessment by a } \\
\text { biologist) }\end{array}$ & July 29-30, 2002 & $\begin{array}{l}\text { Presence (1) } \\
\text { Absence (0) }\end{array}$ \\
\hline $\begin{array}{l}\text { Elevation (z) derived from SRS professionally } \\
\text { surveyed point measurements }\end{array}$ & July 29-30, 2002 & Feet above mean sea level (MSL) \\
\hline $\begin{array}{l}\text { Spectral reflectance using a hand-held Analytical } \\
\text { Spectral Devices (ASD) spectroradiometer }\end{array}$ & July 29-30, 2002 & $\begin{array}{l}\text { Percent reflectance in } 2,150 \text { channels from } 400 \\
-2,500 \mathrm{~nm} \text {. }\end{array}$ \\
\hline
\end{tabular}

Data on vegetation cover included the identification of primary and secondary species and the percentage composition of each. Vegetation species on the clay cap were categorized as either bahia grass, centipede grass, or "other". In situ spectral measurements were collected using an ASD (Analytical Spectral Devices) spectroradiometer that covered the same spectral range as the DAIS 3715 hyperspectral remote sensing device (i.e., $0.4-2.5 \mu \mathrm{m}$ ). Spectroradiometer measurements were calibrated using a standard reference panel as shown in Figure 4a. The reflectance characteristics of large dark and light calibration panels were measured using the ASD spectroradiometer (Figure 4c). 


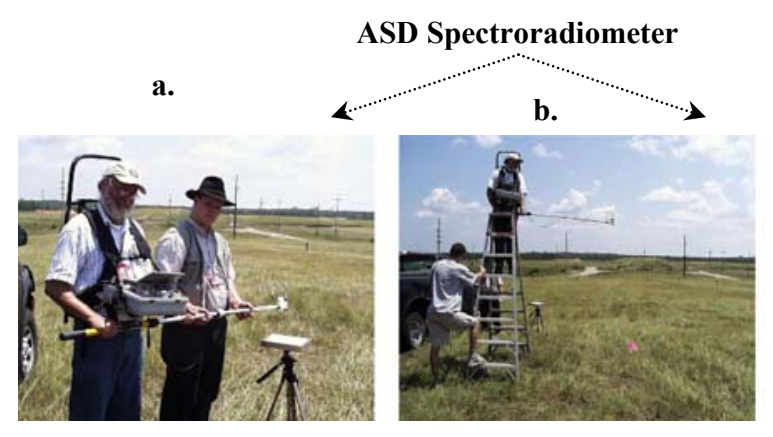

Calibration Panels

c.

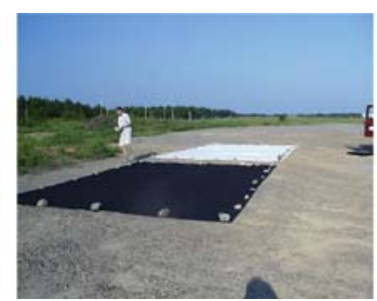

Kaolinite

d.

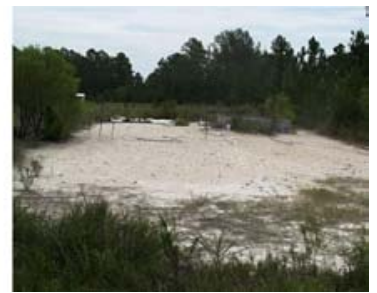

Figure 4. a) In situ spectral measurements were obtained using an ASD handheld spectroradiometer. In this example a measurement is being acquired from the standard reference panel mounted on the tripod. b) Vegetation spectral reflectance was measureed at approximately $2.5 \mathrm{~m}$ above the ground. c) Calibration panels composed of black and white textile were located on tarmac. d) A nearby kaolinite deposit was also used as a ground control/calibration target.

\subsection{Meteorological Conditions July 29-31, 2002}

Weather conditions during the 3-day period were similar with clear hazy mornings with scattered cumulus clouds building during the early afternoon (Pendergast, 2002). A plot of incoming solar radiation measured at the SRS Central Climatology tower $3 \mathrm{~km}$ south of the MWMF is shown in Figure 5. There is a gradual increase in insolation starting at 10:30 GMT and reaching maxima at 16:30 GMT for July 29 and July 30, 2002. On July 31, 2002 scattered clouds passed over the MWMF and the Central Climatology site resulting in insolation fluctuations at about 13:00 GMT.

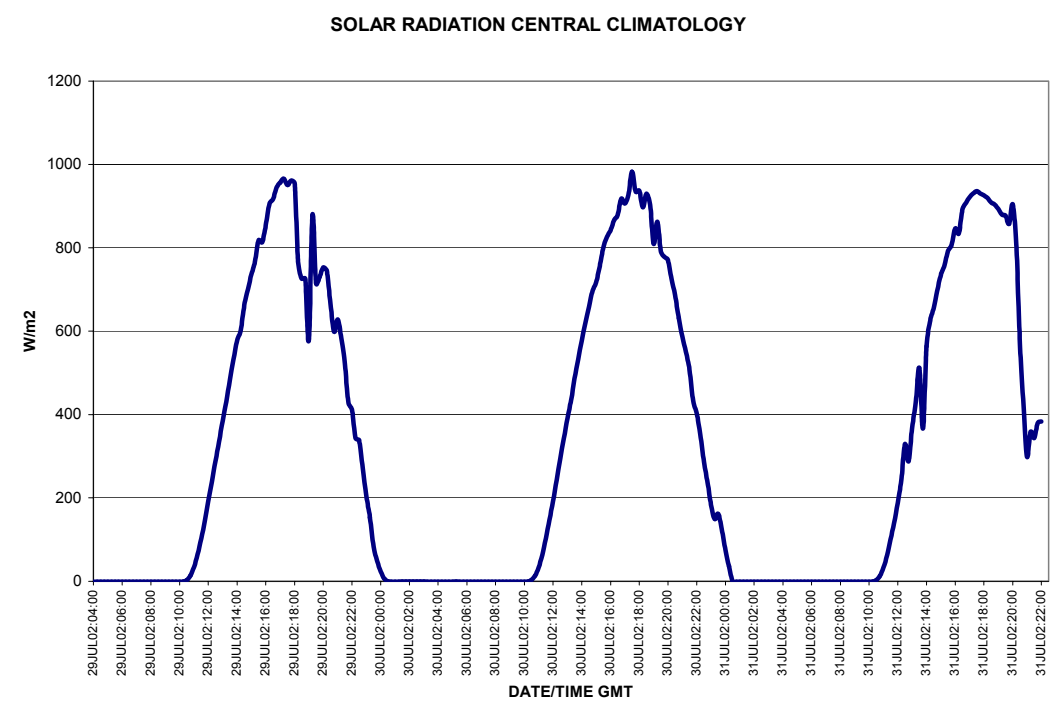

Figure 5. Incoming solar radiation at SRS July 29-31, 2002.

Plots of air and soil temperature at the Central Climatology site are shown in Figure 6. The air temperature at a height of $2 \mathrm{~m}$ above the ground ranged between 23 - 36 C during July 29 and 30 and between $22-35^{\circ} \mathrm{C}$ on July 31,2002 . The soil temperatures respond normally with the time of temperature maxima delayed and the magnitude decreasing with increasing depth. The soil temperature traces show similar patterns for all three days. 
Air and Soil Temperature at Central Climatology July 29-31, 2002

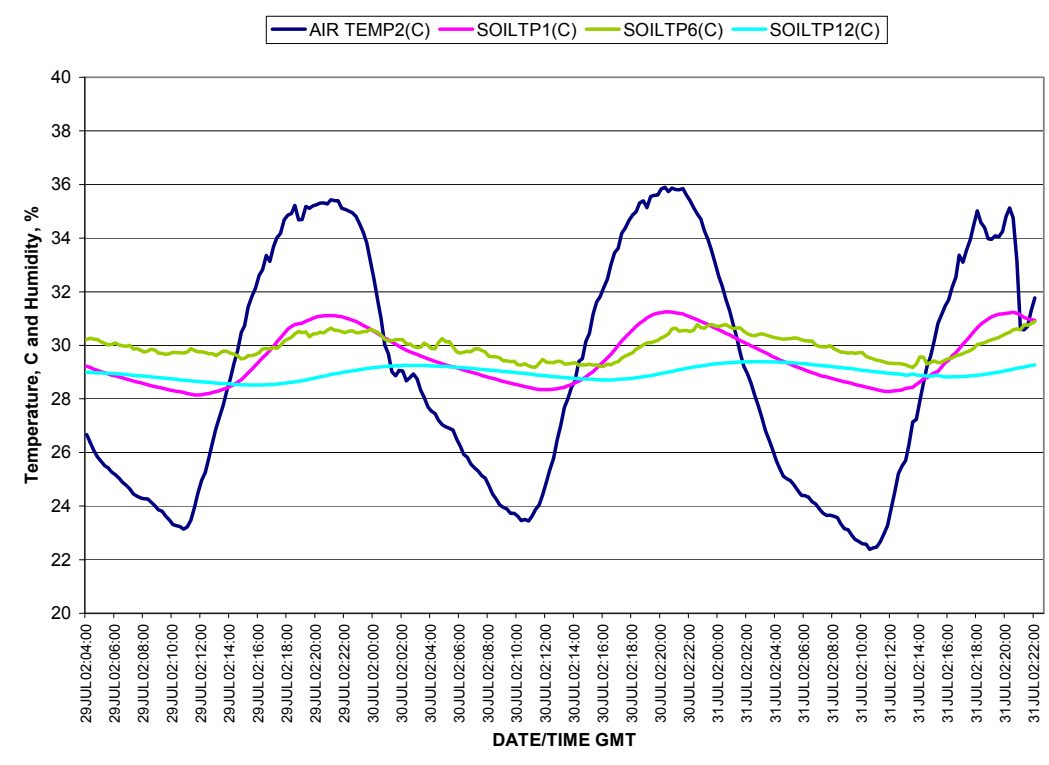

Figure 6. Air and soil temperature at SRS July 29-31, 2002.

Figure 7 is a plot of air temperature and soil moisture near the P-Area tower located $8 \mathrm{~km}$ southeast of the MWMF. Soil moisture measured in the grass field shows a steady decrease during the 3-day period from about $12 \%$ on July 29 to about $9 \%$ on July 31,2002 . The recording rain gauges at P-Area showed a trace of rain falling on July 30, 2002 at 0000 GMT. The soil moisture was not affected by the rain. The 24-hr rainfall amounts recorded at F-Area, H-Area and P-Area security gates showed no rainfall.

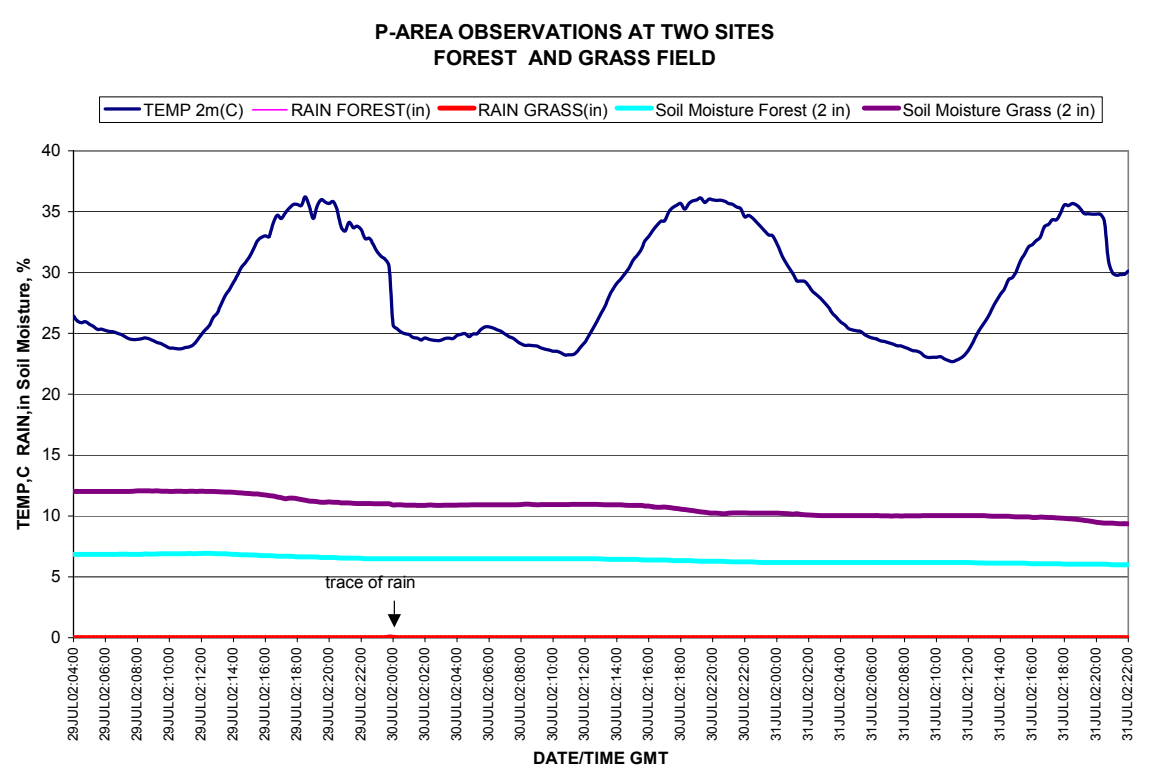

Figure 7. Soil moisture and air temperature at P-Area tower during July 29-31, 2002. 
A plot of temperature and dew-point temperature at 2 and $36 \mathrm{~m}$ above the ground on the Central Climatology tower are shown in Figure 8. Note that the dew-point temperature at $36 \mathrm{~m}$ is about $4{ }^{\circ} \mathrm{C}$ cooler than the $2 \mathrm{~m}$ dew-point temperature from July 29, 00:00 GMT to the start of the aircraft overflights on July 31, 13:30 GMT. At this time the $2 \mathrm{~m}$ and $36 \mathrm{~m}$ dew-points were equal. This indicates that the moisture gradient in the lower atmosphere and transpiration rates during the overflights may not be representative of transpiration rates measured on July 29 and July 30, 2002 at the same time of day.

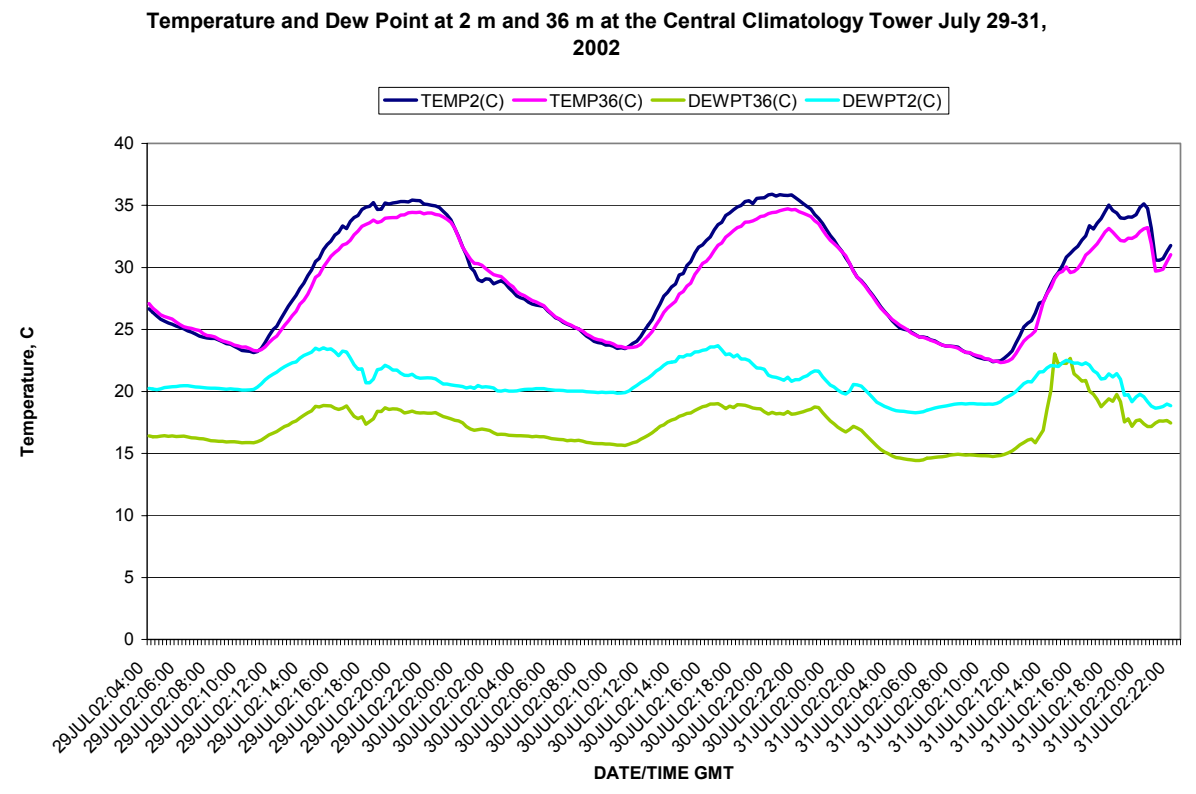

Figure 8. Temperature and dew point at Central Climatology Tower, July 29-31, 2002.

Weather conditions on July 29 and 30, 2002 were cloud free from 12:00-16:30 GMT and solar radiation traces were similar indicating that vegetation spectra and vegetation transpiration rates would be similar for the same time of day. Cloud conditions at 13:30 GMT on July 31, 2002 were partly cloudy with low-level cumulus clouds with bases at $800 \mathrm{~m}$ and stratus clouds at 6,000 m. Cloud conditions improved at 14:00 GMT with clear skies over the MWMF.

Soil moisture measurements at P-Area showed a steady decline of about $25 \%$ during the 3 -day period which could cause a change in the moisture gradient between soil and the value at $2 \mathrm{~m}$. This may or may not affect transpiration and spectra measurements. The dew-point temperature at $36 \mathrm{~m}$ at the Central Climatology tower increased by $2-4$ degrees $C$ at 13:30 GMT on 31 July over values from the previous two days; the value at $2 \mathrm{~m}$ remained unchanged. This change at $36 \mathrm{~m}$ would affect the magnitude of the moisture gradient in the lower atmosphere which may have an effect on transpiration rates. These two above factors my be compensating or additive and may cause transpiration measurements collected on July 29-30, 2002 to be unrepresentative of values measured on July 31, 2002 (Pendergast, 2002). 
WSRC-TR-2003-00275, REVISION 0

\section{Hyperspectral Data Analysis to Extract Thematic Information on Hazardous Waste Sites}

Analysis of hyperspectral data requires the use of specialized digital image processing software because it is usually necessary to calibrate (convert) the raw hyperspectral radiance data to "apparent reflectance" before it can be properly interpreted. This necessitates the removal of atmospheric attenuation, topographic effects (slope, aspect), and any sensor system electronic anomalies. In addition, to maximize hyperspectral information extraction, it is usually necessary to use digital image processing algorithms that: 1) allow one to analyze a typical spectrum to determine its constituent materials, and/or 2) compare the remote sensing derived-spectra with a library of spectra obtained using handheld spectroradiometers such as that provided by the U.S. Geological Survey or NASA's Jet Propulsion Laboratory. The digital image processing operations must usually be performed in a relatively straightforward sequence. The operations identified in the flow diagram shown in Figure 9 were used in this research.

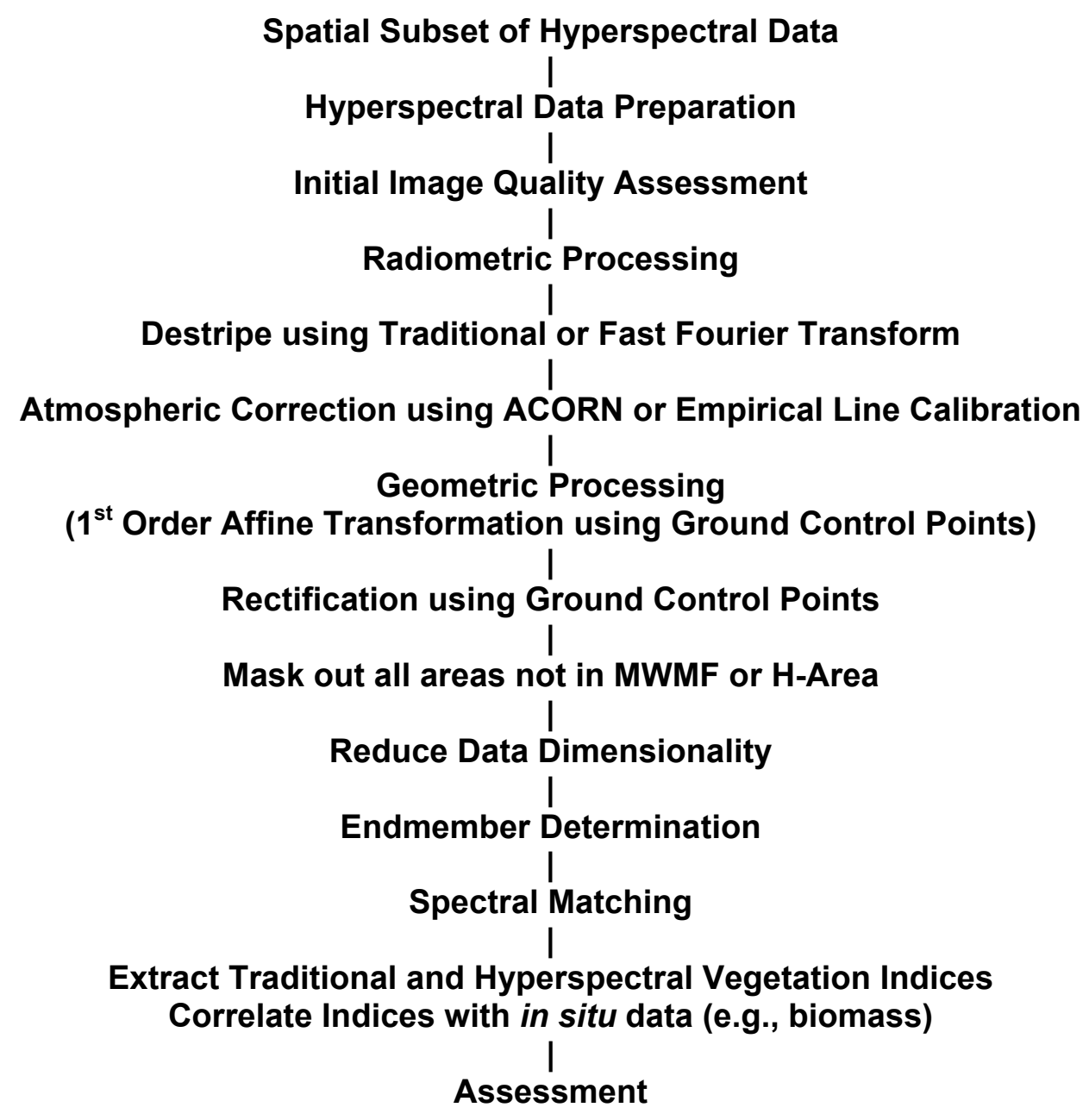

Figure 9. Science plan for processing the hyperspectral imagery. 
WSRC-TR-2003-00275, REVISION 0

\subsection{Initial Image Quality Assessment}

A number of methods can be used to assess image quality including visual examination of individual bands of imagery, examination of multiband color composites, viewing an animated movie of the individual bands, and statistical evaluation of individual bands. Each of these analyses were applied to the SRS GER DAIS 3715 hyeprspectral dataset.

\subsubsection{Visual Examination of Color Composite Images Consisting of Three Individual Bands}

One of the most useful ways to determine if hyperspectral imagery has information of value is to select representative bands and create color composites for visual inspection. For example, a color composite created using near-infrared (e.g., DAIS 3715 band 20), red (e.g., band 10), and green (e.g. band 5) bands is shown in Figure 2. Hopefully, the individual bands are co-registered and contain spectral information of value. Looking at numerous three band color composites from the possible hyperspectral bands can be a tedious process. However, the exercise provides valuable information about the quality of the individual scenes and bands in the hyperspectral dataset. Numerous color composites were evaluated. No band-to-band mis-registration was noted.

\subsubsection{Visual Individual Band Examination}

Sometimes there is simply no substitute for painstakingly viewing each of the hyperspectral bands to judge their quality. Many of the bands appeared sharp with good grayscale tonal variation while others appeared to contain some noise. It is important to determine if certain bands or particular regions within a given band contain null data values (e.g., values of -9999) or if there are serious line drop outs present (i.e., an entire line has a value of -9999). Also, an examination of the individual bands and color composites provided information on whether there were serious geometric problems with the data such as extreme image warping. Extremely deep notches at the edges of the scene are indicative of severe image geometric distortion. The analyst normally keeps a list of bands that exhibit considerable atmospheric noise. Such bands are often deleted from further analysis as described in subsequent sections. All 35 of the visible, near-infrared, and middle-infrared bands were kept for further analysis.

\subsubsection{Animation}

Hyperspectral digital image processing systems typically have an image animation function whereby the analyst selects a certain time rate at which individual bands are displayed on the screen, e.g., perhaps 5 seconds per band. Examination of the hyperspectral bands in this manner made it possible to: 1) identify individual bands that had serious atmospheric attenuation or electronic noise problems as previously discussed, and 2) determine if any misregistration (offset) exists between bands.

\subsubsection{Statistical Individual Band Examination}

The univariate statistics (e.g., mean, median, mode, standard deviation, range) of the individual bands were examined to assess image quality. For example, if a bands' 15 -bit brightness values were constrained to a very small range with a very small standard deviation, this could indicate a serious problem. 
WSRC-TR-2003-00275, REVISION 0

\section{Radiometric Calibration of the GER DAIS 3715 Hyperspectral Data}

The radiance recorded by a remote sensing system in various bands (e.g., panchromatic, multispectral, hyperspectral), is ideally an accurate representation of the radiant flux actually reflected or emitted from the surface of the earth from soil, water, vegetation and other materials. Unfortunately, this is often not the case as spurious noise (error) may be introduced into the remote sensing data. This noise (error) can be introduced by the remote sensing instrument itself during the data collection process. This is commonly called sensor system induced error. In addition, the intervening atmospheric path may add or subtract radiant energy to or from the reflected or emitted energy exiting the landscape. When this attenuation occurs it is necessary to atmospherically correct the remote sensor data to remove the deleterious effects of the unwanted path radiance.

\subsection{Correcting for Remote Sensing System Induced Error}

The two most serious system induced radiometric errors are often line drop-outs and $n$-line stripping. Both can have a serious negative impact when attempting to extract quantitative biophysical information from hyperspectral remote sensor data.

\subsubsection{Line Drop-outs}

Sometimes an individual detector in a multispectral scanning system or a line of detectors in a linear array does not record any information at all. When this takes place the imagery usually exhibits very noticeable black (or white) lines every $n$th line in the dataset. Unfortunately, it is impossible to recreate information that was never collected. Therefore, the only thing that can be done to improve the visual appearance of the imagery is to: 1) select each pixel $(j)$ along the bad line $(i)$ of data, 2$)$ extract the brightness values of the pixel from the line above $(i-1, j)$ and the line below $(i+1, j), 3)$ compute the mean of these two values, and 4$)$ insert the new value at the corresponding pixel location in the band line $(i, j)$. It is difficult to process remotely sensed data that has serious line drop-outs. While the dataset did contain some dropped lines, they were not located in the MWMF portion of the flightline (refer to Figure 2).

\subsubsection{N-line Striping Caused by Miscalibrated Detectors}

Many remote sensing systems collect data by scanning a number of lines of remotely sensed data at a time. The energy collected during each scan is dispersed through a prism or dichoric grate onto individual detectors associated with each band of imagery. Ideally, each detector associated with a band of imagery is calibrated to be in harmony with the other detectors associated with the same band. When one or more of the detectors associated with an individual band is higher or lower in sensitivity than the other detectors associated with the individual band, this causes the pixel values in the line of imagery to have systematically higher or lower values than those collected by the other detectors that are properly calibrated. The detector miscalibration results in imagery that has noticeable darker or brighter lines. The effect is particularly noticeable in areas of homogeneous terrain (e.g., water bodies, uniform fields of vegetation). However, unlike line drop-outs, the remotely sensed data associated with miscalibrated detectors may still contain valuable spectral information. If the systematic nature of the detector miscalibration can be determined, then a systematic bias (plus or minus value) or gain (multiplicative) value may be applied to the original miscalibrated data to bring it into radiometric harmony with the properly calibrated remote sensor data. For example, Figure 10 presents a GER DAIS 3715 band 5 image (centered on $566 \mathrm{~nm}$ ) of the MWMF at the SRS that contains striping. 
WSRC-TR-2003-00275, REVISION 0
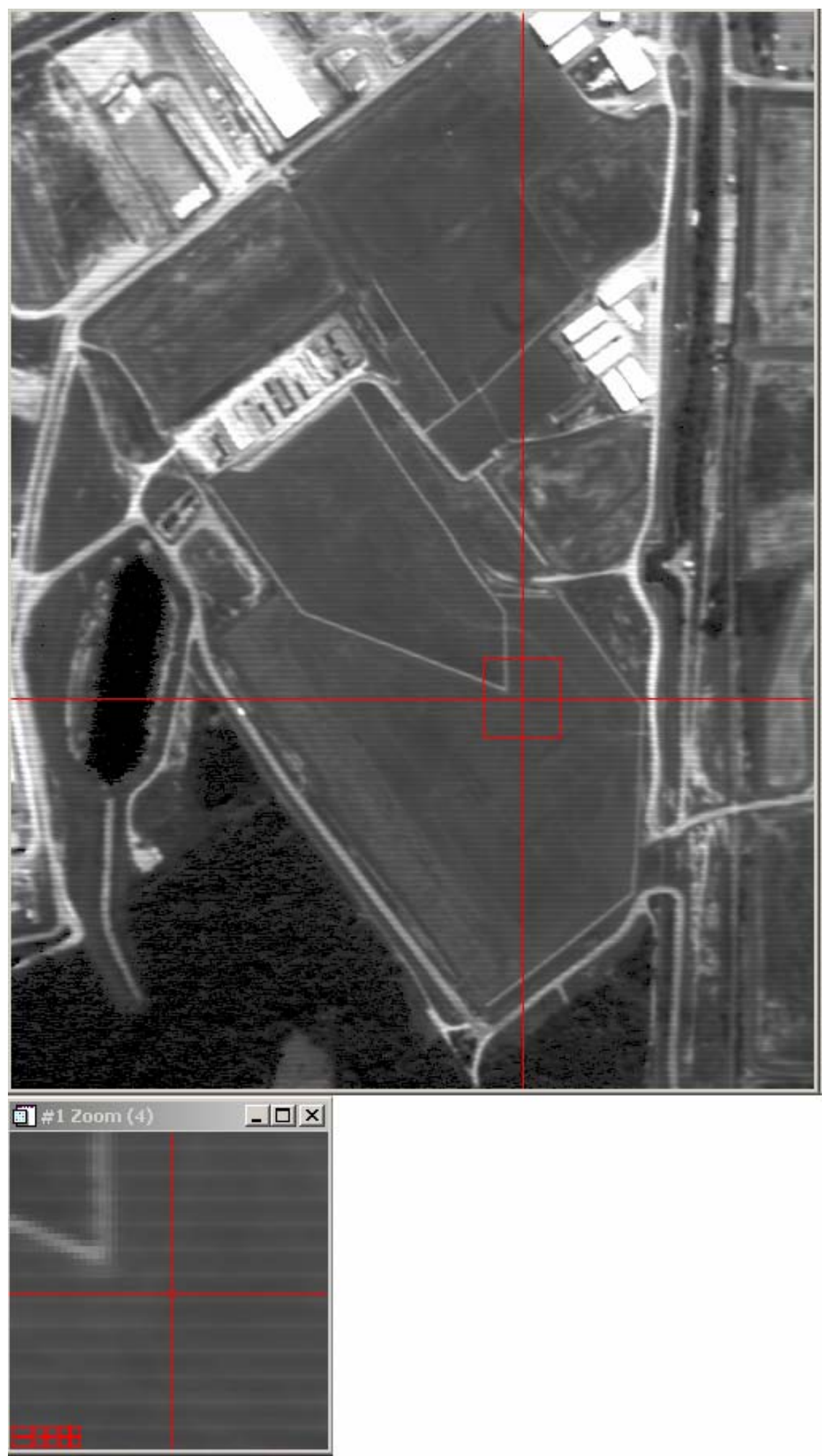

Figure 10. Band 5 DAIS 3715 hyperspectral image (centered on $566 \mathrm{~nm}$ ) of the MWMF at the SRS. Striping is noticeable in the enlarged image. 


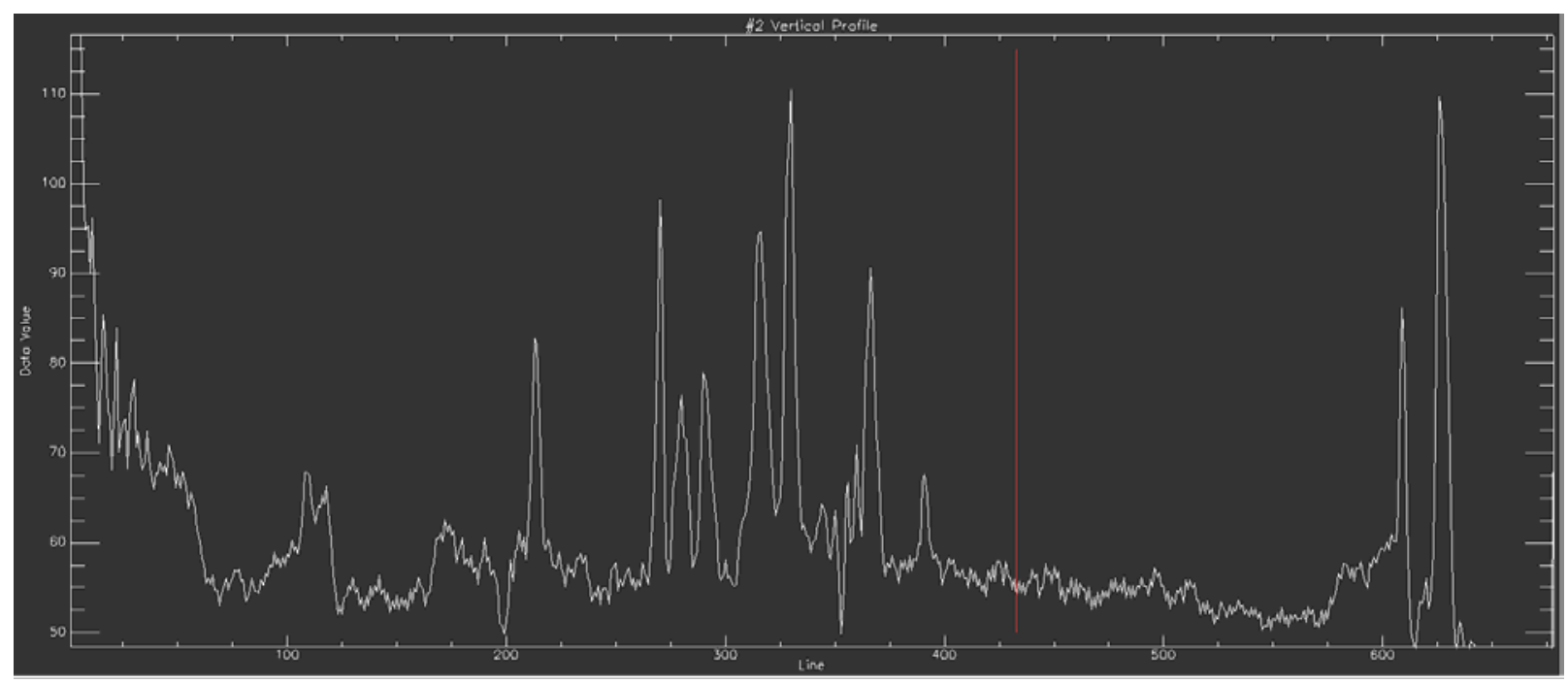

Figure 11. Radiance values encountered in the vertical transect shown in Figure 10.

Note the sawtooth nature of the radiance values indicative of $n$-line striping.

A vertical transect through the image (the red line in Figure 10) reveals a sawtooth pattern demonstrating that none of the detectors recording data during each sweep of the scanning mirror were in calibration one with another (Figure 11). In effect, one detector recorded a relatively low value, the next slightly higher, the next slightly higher, and the final detector considerably higher. The next scan produced approximately the same systematic result. This introduced high-frequency noise in the dataset. A horizontal profile through the data as shown in Figure 12 reveals that striping in the horizontal direction is not an issue.

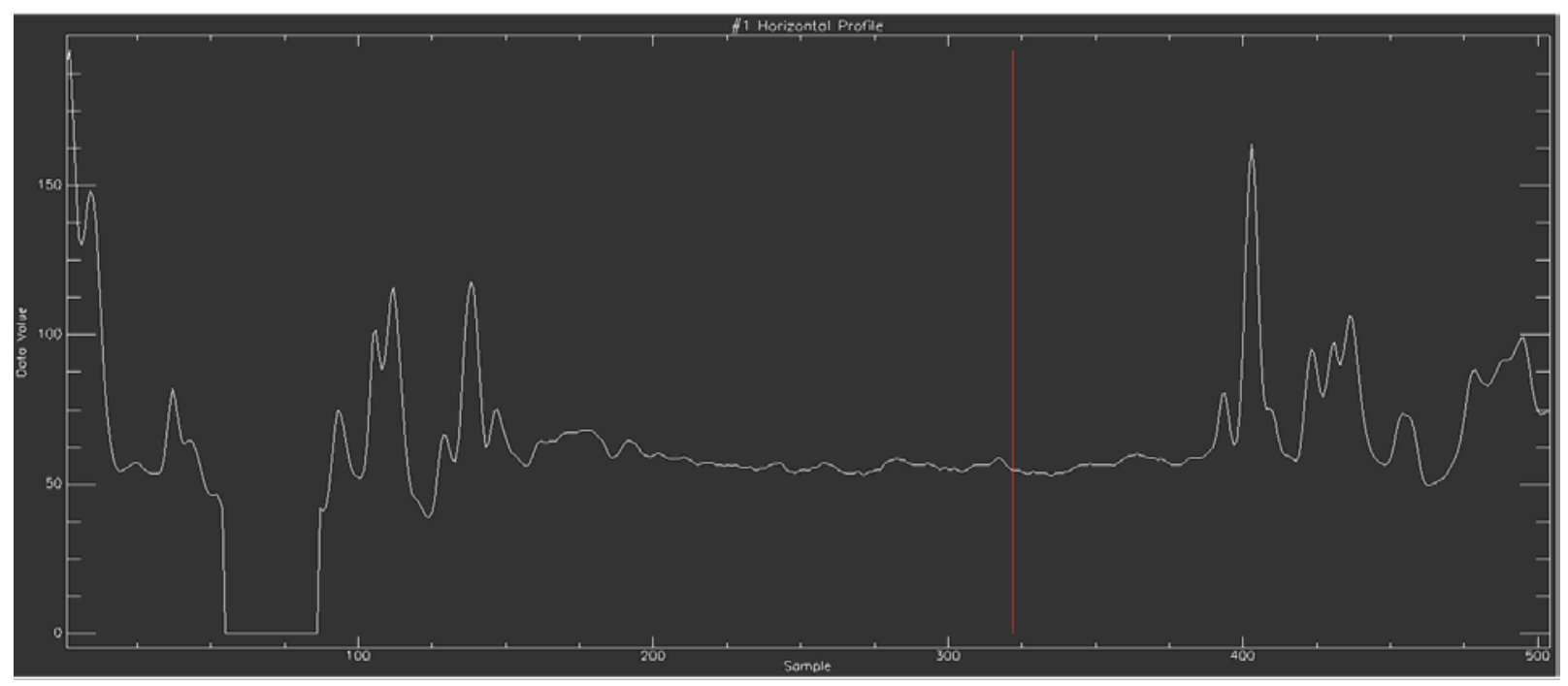

Figure 12. Radiance values encountered in the horizontal transect shown in Figure 10. 
WSRC-TR-2003-00275, REVISION 0

\subsubsection{De-striping Using Band and Line Mean and Standard Deviation Statistics}

One method of de-striping miscalibrated data is to obtain data in an individual band over a relatively homogeneous portion of an image such as a deep, non-turbid water body. A program systematically evaluates every line of data in the dataset to determine the mean and standard deviation of all pixels found along each line of data. In properly calibrated data, the mean and standard deviation of the pixels found in the various lines of data should be similar. In striped data, one or more of the lines will have significantly higher or lower mean values and perhaps substantially different standard deviations. The program identifies the nature of the miscalibration and uses the mean and standard deviation information to compute a correction factor (bias and/or gain) for the offending (miscalibrated) line of data. The gain and/or bias correction is then applied to every $n$th offending line in the dataset. For example, if four lines of data are obtained during each mirror scan and the $3^{\text {rd }}$ line is consistently twice as bright as the other three lines of data, then a gain of 0.5 applied to each pixel in the $3^{\text {rd }}$ scan line throughout the image will hopefully correct the problem. The resulting de-stripped dataset may then be processed using standard digital image processing techniques. We applied this type of destriping algorithm to the MWMF dataset but were not satisfied with the results.

\subsubsection{Destriping Using Fast Fourier Transform (FFT)}

Sometimes the striping in remotely sensed data is so serious and unsystematic that the aforementioned method of destriping may not yield useable results. This is particularly the case when some bands exhibit striping while others do not or when certain portions of the image exhibit unsystematic calibration problems. When such complex radiometric conditions exist it may be possible to remove some of the distortion using a fast Fourier transform (FFT). A Fourier transform is a mathematical technique for separating a single band of remotely sensed image into is various spatial frequency components. Because much of the noise associated with remotely sensed imagery is due to high-frequency striping, it is possible to use a Fourier transform to remove it. The procedure normally requires four steps: 1) a Fourier transform is applied to the remotely sensed data to create an FFT image, 2) the unique FFT image is evaluated and the high-frequency noise is identified, 3) a cutfilter is created based on the isolated noise in the FFT image, 4) the cut-filter is utilized during an inverse FFT procedure that may remove the radiometric striping from the remotely sensed data.

These procedures are demonstrated using the band 5 hyperspectral data previously discussed. An FFT transformation of the original band 5 data is shown in Figure 13a. The low frequency components in the image are found in the center. White features that exist some distance from the center in the FFT image represent high-frequency components in the original remote sensor data. These areas were interactively identified by the analyst in Figure13b. The final cut filter shown in Figure 13c was used in conjunction with the FFT image during the inversion process to create the improved output band of imagery. 

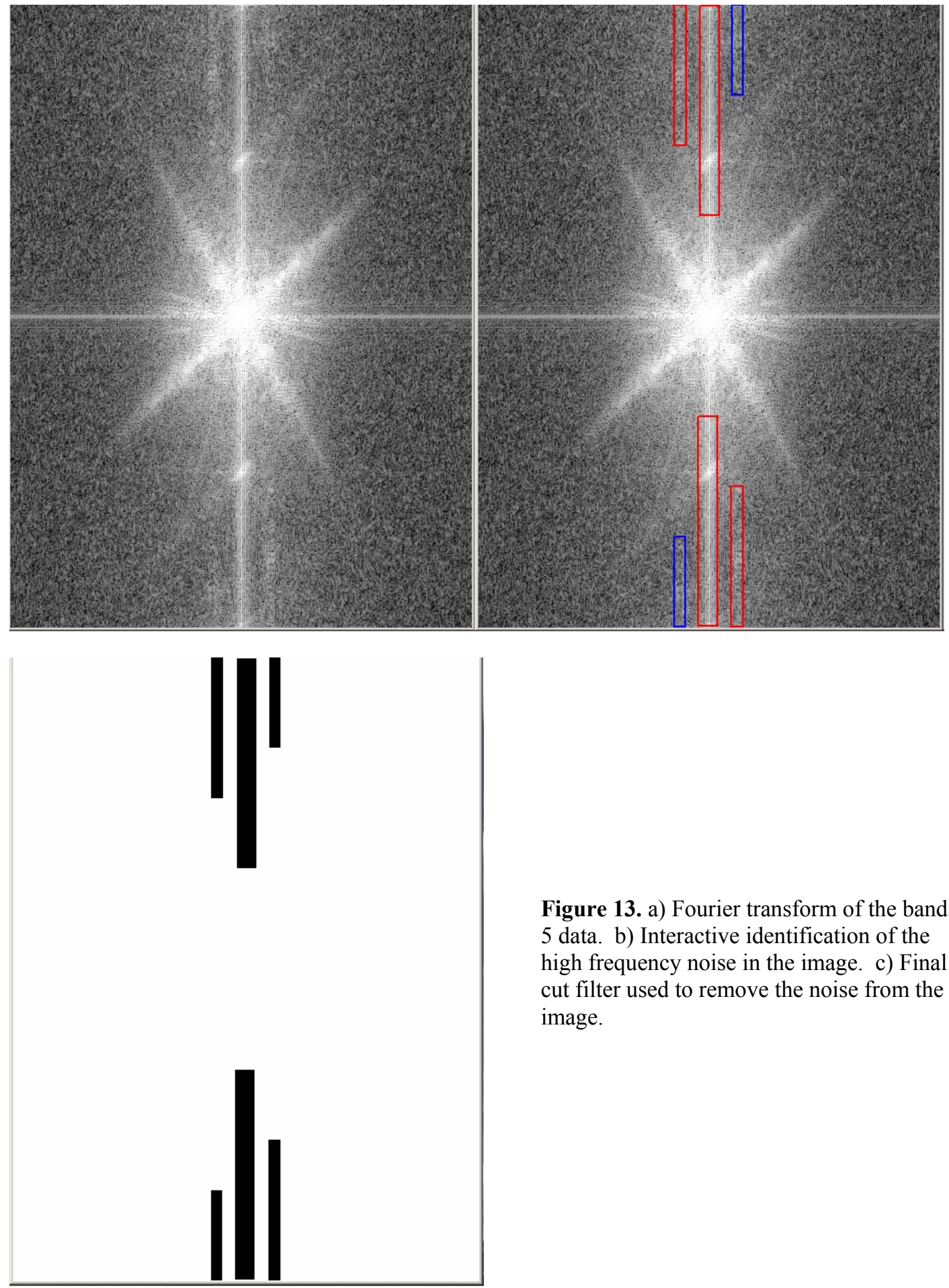

Figure 13. a) Fourier transform of the band 5 data. b) Interactive identification of the high frequency noise in the image. c) Final cut filter used to remove the noise from the image.

FFT transforms and a cut filter for band 26 is shown in Figure 14. 

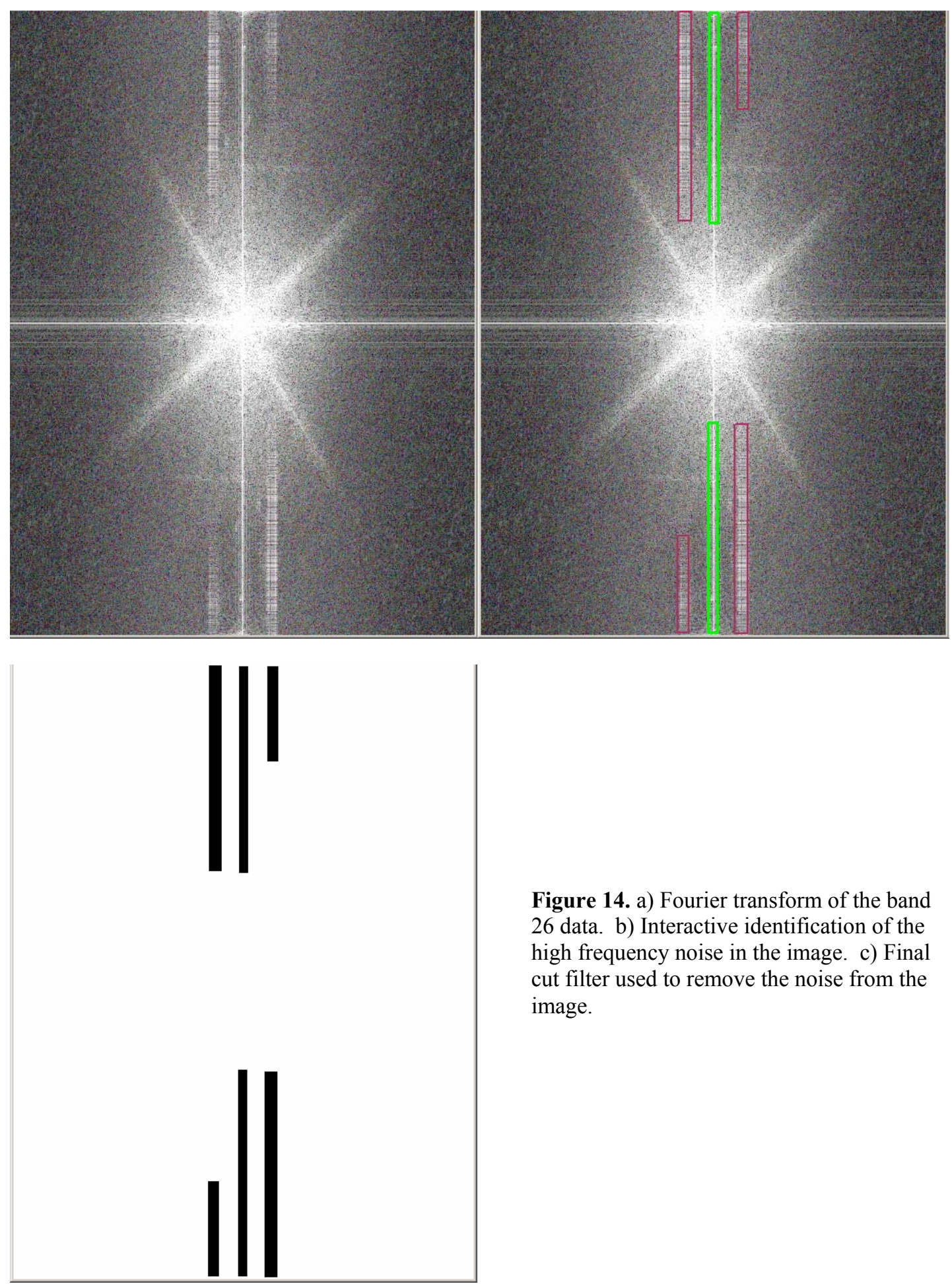

Figure 14. a) Fourier transform of the band 26 data. b) Interactive identification of the high frequency noise in the image. c) Final cut filter used to remove the noise from the image.

The results of inverting the band 5 FFT image with the band 5 cut filter are shown in Figure 15. Note that the striping was substantially reduced while still maintaining the integrity of the spectral radiance values. These data are now ready for additional digital image processing. 


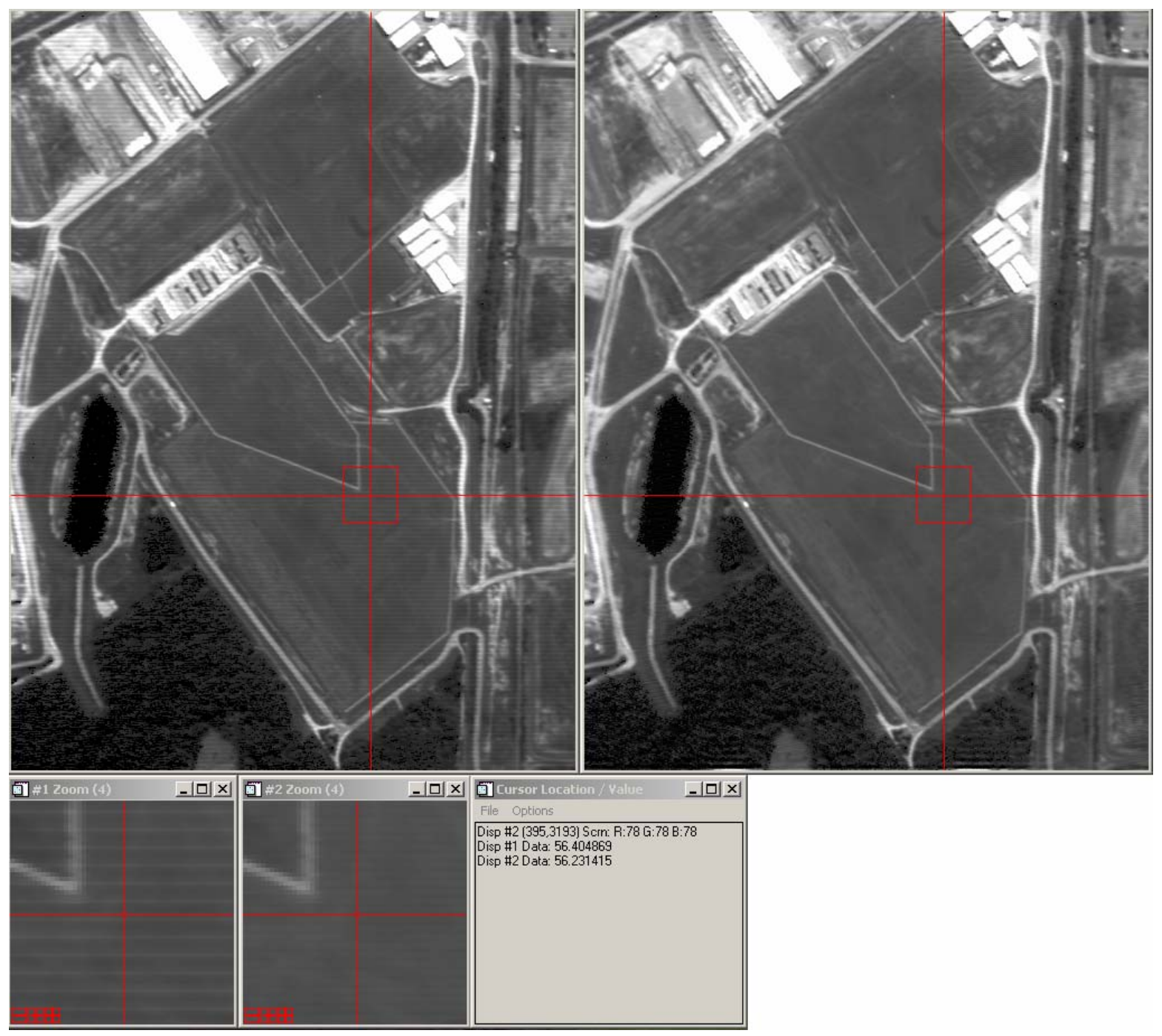

Figure 15. Results of applying the cut filter and inverting the fast Fourier transform. The before and after enlargement reveals that striping was substantially reduced. However, the actual brightness value of the pixel under investigation changed by just a small amount which is important when the data are to be used to extract quantitative biophysical information.

A vertical profile through the FFT destriped band 5 data is shown in the bottom of Figure 16. Notice that the magnitude of the sawtooth pattern has been reduced substantially although there are still remnants. 


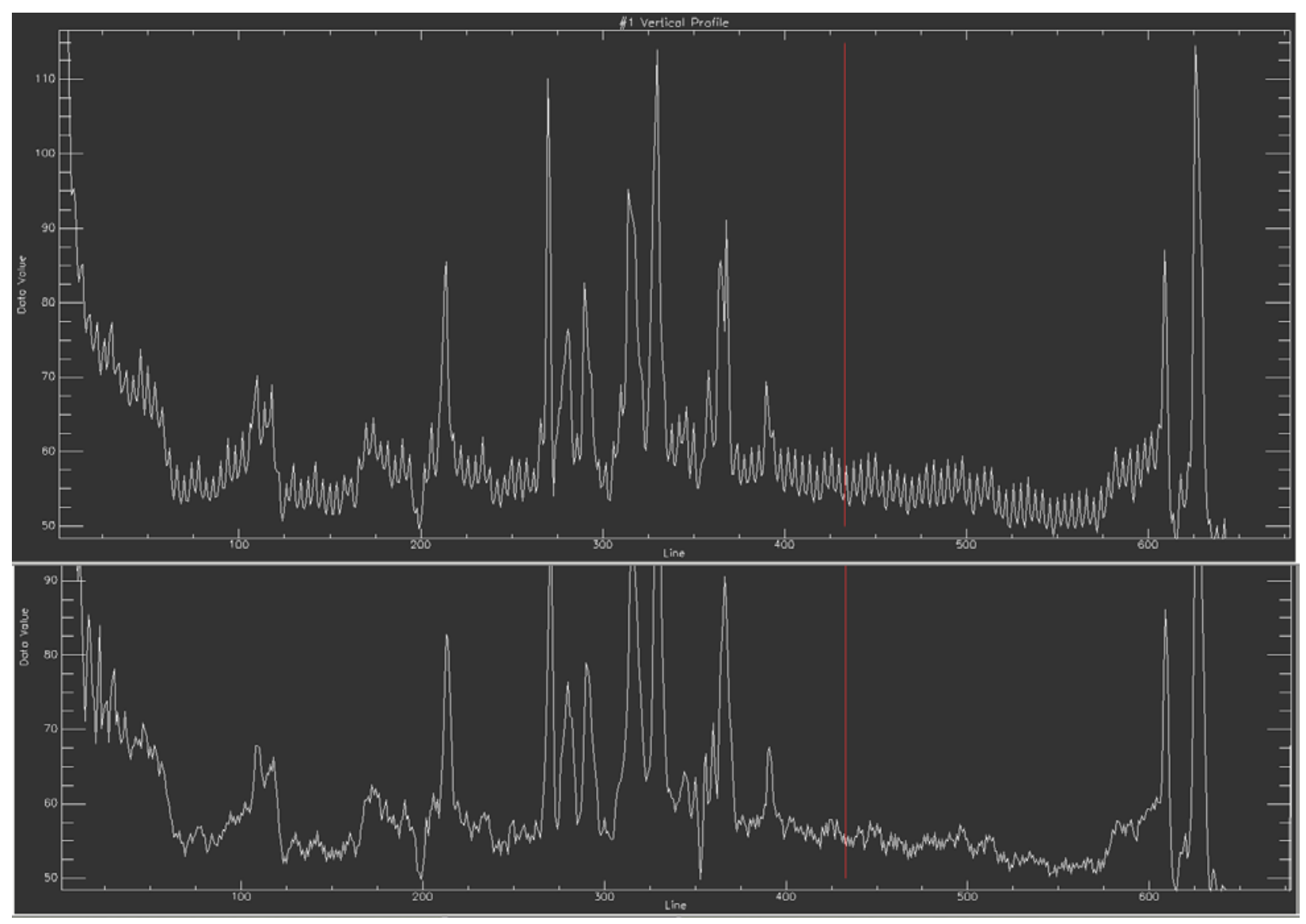

Figure 16. A vertical profile through the original band 5 data (top) and the FFT destriped band 5 data (bottom).

\subsection{Correcting for Atmospheric Attenuation}

Hyperspectral remote sensor data should be radiometrically corrected prior to information extraction and analysis. In addition to removing atmospheric effects, the process normally involves transforming the hyperspectral data from radiance, $L\left(\mathrm{~W} \mathrm{~m}^{-2} \mu \mathrm{m}^{-1} \mathrm{sr}^{-1}\right)$ to apparent surface reflectance. This transformation allows the apparent surface reflectance data obtained by the remote sensor to be quantitatively compared with in situ spectral reflectance data obtained on the ground using a hand-held spectroradiometer, or with laboratoryderived spectral measurements. Such spectroradiometer data are often stored in special libraries. This research applied and evaluated three atmospheric correction techniques: ATmosphere REMoval Program (ATREM), Empirical Line Calibration (ELC), and Atmospheric CORrection Now (ACORN).

\subsubsection{ATmosphere REMoval Program - ATREM}

Ideally, the analyst knows the exact nature of the atmospheric characteristics above each picture element at the time the hyperspectral data are collected, e.g., barometric pressure, water vapor, relative humidity, visibility, and amount of atmospheric molecular (Rayleigh) scattering. Unfortunately, the atmosphere is variable even over relatively short geographic distances. One method of atmospheric correction involves the use of radiance data in selected narrow bands to infer information about the atmospheric conditions above each pixel. This information is then used to remove atmospheric effects for each individual pixel in the scene. One of the more robust algorithms used to remove the effects of atmospheric attenuation from individual pixels of hyperspectral data is the ATmosphere REMoval Program (ATREM) (CSES, 1999; Gao et al., 1999). 
WSRC-TR-2003-00275, REVISION 0

There are approximately 30 gases in the atmosphere. Most of the gases do not produce observable absorption features in the 400 to $2500 \mathrm{~nm}$ region. However, seven gases [water vapor (H2O); carbon dioxide (CO2); ozone $(\mathrm{O} 3)$; nitrous oxide $(\mathrm{N} 2 \mathrm{O})$; methane $(\mathrm{CH} 4)$; carbon monoxide $(\mathrm{CO})$; and oxygen $(\mathrm{O} 2)$ ] do produce observable absorption features in remotely sensed images obtained in this region (Gao et al., 1999). The impact of these gases on the atmospheric transmission of energy in the wavelength interval from 400 to $2500 \mathrm{~nm}$ is graphed in Jensen (2000).

ATREM calculates the amount of molecular scattering (Rayleigh) present using the radiative transfer code "Second Simulation of the Satellite Signal in the Solar Spectrum" and a user-specified aerosol model. ATREM calculates the atmospheric absorption term using the Malkmus narrow band spectral model with a user-selected standard atmospheric model (temperature, pressure, and water vapor vertical distributions) or a user-supplied atmospheric model (Gao et al., 1999). The amount of water vapor is derived on a pixel-by-pixel basis from the hyperspectral data using the $0.94 \mu \mathrm{m}$ and the $1.14 \mu \mathrm{m}$ water vapor bands and a three-channel ratioing technique. The derived water vapor values are then used for modeling water vapor absorption effects over the entire 400 to $2500 \mathrm{~nm}$ region. The result is a radiometrically corrected hyperspectral dataset consisting of scaled apparent surface reflectance. The GER DAIS 3715 remote sensing system did not record radiant energy in the $0.94 \mu \mathrm{m}$ and $1.14 \mu \mathrm{m}$ water vapor absorption bands. Nevertheless, ATREM was run on the data. Unfortunately, the ATREM-corrected apparent surface reflectance data at known locations did not match well with the in situ spectroradiometer measurements.

\subsubsection{Empirical Line Calibration - ELC}

Atmospheric correction may also be performed using an empirical line calibration (ELC) which forces the remote sensing imaging spectrometer data to match in situ reflectance spectra and is based on Equation 2 (Roberts et al., 1986; Conel et al., 1987):

$$
D N_{b}=\rho(\lambda) A_{b}+B_{b}
$$

where $D N_{b}$ is the digital output value for a pixel in band $b, p(\lambda)$ equals the surface reflectance of the materials within the sensor IFOV at a specific wavelength $(\lambda), A_{b}$ is the multiplicative term affecting the DN, and $B_{b}$ the additive term. The multiplicative term is associated primarily with transmittance and instrumental factors, and the additive term deals primarily with atmospheric path radiance and instrumental offset (i.e., dark current). Typically, two or more areas in the scene with different albedos are selected (e.g., one bright target such as a sand pile and one dark target such as a deep non-turbid water body). The areas should be as homogeneous as possible. Empirical spectroradiometer measurements of these same targets are obtained on the ground. The in situ and remote sensing derived spectra are regressed and gain and offset values computed (Farrand et al., 1994). The gain and offset values are then applied to the remote sensor data on a band-by-band basis, removing atmospheric path radiance.

GER DAIS 3715 radiance values of the dark and light $8 \times 8 \mathrm{~m}$ calibration panel targets (Figure 4c) were extracted from flightline \#05 at two locations: dark $(3,682,609 \mathrm{~N} ; 438,864 \mathrm{E})$ and bright $(3,682,608 \mathrm{~N} ; 438,855$ E). In situ ASD spectroradiometer measurements were obtained from the same calibration targets. The nominal spatial resolution of the GER DAIS 3715 data was $2.41 \times 2.41 \mathrm{~m}$. Therefore, it was possible that the remote sensing-derived spectral measurements were not solely a function of the calibration target. Some spurious reflectance from adjacent materials may have been recorded. Ideally, 16 × $16 \mathrm{~m}$ calibration targets would have been available, but this was cost prohibitive. The four input spectra were then used in an empirical line calibration to derive the appropriate gain and offset values. 


\subsubsection{Atmospheric CORrection Now - ACORN}

Like ATREM, ACORN Mode 1 is a radiative transfer atmospheric correction algorithm. It uses both the radiometrically calibrated image data and user defined parameters to derive and model the absorption and scattering characteristics of the atmosphere (InSpec LLC, 2002). These atmospheric characteristics are then used to invert the radiance to apparent surface reflectance. ACORN Mode 1 atmospheric correction is based on radiative transfer equations developed by Chandrasekhar (1960). Equation 3 defines the relationship from contributions of the exo-atmospheric solar source, the atmosphere, and the surface with respect to the radiance measured by an earth-looking sensor for a homogenous plane parallel atmosphere:

$$
L_{T}=\frac{F_{0}(\lambda)\left(\frac{\rho a(\lambda)+T d(\lambda) \rho(\lambda) T u(\lambda)}{(1-s(\lambda) \rho(\lambda))}\right)}{\pi}
$$

where $L_{T}$ is the total radiance arriving at the sensor, $F_{0}$ is the top of the atmospheric solar irradiance, $\rho a$ is the reflectance of the atmosphere, $T d$ is the downward transmittance of the atmosphere, $\rho$ is the spectral reflectance of the atmosphere, $T u$ is the upward transmittance of the atmosphere, $S$ is the downward reflectance of the atmosphere, and $\lambda$ is the spectral wavelength. Equation 3 can then be inverted and solved for apparent surface reflectance (Equation 4):

$$
\rho(\lambda)=\frac{1}{\frac{\left(F_{0}(\lambda) \operatorname{Td}(\lambda) \operatorname{Tu}(\lambda) / \pi\right)}{\left(L_{T}(\lambda)-F_{0}(\lambda) \rho a(\lambda) / \pi\right)}+s(\lambda)}
$$

Radiative transfer atmospheric correction algorithms introduce some artifacts into the output spectral data because it is very difficult to have perfect knowledge about some of the input parameters. Artifacts are a function of the quality of the calibration to radiance discussed in Section 2.2.2, knowledge of the atmosphere, and the ability to model the atmosphere (InSpec LLC, 2002). ACORN Mode 1 offers three types of artifact suppression:

Type 1: Corrects for any mismatch in the spectral calibration of the hyperspectral data and the spectral radiative transfer calculations. It suppresses the artifacts located near the strong atmospheric absorption features at 760, 940, 1150, and $2000 \mathrm{~nm}$.

Type 2: There are often other small artifacts located across the spectral range due to errors in the absolute radiometric calibration and/or errors in the radiative transfer calculations. It identifies and suppresses these artifacts.

Type 3: The spectrum across the 1,400 and 1,900 nm water vapor bands often produces noisy reflectance results because of the low radiance values recorded in these regions. This method assesses the signal levels of the calibrated radiance and suppresses the lowest signal portions where erroneous reflectance calculations may occur. The result is that the lowest signal portions of the spectrum are set to zero on the apparent surface reflectance output. 
ACORN Mode 1 was used with the following input information:

1. altitude of the sensor at the time of data acquisition (e.g., $1500 \mathrm{~m}$ above mean sea level);

2. date and time of data acquisition (GMT);

3. the geographic center of the image (latitude, longitude);

4. wavelength for the channel center of each band (in $\mathrm{nm}$ );

5. full-width at half-maximum (FWHM) value for each of the 35 GER 3715 bands;

6. a scaled, calibrated radiance image in units of $\mathrm{W} \mathrm{m}^{-2} \mu \mathrm{m}^{-1} \mathrm{sr}^{-1}$;

7. a standard atmospheric model (middle latitude summer);

8. average surface elevation (93 $\mathrm{m}$ above mean sea level);

9. average atmospheric visibility $(10 \mathrm{~km})$;

10. average atmospheric water vapor $(25 \mathrm{~mm})$;

11. gain and offset files in ASCII format; and

12. artifact suppression option (Type 1, Type 2, or Type 3 ).

The output of ACORN Mode 1 radiative transfer atmospheric correction was a radiometrically calibrated apparent surface reflectance image stored as values of percent reflectance $* 10,000$. ACORN requires a mean elevation value to characterize the $z$-value of the entire scene. Fortunately, this was not a problem on the MWMF clay cap where the variation in local relief was only around $100 \mathrm{~m}$. However, in mountainous terrain, significant differences in local relief, slope, and aspect would require adjustments to the surface reflectance caused by these variations in lighting geometry. In such cases the "scaled apparent surface reflectance" could be converted to absolute apparent surface reflectance by incorporating topographic information from a digital elevation model (Jensen, 1996).

To appreciate the importance of atmospherically correcting the hyperspectral data prior to data analysis, consider the application of the ACORN Mode 1 program to the MWMF subset of Line \#05 of the GER 3715 SRS dataset. An example of a original GER 3715 Loblolly Pine (Pinus taeda) spectrum for a pixel located at 3,683,438 Northing and 437,895 Easting UTM Zone 17 is shown in Figure 17a. The y-axis measures radiance, $L\left(\mathrm{~W} \mathrm{~m}^{-2} \mu \mathrm{m}^{-1} \mathrm{sr}^{-1}\right)$. For all practical purposes, the original radiance spectrum is not very informative for Earth surface inquires. Notice the rough angular shape of the spectrum and the low radiance values in the middleinfrared portion of the spectrum. Basically, the radiance spectra only moderately resemble the spectra that should be associated with a healthy, photosynthesizing pine canopy. Application of the ACORN program to the raw GER 3715 data resulted in the scaled apparent surface reflectance spectrum shown in Figure 17b. The ACORN atmospherically corrected spectra appears as it should with chlorophyll absorption in the red portion of the spectrum, a peak in the green, and increased reflectance through the near-infrared.

Calibrated Radiance Spectrum of Loblolly Pine (Pinus taeda)

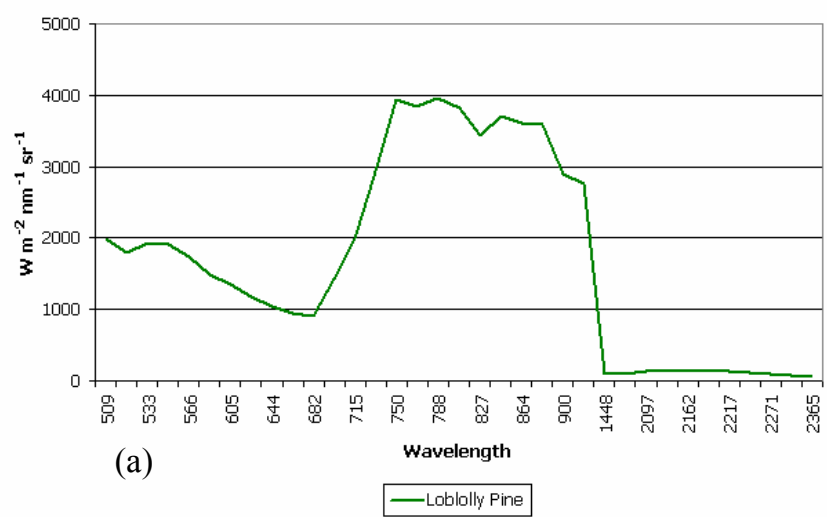

ACORN Atmospherically Corrected Spectrum of Loblolly Pine (Pinus taeda)

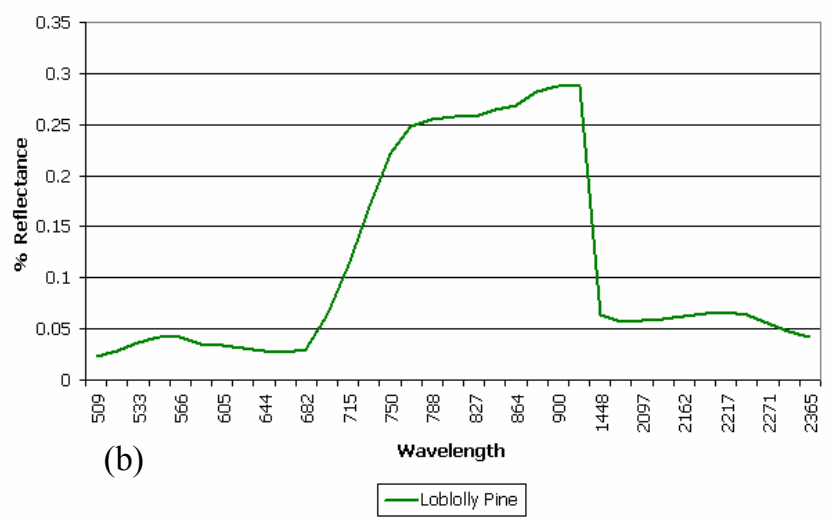

Figure 17. a) Original GER DAIS 3715 radiance, and b) ACORN-derived scaled apparent surface reflectance for a single pixel of Loblolly Pine near the MWMF at the SRS. 
WSRC-TR-2003-00275, REVISION 0

\subsubsection{Single Spectrum Enhancement}

There is often considerable noise in spectra after applying atmospheric correction on a pixel-by-pixel basis due to the cumulative error from sensor system anomalies, limited accuracy of the standards, measurements, and models used and calibrations preformed along the signal processing chain (RSI, 2000). Fortunately, there are additional techniques available that remove more of this cumulative error. Normally this involves deriving a mild linear correction that is applied to the entire band and the entire scene at one time (i.e., it is not a pixel-bypixel correction). Such methods remove some of this error in an attempt to improve the accuracy of the scaled apparent surface reflectance data (Boardman, 1997).

Single spectrum enhancement (SSE) was performed in ACORN Mode 2 for both the empirical line calibration and radiative transfer based (ACORN Mode 1) atmospherically corrected SRS GER 3715 dataset. For SSE of a hyperspectral atmospheric correction, ACORN Mode 2 uses a spectrum extracted from an atmospherically corrected hyperspectral dataset and a known measured spectrum for the same target of equal or greater spectral resolution. With these two spectra, the full atmospherically corrected hyperspectral dataset is then "fitted" to the known spectrum. The SSE treatment was applied using an in situ spectroradiometer bahiagrass [Paspalum notatum Flugge var. saurae Parodi] spectrum consisting of the average of five individual measurements recorded between 400 and $2500 \mathrm{~nm}$. Bahiagrass was judged to be the most appropriate spectrum for application of SSE because it is the dominant species grown on the MWMF clay-cap.

\subsubsection{Assessment of Empirical Line Calibration and ACORN Atmospheric Corrections}

In situ spectral reflectance measured with the ASD spectroradiometer at several sample point locations on the MWMF clay-cap were used to assess the quality of the empirical line calibration and ACORN radiative transfer-based atmospheric correction models. Figure 18a-d depicts the measured reflectance spectrum and the extracted spectrum for the corresponding area in the empirical line calibration and ACORN atmospherically corrected datasets for four different sample point locations on the MWMF clay-cap. Both the ELC and ACORN atmospheric corrections consistently overestimated the amount of reflectance. However, the ELC and the ACORN corrections yielded much more accurate results when the single spectrum enhancement (SSE) was included (Figure 18a-d). Root mean squared error (RMSE) associated with the four atmospheric correction algorithms compared with in situ ASD spectroradiometer measurements collected at the same locations are shown in Figure 19. The ACORN atmospheric correction with a single spectrum enhancement consistently produced the spectra that had the lowest RMSE. Therefore, only ACORN-SSE corrected data were used for the remainder of the analysis.

In addition to the slightly better performance, there are also practical reasons for utilizing a primarily imagebased radiometric correction methodology (i.e., ACORN Mode $1+\mathrm{SSE}$ ), rather than techniques that require field- or laboratory-derived spectroradiometer data (e.g., empirical line calibration). The use of a radiative transfer model-based method reduced or eliminated the requirement for in situ data. ACORN Mode 1 did not require the use of in situ spectral measurements (laboratory or field collected). This may become an even more important consideration when imagery from spaceborne imaging spectrometers, with higher revisit frequencies than airborne sensors, becomes widely available. If relatively high temporal resolution waste site studies are desired, limited financial and or personnel resources may significantly inhibit an atmospheric correction approach that requires the frequent collection of in situ spectral and meteorological data. For instance, other radiative transfer models, such as LOWTRAN (Kniezys et al., 1988) or MODTRAN (Archarya et al., 1998) require more user inputs. Furthermore, if an emergency spill/compromise situation were to arise, a rapid atmospheric correction methodology would be required. 
WSRC-TR-2003-00275, REVISION 0

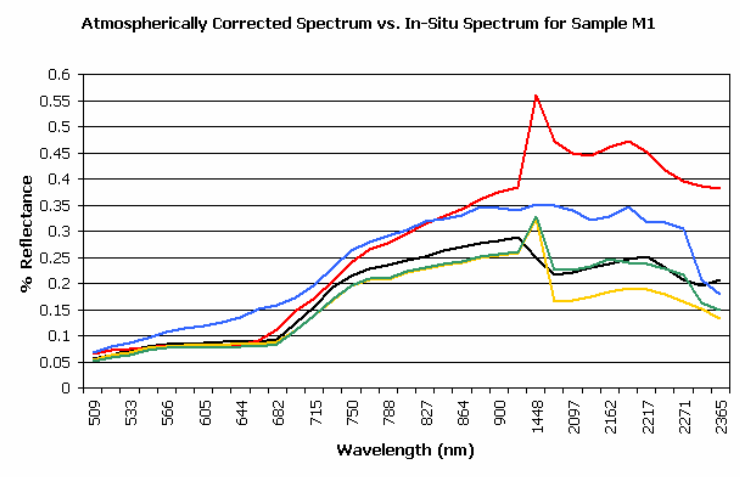

(a)

$$
\text { -In-Situ -ELC —ACORN - ELC-SSE —ACORN-SSE }
$$

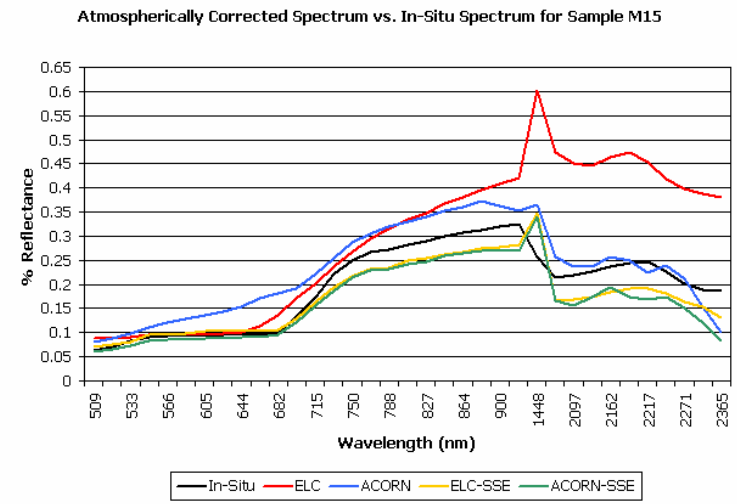

(C)

Figure 18. a) Apparent surface reflectance derived by applying various atmospheric correction algorithms to the GER DIAS 3715 hyperspectral data for a single pixel of bahiagrass at Site \#M1 compared with the in situ ASD spectroradiometer measurement. b) Results from Site \#M10. c) Results from Site \#M15. d) Results from Site \#M16.

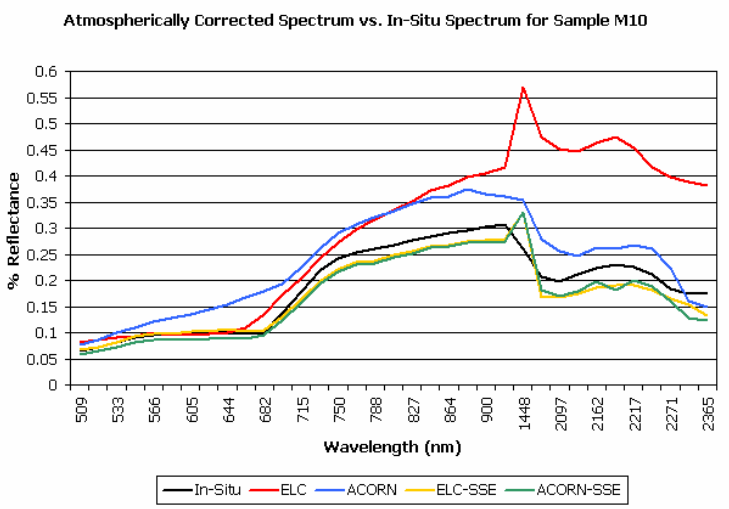

(b)

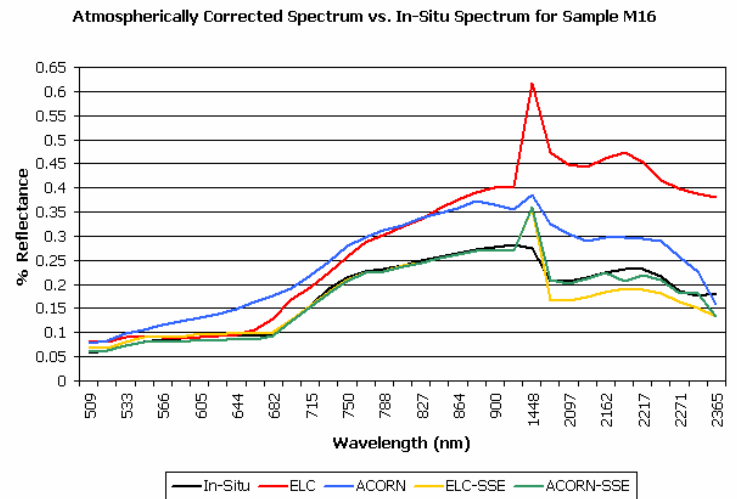

(d) 
WSRC-TR-2003-00275, REVISION 0

Root Mean Square Error (RMSE) for Atmospherically Corrected GER 3715 vs. In Situ ASD Spectroradiometer at 46 Sample Locations on MWMF

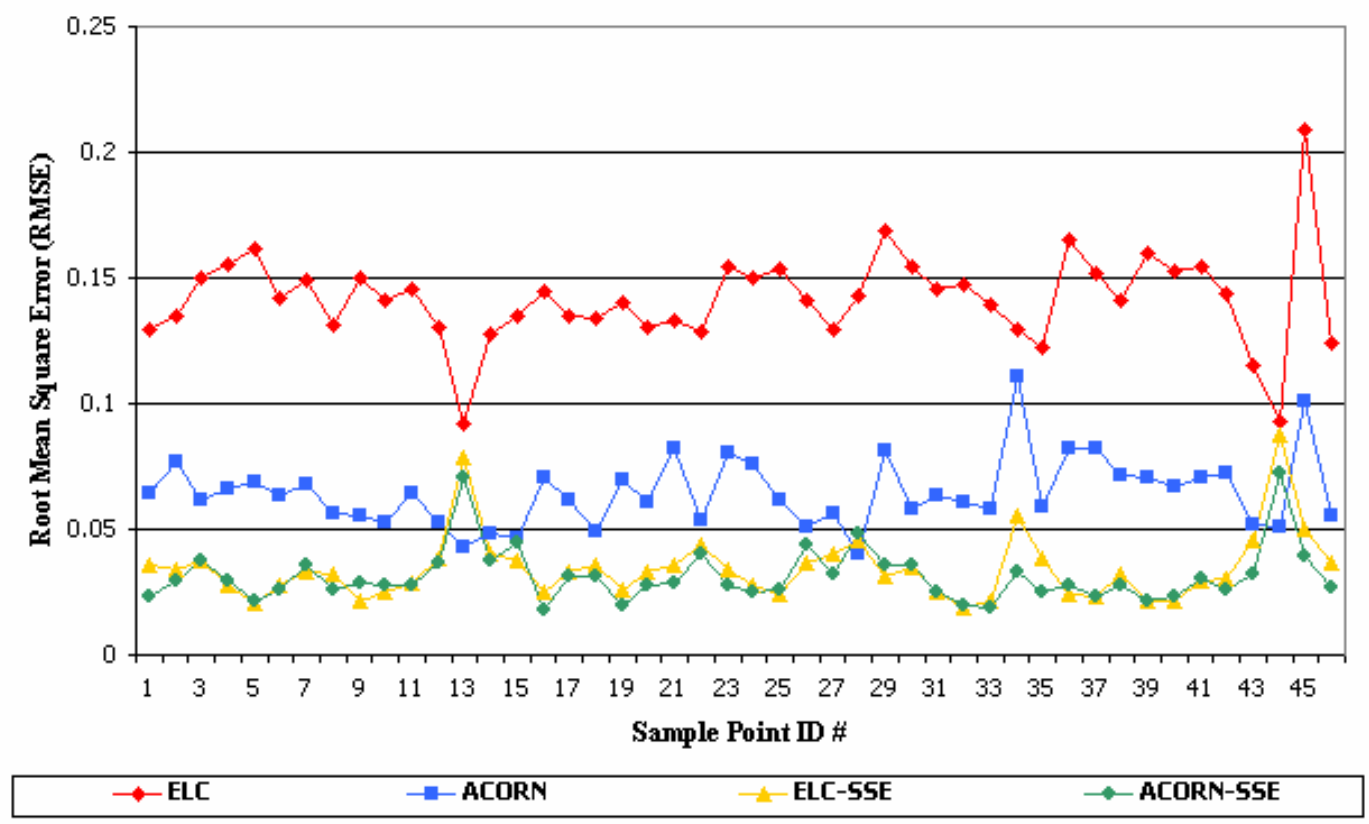

Figure 19. Root mean squared error (RMSE) associated with the output from four atmospheric correction algorithms when compared with in situ ASD spectroradiometer measurements at the same locations.

\section{Geometric Preprocessing of GER Hyperspectral Data}

Remotely sensed airborne scanner data contains systematic (e.g., velocity and direction changes) and nonsystematic (e.g., roll, pitch, yaw, and altitude changes) induced geometric distortions. It was imperative to remove as much of the geometric distortion as possible to utilize the GER 3715 hyperspectral dataset for scientific purposes (e.g. biophysical variable extraction). In this case systematic baseline correction and simple roll correction were performed as part of the vendor's pre-processing. However, the most accurate method to remove geometric distortions involves the use of ground control points (GCPs). Image-to-map rectification is the process by which the geometry of an image is made planimetric (Jensen, 1996). The image-to-map rectification process involves selecting GCP image pixel coordinates (row and column) and associating them with their corresponding map coordinates (e.g., meters in northing and easting in a Universal Transverse Mercator map projection). Image-to-map rectification may not remove all distortion caused by topographic relief displacement. This was not a significant concern for the SRS MWMF clay-cap due to the small variation in local relief.

\subsection{Datum, Map Projection, Ellipsoid and Selection of Ground Control Points}

The MWMF clay-cap and surrounding area was subset (505 rows, 679 columns) from Line \#05 of the GER 3715 hyperspectral dataset. Figure 20 displays the MWMF subset with the locations of the 31 ground control points highlighted in yellow. The GCP locations were selected at the intersections of roads, drainage pipes, and other linear features to limit ambiguity when locating the points in the hyperspectral and orthophoto datsets. The following parameters were selected to be consistent with the coordinate system of the $3 \times 3 \mathrm{~m}$ orthophotography and in situ measurements:

- Datum - North American Datum 1927 (NAD27);

- Map Projection - Universal Transverse Mercator (UTM) Zone 17;

- $\quad$ Ellipsoid - Clarke 1866. 


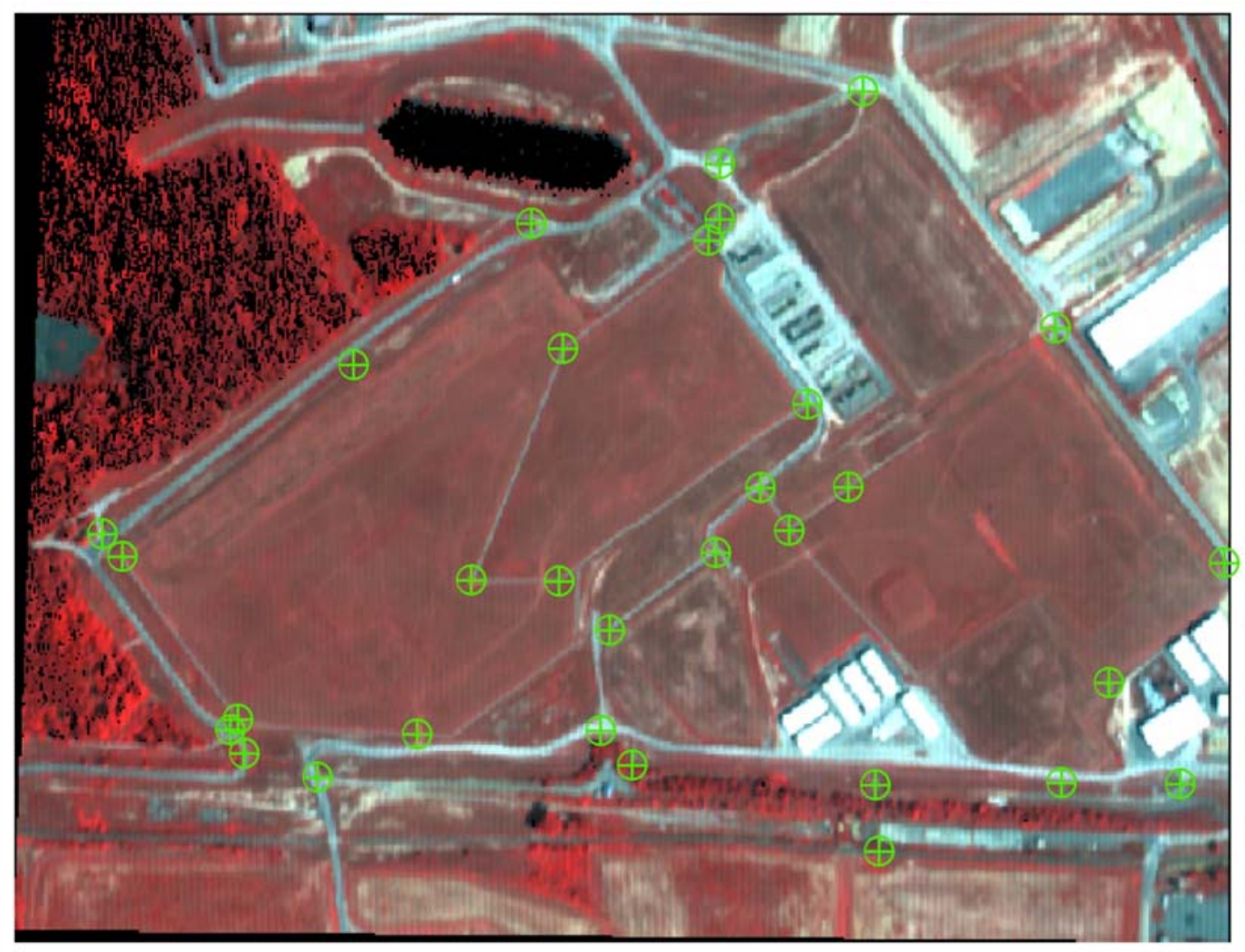

Figure 20. The location of 31 ground control points on the GER 3715 hyperspectral data (color composite bands are $\mathrm{RGB}=20,10,5)$ used to geometrically correct the imagery.

The use of 31 GCPs resulted in a total RMSE of \pm 1.7706 . Table 4 lists the geographic map coordinates (UTM) of the 31 GCPs and their observed and predicted locations in output image space. The RMSE column lists each GCP's individual contribution to the total RMS error. 
WSRC-TR-2003-00275, REVISION 0

Table 4. The location of 31 ground control points and their RMSE. Map coordinates were extracted from the orthophotography and image coordinates were extracted from the GER DAIS 3715 hyperspectral data.

\begin{tabular}{|c|c|c|c|c|c|c|c|c|c|}
\hline GCP \# & Map X & Map Y & Image $X$ & Image $Y$ & Predict X & Predict $Y$ & Error $\mathbf{X}$ & Error $\mathrm{Y}$ & RMSE \\
\hline 1 & 437840.7 & 3682912.8 & 440.13 & 3315.88 & 438.29 & 3317.57 & -1.84 & 1.69 & 2.5 \\
\hline 2 & 437721.9 & 3683079.6 & 349.5 & 3386.25 & 348.97 & 3385.76 & -0.53 & -0.49 & 0.72 \\
\hline 3 & 438171 & 3683054.4 & 360 & 3138.25 & 361.17 & 3138.5 & 1.17 & 0.25 & 1.2 \\
\hline 4 & 438024.9 & 3682897.5 & 445.5 & 3215 & 445.77 & 3216.57 & 0.27 & 1.57 & 1.59 \\
\hline 5 & 438174.9 & 3683292.9 & 233.25 & 3139.5 & 233.46 & 3139.13 & 0.21 & -0.37 & 0.43 \\
\hline 6 & 438407.7 & 3683106.3 & 331.13 & 3009 & 332.74 & 3008.85 & 1.61 & -0.15 & 1.62 \\
\hline 7 & 438681.3 & 3683313.9 & 222.5 & 2858 & 221.52 & 2858.95 & -0.98 & 0.95 & 1.37 \\
\hline 8 & 438324.9 & 3683403.9 & 174.5 & 3057.5 & 173.91 & 3057.14 & -0.59 & -0.36 & 0.69 \\
\hline 9 & 438223.2 & 3683004.3 & 386.75 & 3109 & 387.82 & 3109.28 & 1.07 & 0.28 & 1.11 \\
\hline 10 & 438426.3 & 3683235.6 & 263.2 & 2999.5 & 263.67 & 2999.58 & 0.47 & 0.08 & 0.48 \\
\hline 11 & 438483.6 & 3683556.6 & 94 & 2969.75 & 92.33 & 2970.02 & -1.67 & 0.27 & 1.69 \\
\hline 12 & 438332.1 & 3683083.8 & 343.5 & 3050 & 344.97 & 3050.25 & 1.47 & 0.25 & 1.49 \\
\hline 13 & 438080.7 & 3683055.6 & 360.25 & 3187.75 & 360.8 & 3188.14 & 0.55 & 0.39 & 0.67 \\
\hline 14 & 438855 & 3683073.3 & 351 & 2762.25 & 349.06 & 2762.67 & -1.94 & 0.42 & 1.99 \\
\hline 15 & 438736.5 & 3682950.3 & 416.75 & 2827.75 & 414.82 & 2827.53 & -1.93 & -0.22 & 1.94 \\
\hline 16 & 438809.7 & 3682846.8 & 471 & 2786.5 & 469.54 & 2787.31 & -1.46 & 0.81 & 1.67 \\
\hline 17 & 438213.6 & 3682901.1 & 439.75 & 3112.75 & 443.08 & 3113.41 & 3.33 & 0.66 & 3.4 \\
\hline 18 & 438246.3 & 3682866 & 458.75 & 3094.5 & 461.73 & 3095.16 & 2.98 & 0.66 & 3.05 \\
\hline 19 & 438378 & 3683150.1 & 308 & 3026.75 & 309.43 & 3025.55 & 1.43 & -1.2 & 1.86 \\
\hline 20 & 438142.5 & 3683421 & 165.5 & 3157.75 & 164.9 & 3158.62 & -0.6 & 0.87 & 1.06 \\
\hline 21 & 438336 & 3683425.5 & 160.75 & 3051.5 & 162.36 & 3051.17 & 1.61 & -0.33 & 1.65 \\
\hline 22 & 437959.5 & 3683276.4 & 244.25 & 3256.75 & 242.65 & 3258.09 & -1.6 & 1.34 & 2.09 \\
\hline 23 & 437701.5 & 3683103 & 337.5 & 3397.75 & 336.43 & 3397.43 & -1.07 & -0.32 & 1.12 \\
\hline 24 & 437922.3 & 3682853.7 & 470.75 & 3272.75 & 469.71 & 3271.99 & -1.04 & -0.76 & 1.29 \\
\hline 25 & 438500.1 & 3682777.8 & 508.25 & 2957.25 & 507.69 & 2955.94 & -0.56 & -1.31 & 1.42 \\
\hline 26 & 438336.3 & 3683482.2 & 130.5 & 3053.25 & 132.06 & 3051.51 & 1.56 & -1.74 & 2.34 \\
\hline 27 & 437832.9 & 3682902 & 445.25 & 3323.5 & 444.13 & 3321.65 & -1.12 & -1.85 & 2.16 \\
\hline 28 & 437847.3 & 3682878.3 & 458.5 & 3313.75 & 456.81 & 3313.37 & -1.69 & -0.38 & 1.73 \\
\hline 29 & 438687.6 & 3682847.7 & 471.75 & 2854.75 & 469.6 & 2853.99 & -2.15 & -0.76 & 2.28 \\
\hline 30 & 438468.3 & 3683151 & 308.5 & 2975.75 & 308.73 & 2975.8 & 0.23 & 0.05 & 0.23 \\
\hline 31 & 438496.2 & 3682845.6 & 468.75 & 2958.75 & 471.55 & 2958.49 & 2.8 & -0.26 & 2.81 \\
\hline
\end{tabular}

\subsection{Nearest-Neighbor Resampling}

Intensity interpolation involves the extraction of percent reflectance values from an $x^{\prime}, y^{\prime}$ location in the original (distorted) input image and its relocation to the appropriate $x, y$ coordinate location in the geometrically rectified output image (Jensen, 1996). This pixel filling logic is used to produce the output image line by line, column by column. Most of the time the $x^{\prime}$ and $y^{\prime}$ coordinates to be sampled in the input image are real numbers (i.e. they are not integers). In cases such as this, interpolation (resampling) is required. The primary objective of the resampling process was to maintain the radiometric precision of the original (raw) GER 3715 hyperspectral dataset. Nearest-neighbor or zero-order interpolation assigns each output coordinate with the percent reflectance value closest to the input $\left(x^{\prime}, y^{\prime}\right)$ coordinate. Nearest-neighbor is a computationally efficient procedure and is especially liked by Earth scientists because it does not alter the reflectance values during resampling (Duggin and Rubinove, 1990). 
The diameter of the circular ground area (pixel size) at nadir is a function of the instantaneous field of view (IFOV) of the sensor and the height of the aircraft above ground level (AGL). This function is represented mathematically as:

$$
D=H * \beta
$$

where $D$ is the diameter of the circular ground area viewed by the sensor at nadir, $H$ is the height of the sensor AGL, and $\beta$ is the IFOV of the sensor (radians) (Lilliesand and Kiefer, 1994; Jensen, 1996). Line \#05 was collected at an altitude of 2,400 feet AGL. By applying the correct aperture setting of 3.3 milliradians, the original data acquisition pixel size was calculated to be $2.41 \mathrm{~m}$ in diameter. Therefore, line \#05 of the MWMF subset was resampled using nearest-neighbor interpolation with a pixel size of $2.41 \times 2.41 \mathrm{~m}$.

\section{Reducing the Dimensionality of Hyperspectral Data While Retaining Its Information Content}

The number of spectral bands associated with a remote sensing system is generally referred to as its data dimensionality (Jensen, 1996; 2000). Hyperspectral remote sensing systems such as AVIRIS, the Moderate Resolution Imaging Spectrometer (MODIS) onboard Terra, and the GER 3715 used in this study obtain data in 224 and 34 and 37 bands, respectively. Ultraspectral remote sensing systems collect data in many hundreds of bands. Hyperspectral data contain a tremendous amount of redundant spectral information. This is not surprising when one considers that the individual channels often have a nominal bandwidth of only $10 \mathrm{~nm}$. Thus, in the spectral region from 700 to $800 \mathrm{~nm}$ we can expect to find 10 bands measuring the amount of nearinfrared radiant flux exiting the Earth's surface. While there are certainly subtle differences in the amount of radiant flux recorded in each of these bands, there will probably be a significant amount of redundant spectral information. Statistical analysis usually reveals that many of these 10 bands are in fact highly correlated. Therefore, one can use statistical methods to: a) delete some of the unnecessary redundant bands, or b) transform the data so that the information content is preserved while reducing the dimensionality of the data set. In addition, it is hoped that the data dimensionality reduction method selected will also remove some of the noise present in the hyperspectral dataset.

Statistical measures such as the Optimum Index Factor (OIF), transformed divergence, and traditional Principal Components Analysis (PCA) have been used for decades to reduce the dimensionality of multispectral datasets (Jensen, 1996). Unfortunately, these methods are generally are not sufficient for reducing the dimensionality of hyperspectral data.

\subsection{Minimum Noise Fraction (MNF) Transformation}

A Minimum Noise Fraction (MNF) transformation (Green et al., 1988) was used used to determine the true or inherent dimensionality of the hyperspectral data, to identify and segregate noise in the data, and to reduce the computation requirements of further hyperspectral processing by collapsing the useful information into a much smaller set of minimum noise fraction images (Boardman and Kruse, 1994). The MNF applied two cascaded Principal Components Analyses. The first transformation decorrelated and rescaled the noise in the data. This resulted in transformed data in which the noise had unit variance and no band-to-band correlation. A second Principal Components Analysis transformed the noise-whitened data. The process resulted in the creation of a) coherent MNF eigenimages that contained useful information, and b) noise-dominated MNF eigenimages. Basically, the noise in the hyperspectral dataset was separated from the useful information. This is very important because subsequent hyperspectral data analysis procedures to be discussed function best when the hyperspectral data contain coherent, useful information and very little noise. 
MNF output bands that contain useful image information typically have an eigenvalue an order of magnitude greater than those that contain mostly noise. An analyst can determine the information content of individual MNF eigenimages by a) displaying them on the CRT screen and visually analyzing them, and/or b) plotting their eigenvalues or the amount of variance explained by each eigenvalue. For example, an MNF transformation was applied to GER DAIS 3715 flightline \#05. The first $8 \mathrm{MNF}$ bands were selected for further analysis based on a dual inspection of the spatial coherency of the eigenimages and the corresponding eigenvalue plot. Figure 21 depicts the first $8 \mathrm{MNF}$ eigenimages. Generally, the more spatially coherent the image, the less noise and greater the information content. The graph of the eigenvalues by band reveals that the first 8 eigenimages contained most of the valuable information. MNF eigenimages with values close to 1 contain mostly noise. MNF bands with eigenvalues $>1$ account for most of the variance in the hyperspectral dataset. Great care should be exercised in the selection of the MNF bands to keep for subsequent hyperspectral image processing. Consequently, only the first $8 \mathrm{MNF}$ bands associated with flightline $\# 05$ were deemed useful for subsequent hyperspectral endmember analysis of the Savannah River Site study area. 


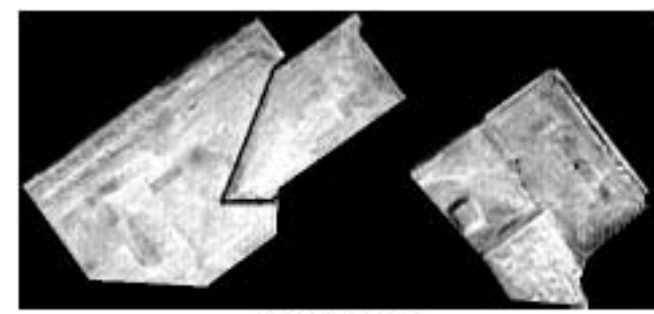

MNFF Band 1

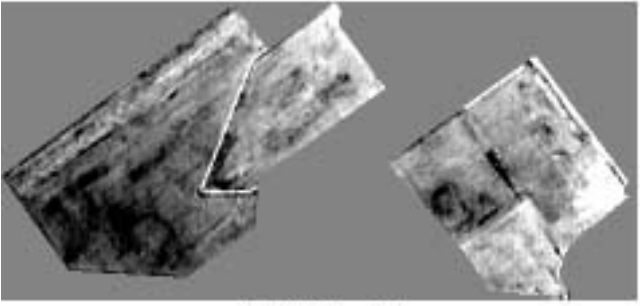

MNFF Band 3

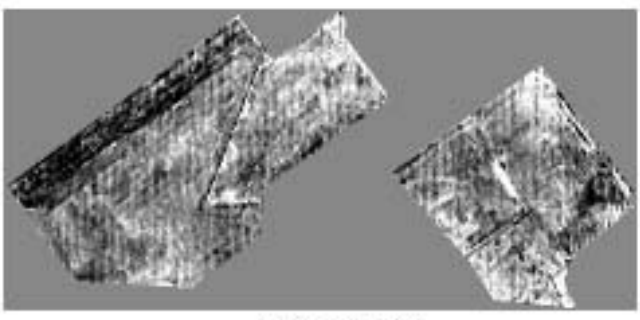

MNF Band 5

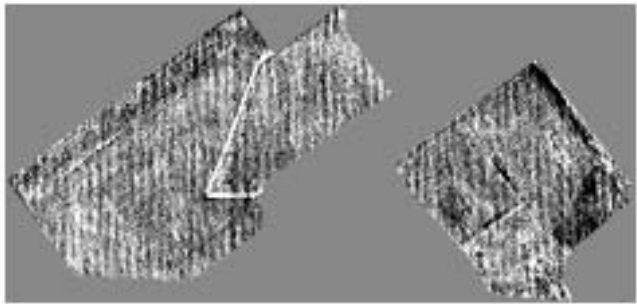

MNF Band $?$

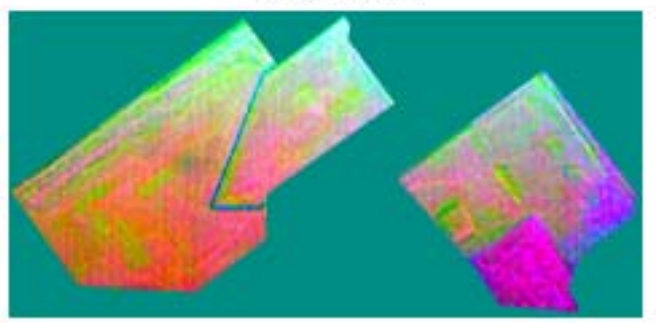

MNF Bands 1,2,3 = RGB

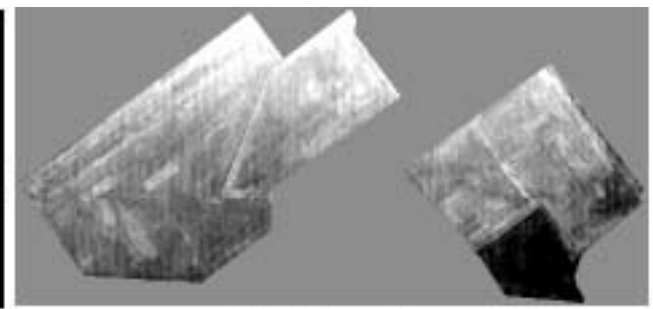

MNF Band 2

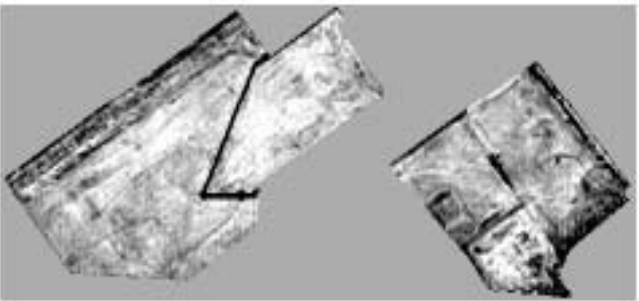

MNF Band 4

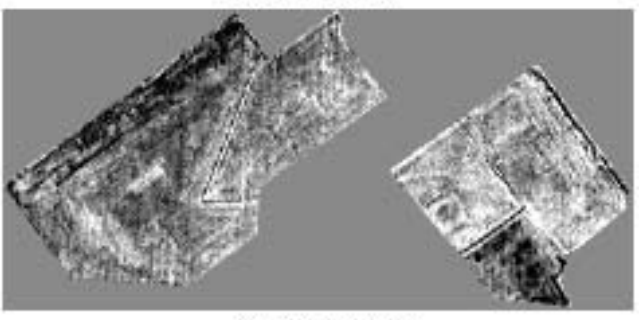

MNF Band 6

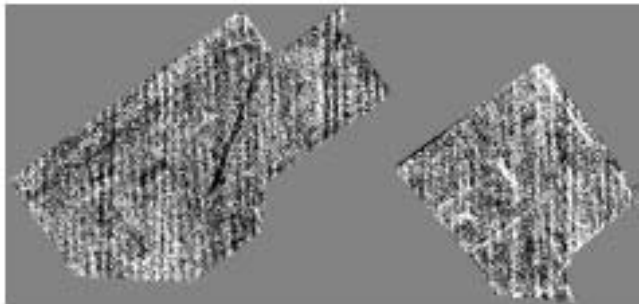

MNF Band 8

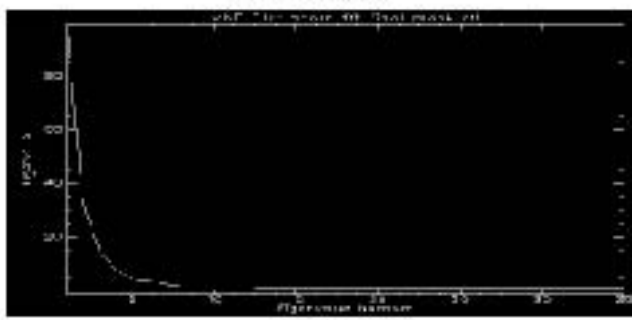

MNF Eigenvalues

Figure 21. Eight minimum noise fraction (MNF) images, a color composite of MNF bands 1, 2 and 3 (RGB), and the eigenvalues associated with each of the MNF bands. 
WSRC-TR-2003-00275, REVISION 0

\section{Endmember Determination - Finding Pixels with Relatively Pure Spectral Characteristics}

One of the goals of this study was to determine the spatial distribution of the various vegetation and other land cover associated with the MWMF. These are called endmembers and represent relatively pure materials such as bahiagrass, centipede, concrete, and bare soil. Most of the time the spectral reflectance entering the IFOV of the sensor system at the instant of data collection is a function of the radiant flux from a variety (mixture) of endmember materials (Theseria et al., 2002). If we can identify the spectral characteristics of the endmember materials, then it may be possible to identify pixels that contain varying proportions of these materials. There are several methods of identifying the most spectrally pure endmembers in a multispectral or hyperspectral scene. This study used the pixel purity index and $n$-dimensional visualization of endmembers in feature space.

\subsection{Pixel Purity Index (PPI) Mapping}

Reflectance measurements (often referred to as spectra) may be obtained in $n$-bands at a specific location on the Earth's surface using a hand-held spectroradiometer or a multispectral or hyperspectral remote sensing instrument. The reflectance spectra from a particular pixel of soil, water, or vegetation may be plotted in $n$ dimensional space. A more rigorous mathematical method of determining the most spectrally pure pixels is to repeatedly project $n$-dimensional scatterplots of the clean minimum noise fraction (MNF) images previously discussed onto a random unit vector. Each time the spectral data are projected the most extreme pixels in each projection are noted (Research Systems, Inc., 2000). By carefully keeping track of which pixels in the scene repeatedly come up as 'extreme' pixels, it is possible to create a pixel purity index (PPI) image. Basically, the higher the pixel value in the pixel purity index image the greater the number of times it was judged to be a spectrally extreme pixel (e.g., a relatively pure concrete or pure vegetation endmember). It is important to include as input to the PPI calculation only MNF images that contain valuable spectral information. MNF bands that contain noise were not be included in the analysis. The PPI image identified the location of the most pure pixels (i.e., endmember candidates). Unfortunately, it is difficult to label the different types of endmembers present by just viewing the 2 -dimensional pixel purity index image. Therefore, $n$-dimensional visualization was used.

\subsection{N-dimensional Endmember Visualization}

By using more than two of the MNF bands at a time it was possible to interactively view the endmembers in $n$ dimensional spectral space on the CRT screen (Boardman, 1993). By comparing the actual spectra of an endmember found within the $n$-dimensional CRT display with where it is actually located in $x, y$ space in the MNF image, it was possible to label the hopefully pure pixel as a specific type of endmember, e.g., vegetation, or asphalt. Endmembers derived in this manner may then be used to perform spectral matching or classification. Masked MNF images were analyzed to produce the pixel purity index image (and spectral profiles of the most pure pixels) previously discussed. These data were then displayed as data clouds in $n$ dimensional feature space (Figure 22). 


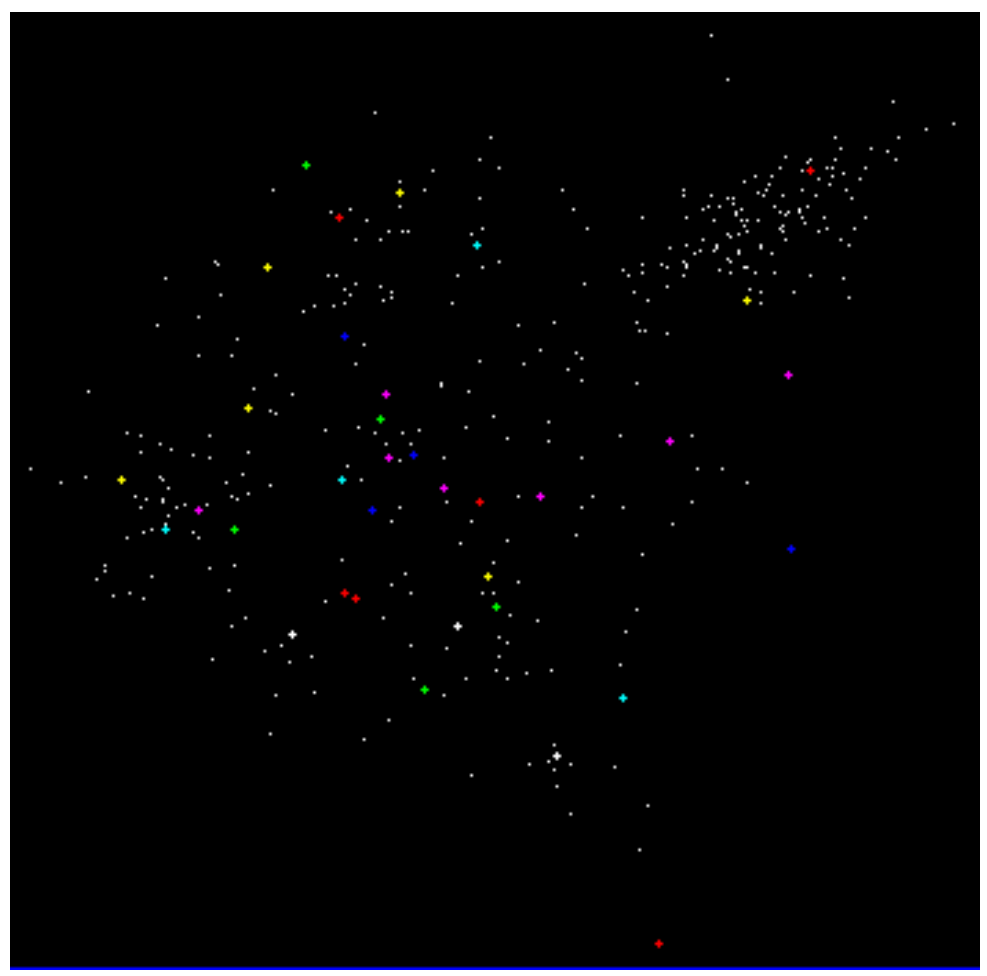

Figure 22. N-dimensional visualization of the most pure pixels found in the DAIS 3715 hyperspectral dataset. The colored points represent unique endmembers.

\section{Methods of Spectral Matching and Mapping Using Hyperspectral Data}

Several algorithms may be used to convert endmember information into thematic maps, including: the Spectral Angle Mapper (SAM), matched filtering, and linear spectral unmixing. This research achieved the best results using the SAM algorithm.

\subsection{Spectral Angle Mapper}

A spectral angle mapping subroutine takes an atmospherically corrected unlabeled pixel (e.g., composed of a DAIS 3715 measurement vector of $n$ reflectance values) and compares it with reference spectra in the same $n$ dimensions. The reference spectra may be obtained using: 1) calibrated in situ or laboratory derived spectroradiometer measurements stored in an ASCII or binary spectral library, 2) theoretical calculations, and/or 3) multispectral or hyperspectral image endmember analysis procedures as previously discussed. The algorithm compares the angle $(\alpha)$ between the reference spectrum $(r)$ and the hyperspectral image pixel measurement vector $(t)$ in $n$-dimensions and assigns it to the reference spectrum class that yields the smallest angle (Figure 23) (Kruse et al., 1993; Boardman and Kruse, 1994). The Spectral Angle Mapper algorithm computes the similarity of an unknown spectrum $t$ to a reference spectrum $r$ using the following equation (Equation 6) where $n$ equals the number of bands in the hyperspectral image (Research Systems, Inc., 2000): 


$$
\alpha=\cos ^{-1}\left[\frac{\sum_{b=1}^{n} t_{b} r_{b}}{\sqrt{\sum_{b=1}^{n} t_{b}^{-2} \cdot \sum_{b=1}^{n} r_{b}^{2}}}\right]
$$

Basically, for each reference spectrum $r$ (this could be an in situ-derived endmember or a remote sensingderived endmember) a spectral angle $(\alpha)$ was computed for each unknown image spectrum (pixel) in the dataset. The output from SAM is a classified image and a set of rule images corresponding to the spectral angle calculated between each pixel and each endmember (one rule image per endmember).

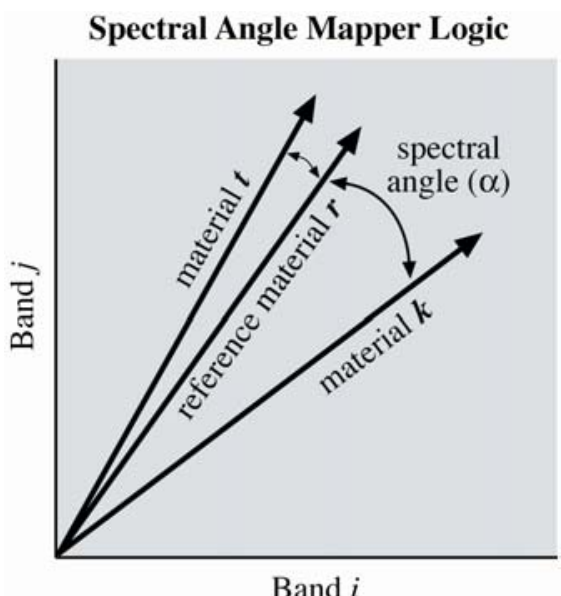

Figure 23. The nomenclature of the Spectral Angle Mapper (SAM) algorithm.

Analysis of the SAM-derived classified image was performed inconjucntion with a) the set of 35 rule images, and b) knowledge of the land cover characteristics at 47 sites in the MWMF. The information content from the SAM classified image was collapsed into a hardened thematic classification of the MWMF containing just four classes (Figure 24):

1. Bahiagrass [Paspalum notatum Flugge var. saurae Parodi];

2. Centipede [Eremochloa ophiuroides (Munro) Hack.];

3. Bare soil; and,

4. Concrete.

The thematic map documents show much of the MWMF facility consists of predominantly bahiagrass. The proportion of centipede generally increases toward the northwest. There is an extensive area of relatively bare soil in the east portion of the MWMF. A concrete culvert runs through the MWMF. Clay-capped hazardous waste sites are supposed to have a relatively uniform, homogenous cover of turfgrass. Maps such as this suggest that on this date the turfgrass may not have been uniformly distributed. The centipede patch centered on in situ measurement sites \#44 and \#45 is a good example. The display provides valuable spatial information that can be of significant value to the personnel responsible for clay-cap maintenance. 


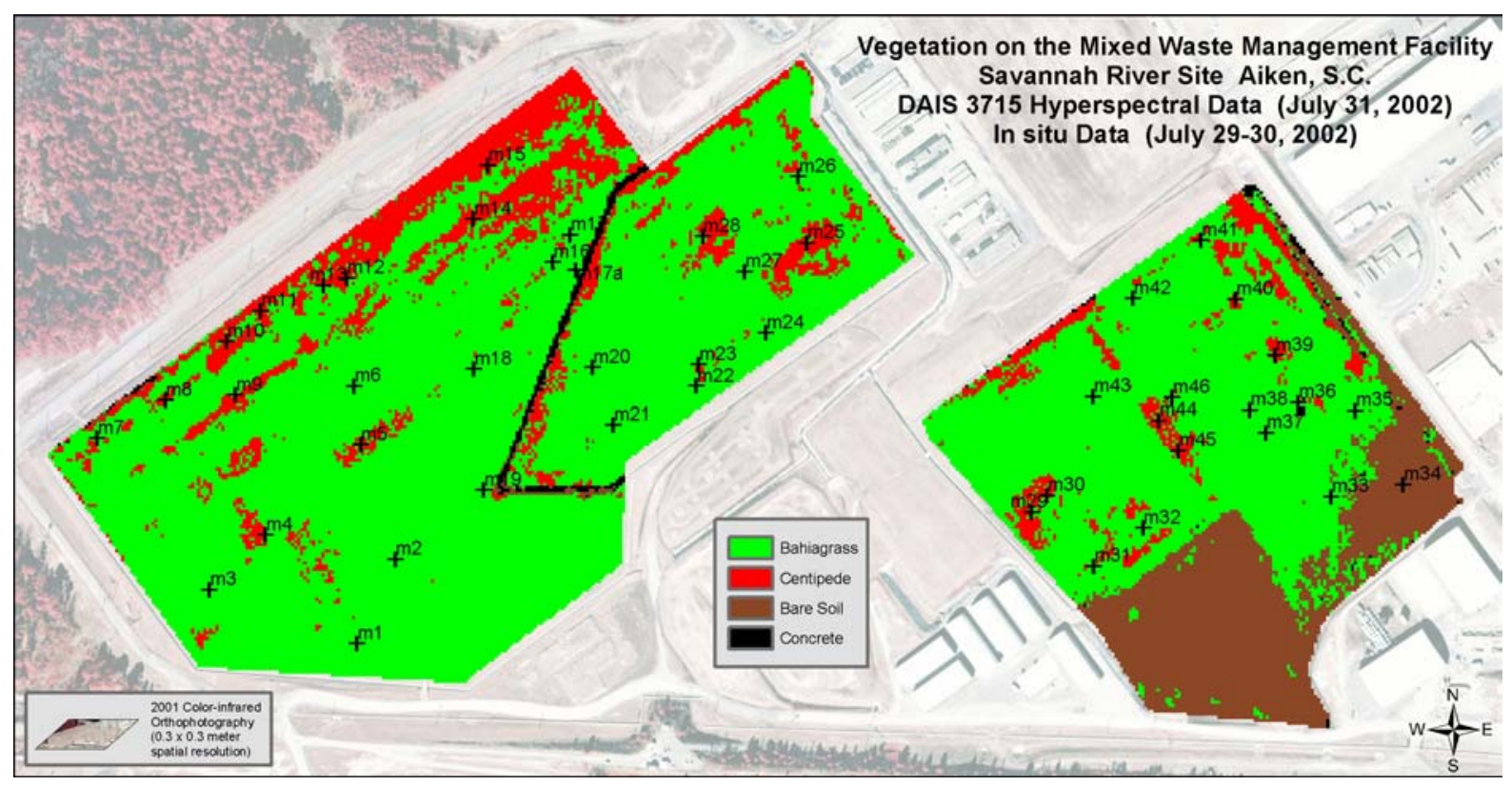

Figure 24. The spatial distribution of Bahiagrass, Centipede, Bare Soil, and Concrete on the MWMF derived using DAIS 3715 hyperspectral image-derived endmembers and a spectral angle mapper (SAM) algorithm.

\subsubsection{Accuracy of the SAM-derived Thematic Map}

A thematic map is of no value unless its accuracy can be verified. Standard accuracy assessment techniques were applied to assess the accuracy of Figure 24. Ground reference information consisted of 47 in situ observations obtained from July 29-30, 2002 (37 Bahiagrass, 9 Centipede, and 1 Bare Soil). Using large-scale aerial photography obtained at the time of data acquisition, an additional 29 reference points were allocated in the bare soil region using random sampling techniques. Twenty concrete reference points were collected in a similar random manner along the culvert. An example of the large-scale aerial photography is shown in Figure 25.

The overall accuracy of the classification map was 89\% with a Kappa Coefficient of Agreement (Feinstein, 1998) of 0.8581 (Table 5). Errors of commission and omission and Producer's and User's accuracy are also presented. Bahiagrass and centipede were classified correctly $83.78 \%$ and $77.78 \%$ of the time, respectively. The SAM algorithm had little problem identifying bare soil or concrete pixels (100\% and $90.91 \%$ accuracy, respectively). 
WSRC-TR-2003-00275, REVISION 0

Table 5. Classification accuracy of the MWMF thematic map produced from GER DAIS 3715 hyperspectral image-derived endmembers and a spectral angle mapper (SAM) algorithm.

\begin{tabular}{|c|c|c|c|c|c|}
\hline & \multicolumn{4}{|c|}{ Ground Reference Information (Pixels) } & \multirow[b]{2}{*}{ Total } \\
\hline Class & Bahiagrass & Centipede & Bare soil & Concrete & \\
\hline Bahiagrass & 31 & 2 & 0 & 0 & 33 \\
\hline Centipede & 6 & 7 & 0 & 2 & 15 \\
\hline Bare soil & 0 & 0 & 30 & 0 & 30 \\
\hline Concrete & 0 & 0 & 0 & 20 & 20 \\
\hline Total & 37 & 9 & 30 & 22 & 98 \\
\hline & \multicolumn{4}{|c|}{ Ground Reference Information (Percent) } & \\
\hline Class & Bahiagrass & Centipede & Bare soil & Concrete & Total \\
\hline Bahiagrass & 83.78 & 22.22 & 0 & 0 & 33.67 \\
\hline Centipede & 16.22 & 77.78 & 0 & 9.09 & 15.31 \\
\hline Bare soil & 0 & 0 & 100 & 0 & 30.61 \\
\hline Concrete & 0 & 0 & 0 & 90.91 & 20.41 \\
\hline \multirow[t]{2}{*}{ Total } & 100 & 100 & 100 & 100 & 100.00 \\
\hline & $\begin{array}{c}\text { Commission } \\
\text { (Percent) }\end{array}$ & $\begin{array}{l}\text { Omission } \\
\text { (Percent) }\end{array}$ & $\begin{array}{c}\text { Comission } \\
\text { (Pixels) }\end{array}$ & $\begin{array}{c}\text { Omission } \\
\text { (Pixels) }\end{array}$ & \\
\hline Class & 6.06 & 16.22 & $2 / 33$ & $6 / 37$ & \\
\hline Bahiagrass & 53.33 & 22.22 & $8 / 15$ & $2 / 9$ & \\
\hline Centipede & 0 & 0 & $0 / 30$ & $0 / 30$ & \\
\hline \multirow[t]{2}{*}{ Bare soil } & 0 & 9.09 & $0 / 20$ & $2 / 22$ & \\
\hline & $\begin{array}{c}\text { Producer's } \\
\text { Accuracy } \\
\text { (Percent) }\end{array}$ & $\begin{array}{c}\text { User's } \\
\text { Accuracy } \\
\text { (Percent) }\end{array}$ & $\begin{array}{c}\text { Producer's } \\
\text { Accuracy } \\
\text { (Pixels) }\end{array}$ & $\begin{array}{c}\text { User's } \\
\text { Accuracy } \\
\text { (Pixels) }\end{array}$ & \\
\hline Class & 83.78 & 93.94 & $31 / 37$ & $31 / 33$ & \\
\hline Bahiagrass & 77.78 & 46.67 & $7 / 9$ & $7 / 15$ & \\
\hline Centipede & 100.00 & 100.00 & $30 / 30$ & $30 / 30$ & \\
\hline Bare soil & 90.91 & 100.00 & $20 / 22$ & $20 / 20$ & \\
\hline \multicolumn{6}{|c|}{ Overall classification accuracy $=(88 / 98)=89.79 \%$} \\
\hline \multicolumn{6}{|c|}{ Kappa Coefficient of Agreement $=0.8581$} \\
\hline
\end{tabular}




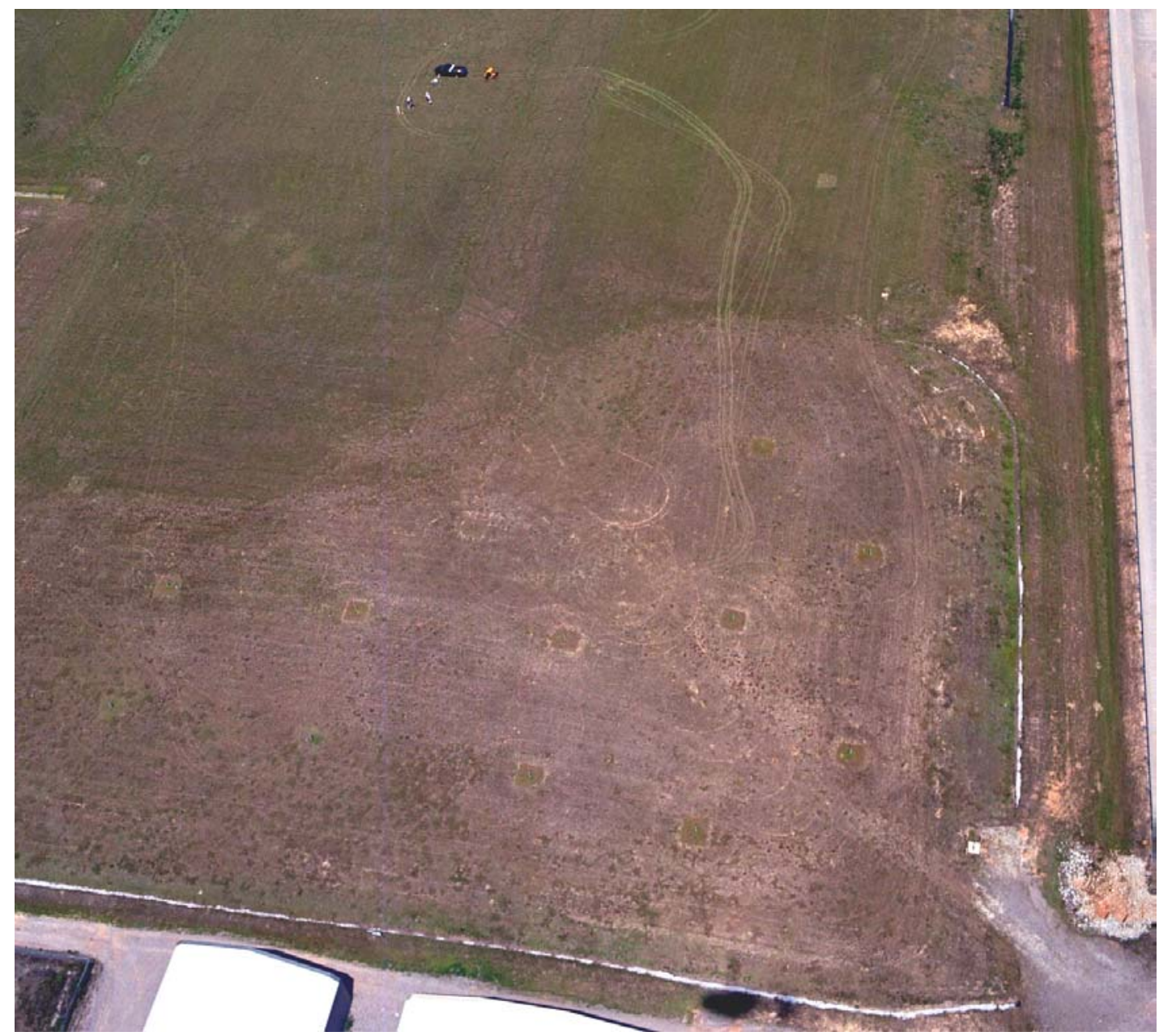

Figure 25. An example of the large-scale aerial photography used to obtain additional bare soil and concrete reference points. A field crew is in the process of collecting spectroradiometer data and biomass samples. A portion of the bare soil region is in the foreground.

\section{Derivative Spectroscopy}

\subsection{First, Second, and Higher-order Derivative Images Derived from GER DAIS 3715 Data}

Due to the inherent differences between laboratory- and remotely sensed data, not all laboratory-based spectroscopic procedures translate well to remotely sensed inquiries. Laboratory analysis is characterized by controlled illumination sources and viewing geometries, as well as the by the typical assumption of homogenous target samples and the use of a known standard. Conversely, imaging spectroscopic remote sensing entails a natural illumination source, mixed pixels, varying topography, coarser spectral resolution than laboratory spectrophotometers, and the general lack of useful reference standards (Tsai and Philpot, 1998). While derivative techniques have been applied to remote sensor imagery (e.g., Demetriades-Shah et al., 1990; Philpot, 1991; Li et al., 1993; Penuelas et al., 1993; Tsai and Philpot, 1998), such applications have been rather limited to date. Nevertheless, there are advantages to utilizing derivative-based analytical techniques with remotely sensed data. Derivative spectra are sometimes more informative than zero-order reflectance spectra when attempting to glean certain information and/or relationships from the data. For example, Malthus and Madeira (1993) found first-order derivative spectra in the visible wavelengths to be more highly correlated with percent leaf surface area infected by the fungus Botrytis fabae than the original zero-order reflectance data. 
WSRC-TR-2003-00275, REVISION 0

$1^{\text {st }}, 2^{\text {nd }}, 3^{\text {rd }}, 4^{\text {th }}, 5^{\text {th }}$, and $10^{\text {th }}$-order derivative spectra were computed on a pixel-by-pixel basis for the DAIS 3715 hyperspectral data of the MWMF. Numerical differentiation of tabulated functions at tabular points was employed. The differentiation was performed using three-point Lagrangian formulas (Equation 7) (Hildebrand, 1956):

$$
\begin{aligned}
& f_{-1}^{\prime}=\frac{1}{2 h}\left(-3 f_{-1}+4 f_{0}-f_{1}\right)+\frac{h^{2}}{3} f^{\prime \prime \prime}(\xi) \\
& f_{0}^{\prime}=\frac{1}{2 h}\left(-f_{-1}+f_{1}\right)-\frac{h^{2}}{6} f^{\prime \prime \prime}(\xi) \\
& f_{1}^{\prime}=\frac{1}{2 h}\left(f_{-1}-4 f_{0}+3 f_{1}\right)+\frac{h}{3} f^{\prime \prime \prime}(\xi)
\end{aligned}
$$

where $f_{0}^{\prime}$ is the $1^{\text {st }}$ derivative at the center point; the subscripts $0,-1$, and 1 denote the $1^{\text {st }}$ derivative at the center point, and points to the left and right of the center point, respectively; and $h$ and $\xi$ are distance and error terms, respectively. Differentiating three-point Lagrangian interpolation formulas and evaluating the results at tabular points yields these derivative formulas. Each $\xi$ lies within the range of data values of the abscissas involved in that particular formula. The truncation error is minimized when the derivative is computed at the central point, and the ordinate at that point is not used in the computation (Hildebrand, 1956). The higher-order derivative spectra were calculated in an analogous manner.

Higher-order derivative spectra can in some cases accrue advantages over first-order spectra. In remote sensing, higher-order derivatives (second-order and higher) are relatively insensitive to illumination intensity variations due to cloud cover, sun angle variance, or topographic effects. In addition, derivatives are typically insensitive to changes in spectral solar flux and skylight, given the spectral resolution of most current imaging spectrometers (Tsai and Philpot, 1998). Derivative techniques can also be used to address interference from soil background reflectance in vegetation remote sensing studies (i.e., separating the vegetative signal from background noise). $2^{\text {nd }}$ derivative spectra, which are insensitive to soil reflectance, specifically mitigate this problem, while $1^{\text {st }}$ derivative spectra do not (Demetriades-Shah, 1990; Li et al., 1993;). A derivative ratio algorithm that makes use of derivatives of a radiative transfer equation can also be relatively insensitive to some atmospheric effects (Philpot, 1991). In general, derivative spectroscopic techniques have been applied to remotely sensed data to only a limited extent in the literature, and most existing studies only consider derivatives of the $1^{\text {st }}$ and $2^{\text {nd }}$ order (Tsai and Philpot, 1998).

Derivative spectroscopic techniques can also be disadvantageous. For instance, the signal-to-noise ratio (SNR) degrades at increasingly higher derivative orders (Talsky, 1994). Derivative spectra are sensitive to noise, and the DAIS 3715 dataset contained noise (especially banding) even after radiometric correction. Algorithms based on least square fitting are commonly utilized to reduce random noise in the spectral data (Tsai and Philpot, 1998). Differentiation acts as a high-pass filter, the effects of which can be countered by a low-pass filter-smoothing step (O'Haver, 1982). It is important, however, to strike a good balance between smoothing for noise reduction and signal retention. For instance, Malthus and Madeira (1993) found lower correlations between $2^{\text {nd }}$ derivative spectra and percent leaf surface area infected by a fungus, likely due at least in part to a decrease in signal detail in the $2^{\text {nd }}$ derivative spectra after smoothing. Smoothing can significantly decrease the effective spectral resolution and broaden peak widths; there is a trade-off between potential increases in SNR and peak-height attenuation as the level of smoothing increases (O'Haver, 1982). Also note that the low-altitude GER DAIS 3715 data was of relatively high radiometric resolution (15-bit) faclitating the generation of high quality higher-order derivative spectra. 
WSRC-TR-2003-00275, REVISION 0

Derivative spectroscopy data are often correlated with biophysical variables such as leaf surface area (Malthus and Madeira, 1993). Therefore, each of the derivative images were correlated with the in situ biomass data for bahiagrass and centipede. Graphs depicting the correlation coefficient of each derivative band (1-35) with biomass for the $1^{\text {st }}, 2^{\text {nd }}, 3^{\text {rd }}, 4^{\text {th }}, 5^{\text {th }}$, and $10^{\text {th }}$ derivatives are found in Figure 26 a-f. Note that the visible and near-infrared bands do not contribute much information. Conversely, several middle-infrared derivative bands are correlated with biomass. The highest correlation with biomass was found using the $1^{\text {st }}$ derivative band 25 where $r=0.6417(\mathrm{y}=-0.1857 \mathrm{x}+85.187)$. When an exponential function is used $r=0.696\left(\mathrm{y}=84.654 \mathrm{e}^{-0.0015 \mathrm{x}}\right)$. While this is encouraging, biomass maps were not produced from this relationship because higher correlations were obtained using other indices to be discussed.

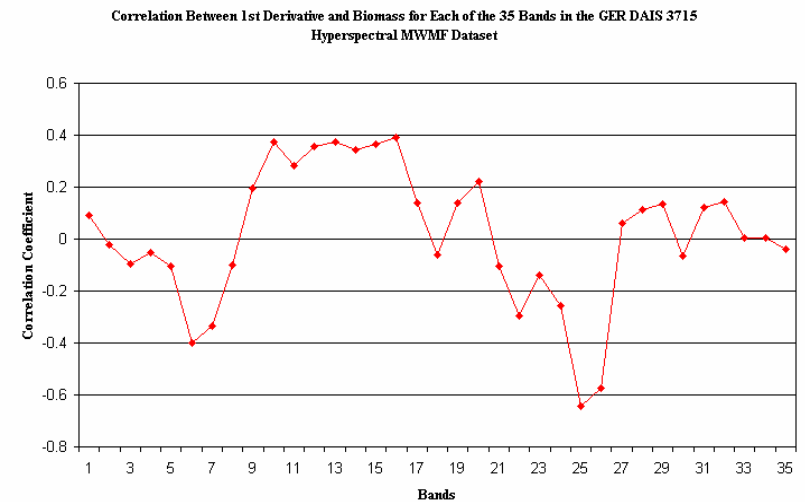

(a)

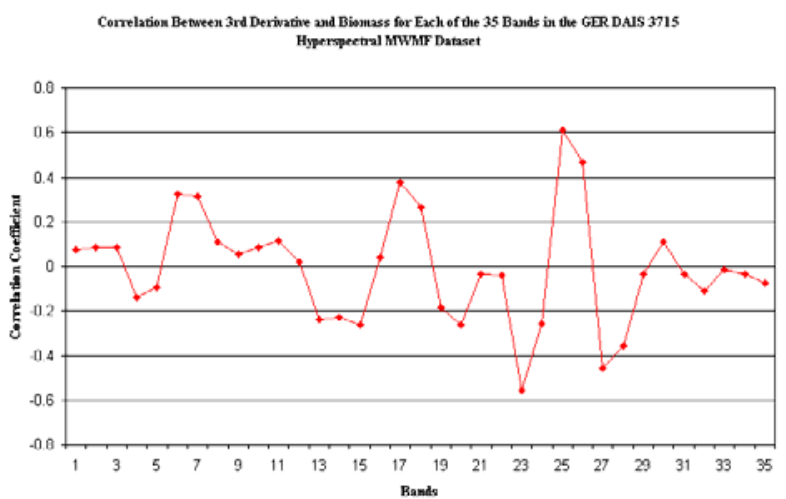

(c)

Correlation Betreen Sth Derivative and Bionmass for Each of the 35 Bands in the GER DAus 3715 Hyperspeetral MWMF Datasert

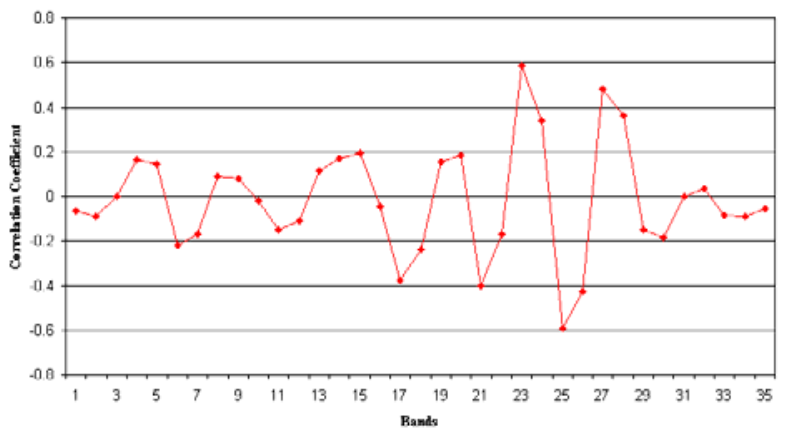

(e)

Figure 26. a) Correlation of the individual $1^{\text {st }}$ derivative hyperspectral bands with in situ biomass. b) $2^{\text {nd }}$ derivative. c) $3^{\text {rd }}$ derivative. d) $4^{\text {th }}$ derivative. e) $5^{\text {th }}$ derivative. f) $10^{\text {th }}$ derivative. Note that most of the high correlation is associated with the middle-infrared bands from $21-26$. The highest correlation with biomass was found using $1^{\text {st }}$ derivative band 25 where $r=0.6417(\mathrm{y}=-0.1857 \mathrm{x}+85.187)$. If an exponential function is used the $r=0.696\left(\mathrm{y}=84.654 \mathrm{e}^{-0.0015 \mathrm{x}}\right)$.

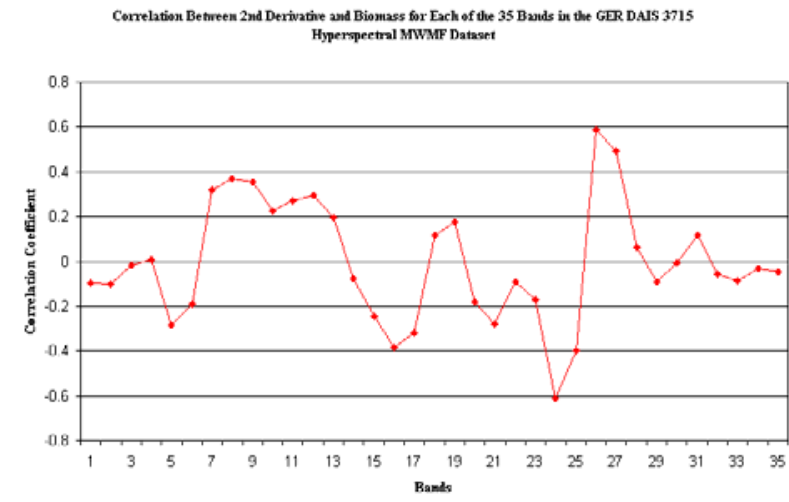

(b)

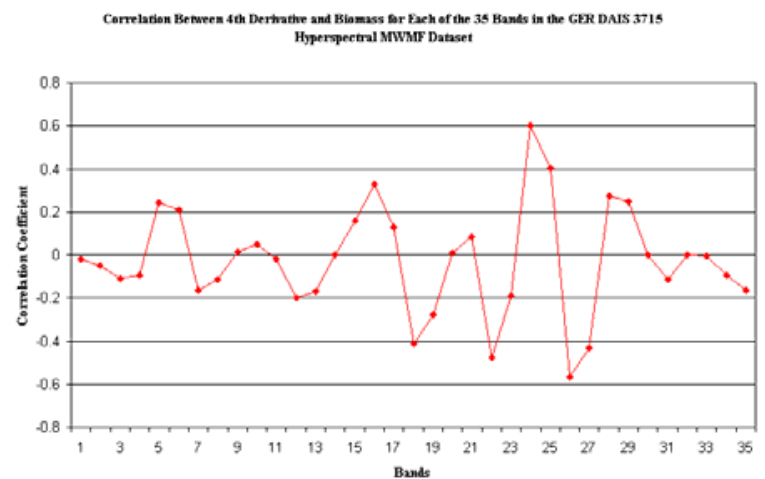

(d)

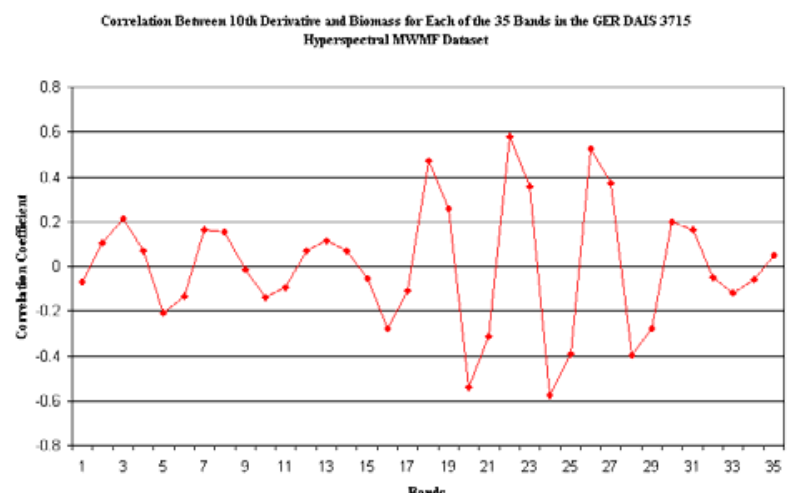


WSRC-TR-2003-00275, REVISION 0

\section{Traditional and Hyperspectral Vegetation Indices}

Traditional vegetation indices have been developed for use with multispectral data that can be of value for monitoring the condition of vegetation on hazardous waste sites. There are also indices developed especially for use with hyperspectral data.

\subsection{Normalized Difference Vegetation Indices}

One common index is the normalized difference vegetation index (NDVI)) based on the following equation (Equation 8) (Tucker, 1979; Jensen, 2000):

$$
N D V I=\frac{N I R-R E D}{N I R+R E D}
$$

where $N I R$ and $R E D$ are reflectance values in the near-infrared and visible spectral regions, respectively. Generally, reflectances from a red channel centered around $660 \mathrm{~nm}$ and a near-infrared channel centered on $860 \mathrm{~nm}$ are used to calculate the NDVI. In this study, the NDVI was implemented in a manner based on the work of Elvidge and Chen (1995) to facilitate comparisons with the derivative-based vegetation indices investigated. One NIR and 2 red channels were used to derive 2 different NDVI images (Equations 9 and 10):

$$
\begin{aligned}
& N D V I \# 1=\frac{N I R(864.1 \mathrm{~nm})-R E D(663.4 \mathrm{~nm})}{N I R(864.1 \mathrm{~nm})+R E D(663.4 \mathrm{~nm})} \\
& N D V I \# 2=\frac{N I R(864.1 \mathrm{~nm})-R E D(682.4 \mathrm{~nm})}{N I R(864.1 \mathrm{~nm})+R E D(682.4 \mathrm{~nm})}
\end{aligned}
$$

The near-infrared band empirically corresponds to the long-wavelength shoulder of the chlorophyll red-edge and the red band is associated with the maximum chlorophyll absorption. Note that this is only one possible narrow-band implementation of the standard NDVI. Many other band combinations could be used instead, and the optimal combination could be determined via an in-depth sensitivity analysis. The purpose of this component of the present research, however, was to demonstrate the utility of true hyperspectral vegetation indices, which have yielded promising results elsewhere (e.g., Elvidge and Chen, 1995) in that they perform better than narrow-band implementations of broadband equations such as NDVI and SAVI (Jensen, 2000). Thus, the inclusion of a narrow-band NDVI in this work was for the purpose of general comparison with the hyperspectral indices discussed below, with the caveat that they may or may not be the optimal NDVI.

Interestingly, neither the NDVI\#1 or NDVI\#2 vegetation index images correlated well with the in situ unstressed bahiagrass and centipede biomass data. Visual examination of the input red and near-infrared bands revealed that there was not much contrast among the various vegetation types found on the MWMF in these particular bands, suggesting that they do not contain much spectral information of value. Conversely, several of the GER middle-infrared bands (e.g., \#29) appeared to contain a substantial amount of contrast suggesting that they might contain useful spectral information. Thus, in addition to the traditional near-infrared normalized difference vegetation indexes, an additional normalized difference vegetation index based on the use of GER middle-infrared band $29(2161.6 \mathrm{~nm})$ and GER band $11(682.4 \mathrm{~nm})$ was developed (Equation 11):

$$
M I D-N D V I=\frac{M I R(2162.6 n m)-R E D(682.4 n m)}{M I R(2162.6 n m)+R E D(682.4 n m)}
$$


The MID-NDVI image was regressed with the in situ unstressed bahiagrass and centipede biomass data at 28 locations. This resulted in a correlation coefficient $(r)$ of 0.74 which accounted for $55 \%$ of the variance $\left(r^{2}\right)$ (Figure 27).

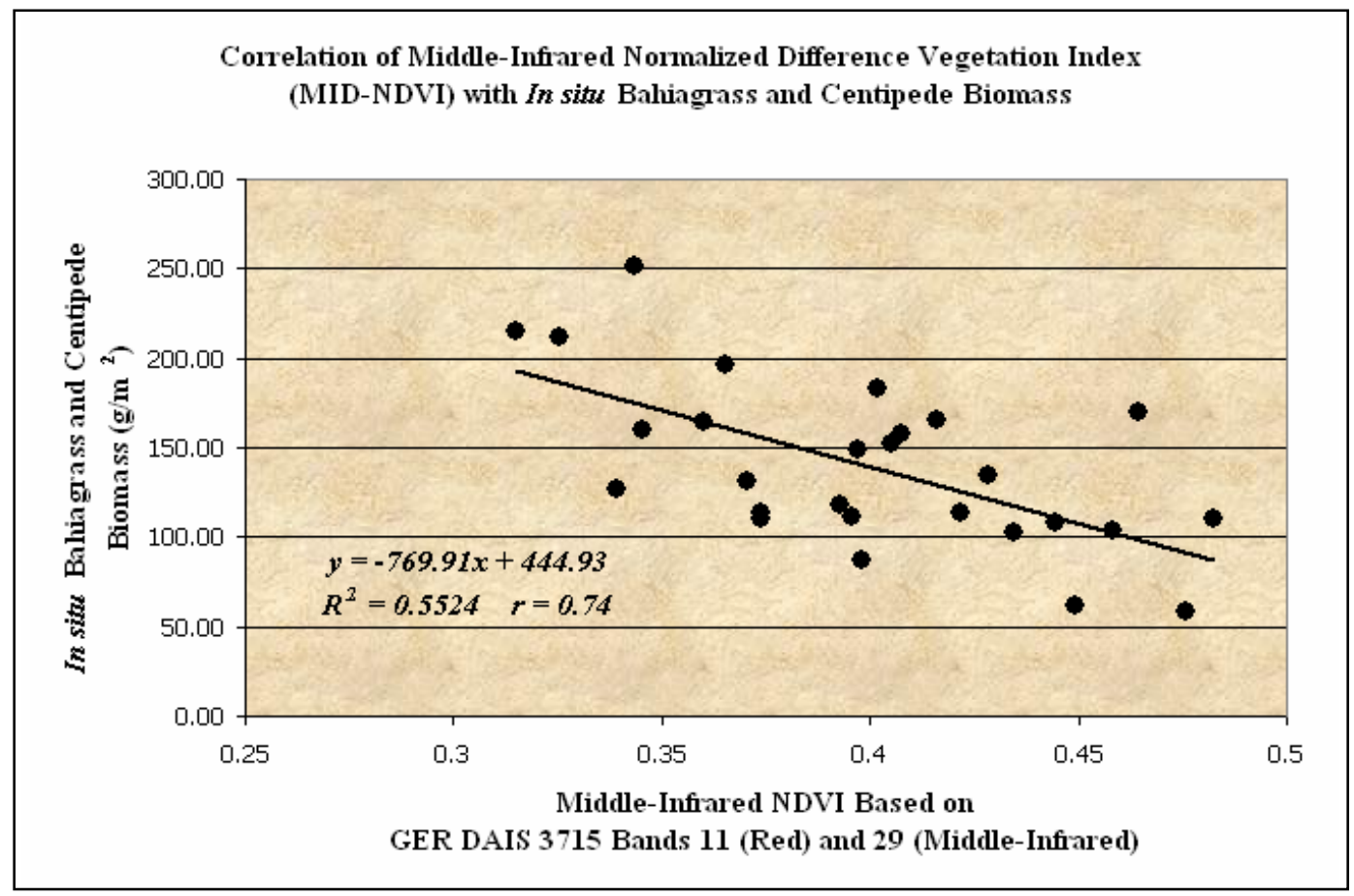

Figure 27. The regression relationship between a vegetation index derived from GER middle-infrared (Band $29 ; 2161.6 \mathrm{~nm}$ ) and red (Band 11; $682.4 \mathrm{~nm}$ ) reflectance data and 28 in situ unstressed bahiagrass and centipede biomass measurements.

The regression relationship was used to create a map of the biomass of the MWMF (Figure 28). MWMF biomass tends generally to increase from south to north and northwest. There are specific pockets of greater biomass that may be a function of unique soil type or soil preparation techniques that were applied. Centipede in the northwest portion of the study area appears to have the greatest biomass while the bare soil region is particularly devoid of biomass (please refer to the classification map in Figure 24 and the biomass map in Figure 28). 


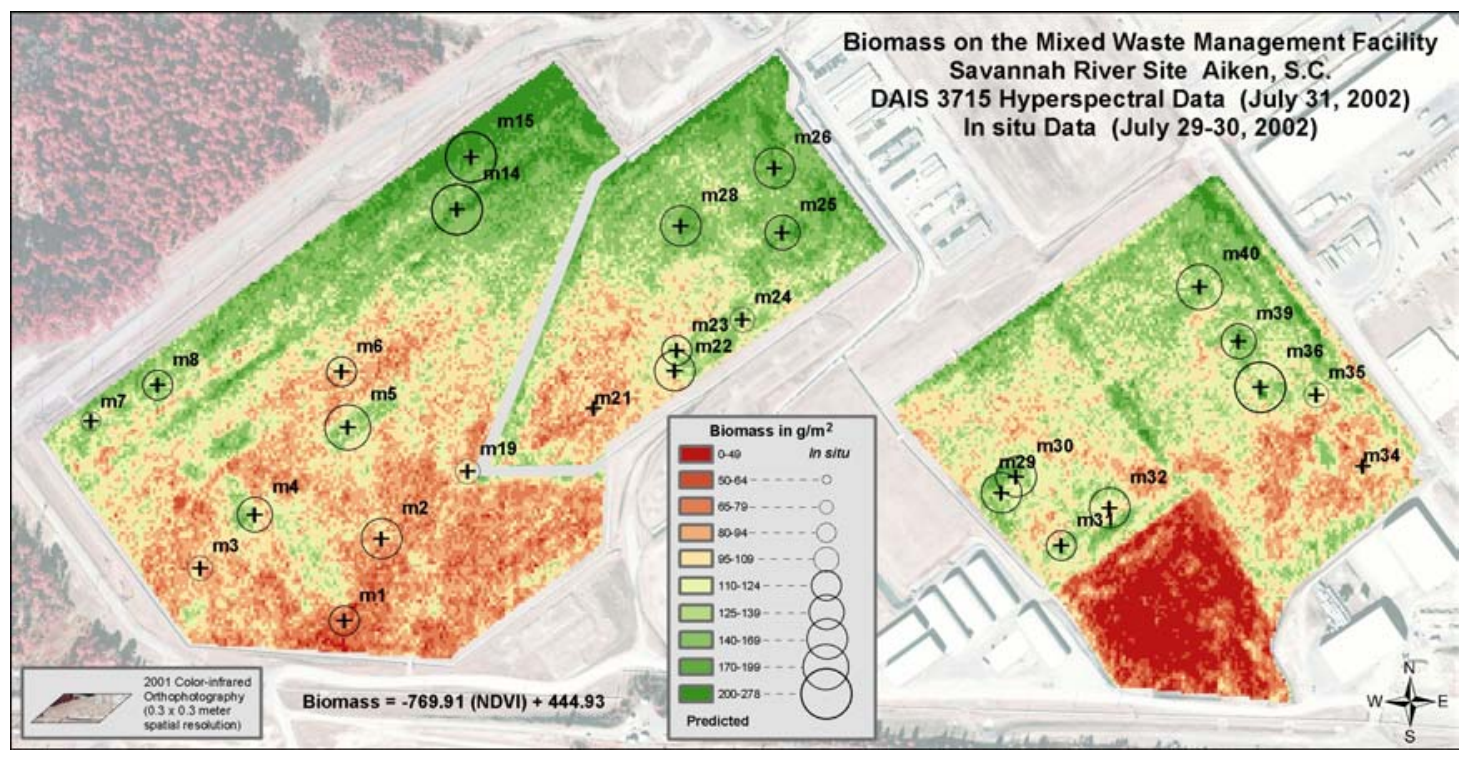

Figure 28. The spatial distribution of biomass on the Mixed Waste Management Facility. This map was created using a vegetation index derived from GER middle-infrared (Band 29; $2161.6 \mathrm{~nm}$ ) and red (Band 11; $682.4 \mathrm{~nm}$ ) reflectance data correlated with 28 in situ bahiagrass and centipede biomass measurements shown.

\subsection{Narrow-band Derivative-based Vegetation Indices}

A variety of narrow-band derivative-based vegetation indices were computed and analyzed. For instance, several derivative vegetation indices that measure the amplitude of the chlorophyll red-edge using hyperspectral data in the $626 \mathrm{~nm}$ to $795 \mathrm{~nm}$ spectral range were implemented based on the following algorithms (Equations 12-14) (Elvidge and Chen, 1995):

$$
\begin{aligned}
& \text { 1DL_DGVI }=\sum_{\lambda_{1}}^{\lambda_{n}}\left|R^{\prime}\left(\lambda_{i}\right)-R^{\prime}\left(\lambda_{1}\right)\right| \Delta \lambda_{i} \\
& \text { 1DZ_DGVI }=\sum_{\lambda_{1}}^{\lambda_{n}}\left|R^{\prime}\left(\lambda_{i}\right)\right| \Delta \lambda_{i} \\
& \text { 2DZ_DGVI }=\sum_{\lambda_{1}}^{\lambda_{n}}\left|R^{\prime \prime}\left(\lambda_{i}\right)\right| \Delta \lambda_{i}
\end{aligned}
$$

where $i$ is the band number; $\lambda_{i}$ is the center wavelength for the $i$ th channel; $\lambda 1=626 \mathrm{~nm} ; \lambda 2=795 \mathrm{~nm}$; $1 \mathrm{DZ}$ is the $1^{\text {st }}$ derivative reflectance; and $2 \mathrm{DZ}$ is the $2^{\text {nd }}$ derivative reflectance. The actual red-edge wavelength range used in this study included GER band $8(627.6 \mathrm{~nm})$ to band $17(787.6 \mathrm{~nm})$. We also extended the logic of Elvidge and Chen (1995) and computed a third-order narrow-band derivative-based vegetation index (Equation 15):

$$
\text { 3DZ_DGVI }=\sum_{\lambda_{1}}^{\lambda_{n}}\left|R^{\prime \prime \prime}\left(\lambda_{i}\right)\right| \Delta \lambda_{i}
$$

where $R^{\prime \prime \prime}$ is the $3^{\text {rd }}$ derivative reflectance. Unfortunately, none of these narrow-band derivative-based vegetation indices were highly correlated with the in situ biomass data. 


\subsubsection{Physiological Reflectance Index (PRI)}

The physiological reflectance index (PRI) (Gamon et al., 1992) is a narrow-band index that has been correlated with the epoxidation state of the xanthophyll cycle pigments and with photosynthetic efficiency with respect to control (unstressed) and nitrogen-stressed canopies. However, the PRI is generally not well correlated with water-stressed canopies experiencing mid-day wilting. The PRI employs the reflectance at approximately 531 $\mathrm{nm}$ and a reference channel in order to minimize the effects of diurnal sun angle changes; thus, the PRI can track diurnal changes in photosynthetic efficiency. The best PRI noted in Gamon et al. (1992) was (Equation 16):

$$
P R I=\frac{550 \mathrm{~nm}-531 \mathrm{~nm}}{550 \mathrm{~nm}+531 \mathrm{~nm}}
$$

Since the present research was only concerned with imagery acquired at one time on one date, this specific feature was not particularly important, but the nature of the information provided by the PRI was believed to be useful. In addition, such an index may be useful in situations where in situ spectroradiometer data are acquired at a different time and/ or light regime geometry than the remote sensor data; the PRI could be computed from both data sources. This study used the following bands for the PRI (Equation 17):

$$
P R I \# 1=\frac{549.6 \mathrm{~nm}-532.9 \mathrm{~nm}}{549.6 \mathrm{~nm}+532.9 \mathrm{~nm}}
$$

where GER band 4 is centered on $549.6 \mathrm{~nm}$ and GER band 3 is centered at $532.9 \mathrm{~nm}$. A reference wavelength of $549.6 \mathrm{~nm}$ seems to be appropriate at the canopy level; for leaf-scale spectra, a reference wavelength of 570 $\mathrm{nm}$ is likely more optimal for a xanthophyll signal (Equation 18).

$$
P R I \# 2=\frac{566 n m-532.9 n m}{566 n m+532.9 n m}
$$

Note that a single PRI is not likely to be applicable across all spatial and temporal scales, as well as various canopy types and diurnally dynamic canopy structures.

In contrast with the PRI, the NDVI does not accurately indicate real-time photosynthetic fluxes. While NDVI is often sensitive at low leaf area index (LAI) values, it often saturates at high LAI values. The PRI may be able to indicate short-term changes in photosynthetic efficiency, especially in canopies with high LAI values where the NDVI is least effective (Gamon et al., 1992). Unfortunately, none of these narrow-band derivative-based vegetaton indices were highly correlated with the in situ biomass data.

\subsubsection{Normalized Difference Water Index (NDWI)}

The amount of water present in the leaves of turfgrass was deemed to be important. The Normalized Difference Water Index (NDWI) was used to remotely determine vegetation liquid water content. Two near-IR channels were used in the computation of the NDWI; one centered at approximately $860 \mathrm{~nm}$ and the other centered as close as possible to $1240 \mathrm{~nm}$ (Equation 19) (Gao, 1996):

$$
N D W I=\frac{864.1 \mathrm{~nm}-1147.8 \mathrm{~nm}}{864.1 \mathrm{~nm}+1147.8 \mathrm{~nm}}
$$

In this research, the actual wavelengths used in the computation of the NDWI were GER bands $21(864.1 \mathrm{~nm})$ and $25(1447.8 \mathrm{~nm})$. 
In addition to the traditional normalized water index based on reflectance centered on $864 \mathrm{~nm}$, an additional normalized difference vegetation index based on the use of middle-infrared reflectance was developed (Equation 20):

$$
M I D-N D W I=\frac{864.1 \mathrm{~nm}-2161.6 \mathrm{~nm}}{864.1 \mathrm{~nm}+2161.6 \mathrm{~nm}}
$$

based on the use of band $21(864.1 \mathrm{~nm})$ and band $29(2161.6 \mathrm{~nm})$. The MID-NDWI image was regressed with the in situ unstressed bahiagrass and centipede biomass data at 28 locations. This resulted in a correlation coefficient $(r)$ of 0.71 based on a linear function and 0.81 when a power function was applied accounting for $51 \%$ and $65 \%$ of the variance, respectively (Figure 29).

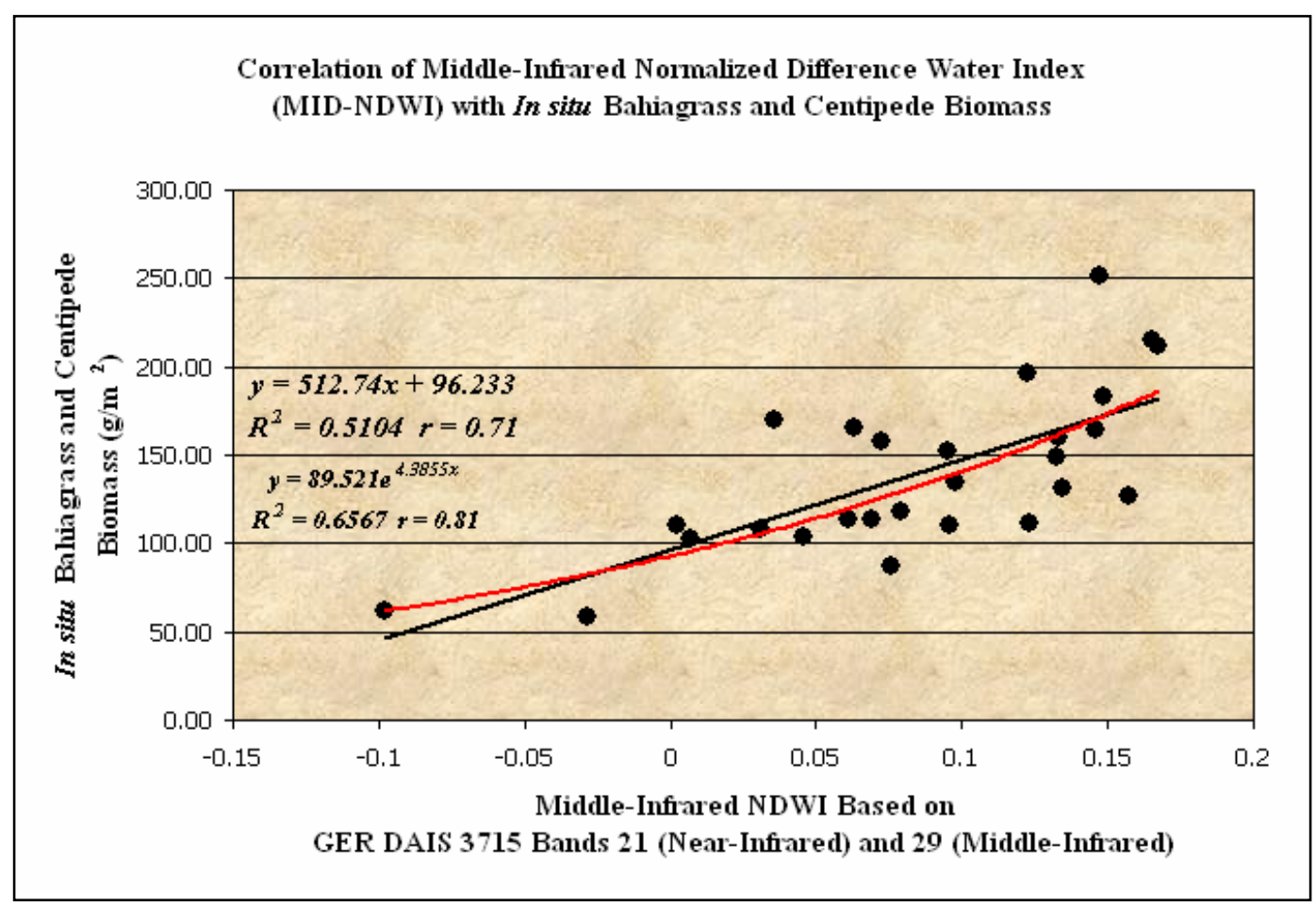

Figure 29. The regression relationship between a normalized diffferenc water index (MID-NDWI) derived from GER middle-infrared (Band 21; $864.1 \mathrm{~nm}$ ) and red (Band 29; $2161.6 \mathrm{~nm}$ ) reflectance data and $28 \mathrm{in} \mathrm{situ}$ bahiagrass and centipede biomass measurements.

The regression relationship was used to create a map of the biomass of the MWMF (Figure 30). The general north to south trends previously discussed appear to apply. However, the MID-NDWI predicts slightly more biomass than the MID-NDVI map previously discussed (refer to Figure 28). The MID-NDWI biomass map may be more accurate, however, because it is based on an equation that accounts for more of the variance in the relationship (MID-NDWI accounts for 65\% versus MID-NDVI 55\%). 


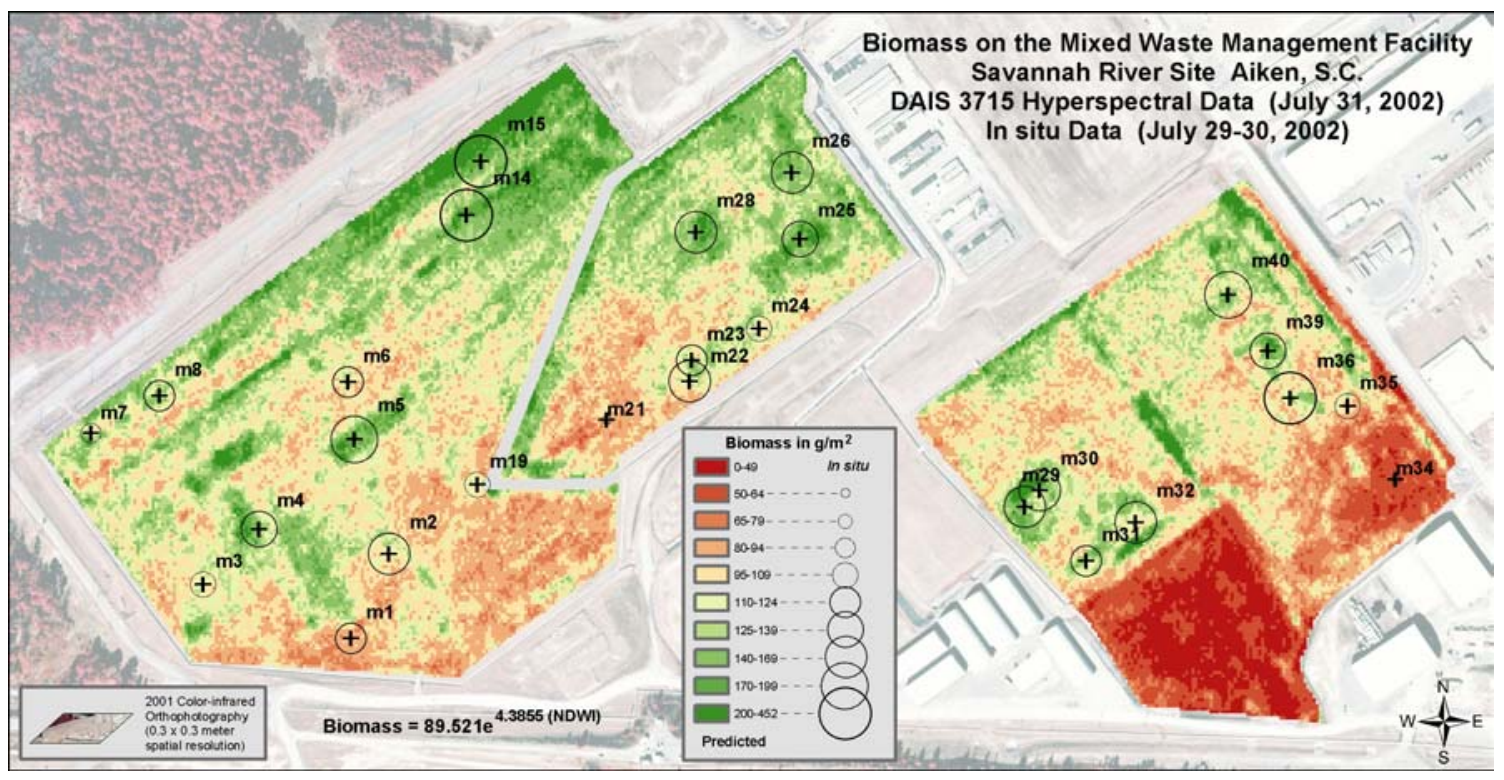

Figure 30. The spatial distribution of biomass on the Mixed Waste Management Facility. This map was created using a normalized difference water index (MI-NDWI) derived from GER middle-infrared (Band 21; $864.1 \mathrm{~nm}$ ) and red (Band 29; $2161.6 \mathrm{~nm}$ ) reflectance data correlated with 28 in situ bahiagrass and centipede biomass measurements shown.

\subsubsection{Red-edge Position (REP) Determination}

The red edge position (REP) is defined as the point of maximum slope on a vegetation reflectance spectrum between the red and near-infrared wavelengths. The REP is useful because it is strongly correlated with foliar chlorophyll content and can be a sensitive indicator of vegetation stress. Estimating the REP can be sensitive to the bandwidths and their positions. Furthermore, although the GER sensor has a nominal band separation of 30 $\mathrm{nm}$, subtle REP shifts may still not be discernible since the spectra are still sampled coarsely relative to laboratory spectrometers (Dawson and Curran, 1998). However, given this caveat, an attempt was made to correlate in situ biomass data with initial REP estimates.

In the present research, a linear method proposed by Clevers (1994) was implemented that makes use of four relatively narrow GER DAIS 3715 channels (Equation 21 and 22):

$$
R E P=700+40\left[\frac{R_{\text {red edge }}-701.1 n m}{732.1 n m-701.1 n m}\right]
$$

where

$$
R_{\text {red edge }}=\frac{663.4 \mathrm{~nm}-787.6 \mathrm{~nm}}{2}
$$

and band $10=663.4 \mathrm{~nm}$; band $12=701.1 \mathrm{~nm}$; band $14=732.1 \mathrm{mn}$; and band $17=787.6 \mathrm{~nm}$. Unfortunately, the REP image did not correlate well with the in situ biomass data. 


\section{Summary}

Waste storage site inspection has traditionally been a labor intensive, time consuming job, performed primarily on the ground using visual inspection and hand-held instrumentation. Waste storage site inspection is a particularly important issue at the Westinghouse Savannah River Site because there are over 100 sites scattered throughout the 300 square mile Department of Energy facility making it difficult to continually monitor all of the facilities. Thus, the use of remote sensing has the potential for assisting in the systematic monitoring of the waste sites. The goal is to use remote sensing technology to identify surface anomalies on the storage sites as early as possible. The anomalous areas are then targeted for intensive in situ human examination and measurement. The goal is to identify problems as soon as possible so that remedial work can take place rapidly to maintain the integrity of the storage sites (Kelch et al., 2001).

The central and southeast portions of the MWMF were built in 1989-1990. The mixed waste materials were stored by covering them with a compacted layer of kaolin clay and over-seeding primarily with bahiagrass. The area was not dynamically compacted by dropping a large weight. It has several linear concrete surface drains but no internal (subsurface) drainage system.

Engineers responsible for maintaining the integrity of the capped facilities go to great lengths to stabilize the topsoil in order to avoid surface erosion and subsequent compromise of the clay caps. Stabilization of the surface is usually performed by seeding or sodding it with a low-maintenance turfgrass that is adapted to southeastern environments. Until recently, bahiagrass [Paspalum notatum Flugge var. saurae Parodi] was the ground cover vegetation of choice because it is widely adapted to sandy soils, tolerates low fertility, drought, intermittent flooding, and heavy, continuous grazing (Gates et al., 1999). Recently, some centipede grass was introduced in specific locations to increase ground cover. Centipedes [Eremochloa ophiuroides (Munro) Hack.] is a common low-maintenance warm-season turfgrass adapted to the southeastern United States that yields seedheads from mid-summer to early fall. Regular mowing is often needed in order to maintain a quality turf (Johnson, 1993). It is adapted to low fertility, shoot growth rate is slow, and frequent mowing is not needed until mid- summer (Johnson, 1993). In areas where the centipede competes with bahiagrass, the bahiagrass may become stressed. All vegetation on the clay caps is now mowed. Tree saplings or shrubs are removed. Prior to 1998, the dead biomass was harvested as hay. In January, 1999, the grass on the facilities was burned to remove the buildup of dead biomass and thatch.

Based on this hyperspectral investigation, the following observations can be made:

- Hyperspectral data were useful for preparing a land cover classification of the Mixed Waste Management Facility (MWMF) using a spectral angle mapper (SAM) algorithm and image-derived spectral endmembers. The overall accuracy for four classes (Bahaigrass, Centipede, Bare Soil, and Concrete) was $89.79 \%$ with a Kappa Coefficient of Agreement of 85. This suggests that the type of vegetation present on a clay-cap may be monitored accurately though time to document the spatial distribution and conditions (i.e. biomass) of desired species, and possible invasion by unwanted species.

- Correlation coefficients $(r)$ of approximately 0.74 to 0.81 were obtained when middle-infrared vegetation and water indices (MID-NDVI and MID-NDWI, respectively) were regressed with the biomass present in 28 unstressed bahiagrass and centipede in situ locations. This methodology accounted for $55 \%$ to $65 \%$ of the variance in the relationship. This suggests that the methodology may be used to monitor the spatial distribution of biomass on a clay-cap through time to identify analmous vegetation behavior.

- Derivative spectroscopy yielded relatively good correlation with in situ biomass measurement but not to the degree of the aforementioned MID-NDVI and MID-NDWI. The highest derivative correlation with biomass was found using $1^{\text {st }}$ derivative band 25 where $r=0.6417$. If an exponential function is used $r=0.696$. It is interesting to note that the derivative bands that showed the greatest promise of predicting biomass were also associated with the middle-infrared region. 
WSRC-TR-2003-00275, REVISION 0

Future research on the monitoring of hazardous waste site surface conditions using remote sensing techniques should consider:

- obtaining more in situ information about the exact treatment of the hazardous waste sites, including: age of the closure, degree of soil compaction, soil taxa, type of cap (clay, geosynthetic), soil moisture at the exact time of overflight, and location of buried hazardous waste (especially burial ground layout).

- incorporating a multispectral approach wherein information on soil and plant moisture is obtained directly using passive microwave and/or thermal infrared remote sensing techniques.

- obtaining precise information on elevation using either photogrammetric and/or LIDAR remote sensing techniques.

- obtaining hyperspectral data using an instrument that collects data in programmable regions of the electromagnetic spectrum (e.g., CASI-2, HyMap).

- documenting the bi-directional reflectance distribution function (BRDF) associated with the major hazardous waste site cover types so that the hyperspectral data are obtained at the optimum time of day and/or time of year and at the most appropriate altitude and sensor look direction.

- applying the remote sensing technology to a controlled hazardous waste site environment where there are programmed, known treatments applied to the sites, including: controlled subsidence, soil moisture variation, plant moisture stress, the introduction of scrub-shrub deep-rooted vegetation, fertilization variation, various mowing methods and/or directions, and prescribed burning treatments. 


\section{References}

Boardman, J. W., 1993, "Automating Spectral Unmixing of AVIRIS Data Using Convex Geometry Concepts," Summaries of the 4th Annual JPL Airborne Geoscience Workshop, JPL Publication 93-26, 1:11-14.

Boardman, J. W., 1997, "Mineralogic and Geochemical Mapping at Virginia City, Nevada Using 1995 AVIRIS Data," Proceedings, 12th Thematic Conference on Geological Remote Sensing, Ann Arbor: Environmental Research Institute of Michigan, Vol I:21-28.

Boardman, J. W. and F. A. Kruse, 1994, “Automated Spectral Analysis: A Geological Example Using AVIRIS Data, North Grapevine Mountains, Nevada," Proceedings, 10th Thematic Conference on Geologic Remote Sensing, Ann Arbor: Environmental Research Institute of Michigan, Vol I:407-418.

Boardman, J. W., and J. F. Huntington, 1997, "Mineralogic and Geochemical Mapping at Virginia City, Nevada using 1995 AVIRIS Data," Twelfth International Conference and Workshops on Applied Geologic Remote Sensing, Denver, CO, 17-19 November, I:191-196.

Chang, 2002, Correspondence with personnel of the Geophysical and Environmental Research Corporation.

Clevers, J. G. P. W., 1994, “Imaging Spectrometry in Agriculture - Plant Vitality and Yield Indicators", in Imaging Spectrometry A Tool for Environmental Observations, J. Hill and J. Megier (Eds.), Dordrecht: Kluwer Academic, 193-219.

Conel, J. E., Green, R. O., Vane, G., Bruegge, C. J., and R. E. Alley, 1987, “AIS-2 Radiometry and a Comparison of Methods for the Recovery of Ground Reflectance", Proceedings 3rd Airborne Imaging Spectrometer Data Analysis Workshop (G. Vane, Ed.), JPL Publication 87-30, Jet Propulsion Laboratory, Pasadena, CA, 18-47.

CSES, 1999, ATmosphere REMoval Program (ATREM) User's Guide 3.1, Boulder, Center for the Study of Earth from Space, $31 \mathrm{p}$.

Dawson, T. P. and P. J. Curran, 1998, “A New Technique for Interpolating the Reflectance Red Edge Position," International Journal of Remote Sensing, 19(11):2133-2139.

Demetriades-Shah, T. H., Steven, M. D., and J. A. Clark, 1990, "High Resolution Derivative Spectra in Remote Sensing," Remote Sensing of Environment, 33:55-64.

Elvidge, C. D., and Z. Chen, 1995, "Comparison of Broad-band and Narrow-band Red and Near-infrared Vegetation Indices," Remote Sensing of Environment, 54:38-48.

Farrand, W. H., Singer, R. B., and E. Merenyi, 1994, "Retrieval of Apparent Surface Reflectance from AVIRIS Data: A Comparison of Empirical Line, Radiative Transfer, and Spectral Mixture Methods," Remote Sensing of Environment, 47:311-321.

Feinstein, A. R., 1998, “Kappa Test of Concordance,” in Encyclopedia of Statistical Sciences, New York: Wiley-Interscience, Vol. 2, 351-352.

Filippi, A. M., 1998, "Hyperspectral Image Classification Using a Batch Descending Fuzzy Learning Vector Quantization Artificial Neural Network: Vegetation Mapping at the John F. Kennedy Space Center," unpublished Masters Thesis, Columbia: University of South Carolina, 276 p.

Gamon, J. A., Penuelas, J., and C. B. Field, 1992, “A Narrow- waveband Spectral Index That Tracks Diurnal Changes in Photosynthetic efficiency," Remote Sensing of Environment, 41:35-44.

Gao, B. C., Heidebrecht, K. B. and A. F. H. Goetz, 1999, ATmosphere REMoval Program (ATREM) User's Guide 3.1, Bolder, Center for the Study of Earth from Space, $31 \mathrm{p}$. 
WSRC-TR-2003-00275, REVISION 0

Gao, B. C., 1996, "NDWI - A Normalized Difference Water Index for Remote Sensing of Liquid Water from Space," Remote Sensing of Environment, 58:257-266.

Gates, R. N., Hill, G. M. and G. W. Burton, 1999, "Response of Selected and Unselected Bahiagrass Populations to Defoliation," Agronomy Journal, 91:787-795.

GER, 1998, Correspondence with personnel of the Geophysical and Environmental Research Corporation.

Goetz, A., Vane, G., Solomon, J. E., and B. N. Rock, 1985, "Imaging Spectrometry for Earth Remote Sensing," Science, 228(4704):1147-1153.

Green, A. A., Berman, M., Switzer, P., and M. D. Craig, 1988, “A Transformation for Ordering Multispectral Data in Terms of Image Quality with Implications for Noise Removal," IEEE Transactions on Geoscience and Remote Sensing, 26(1):65-74.

Hildebrand, F. B., 1956, Introduction to Numerical Analysis, New York: McGraw-Hill, 511 p.

InSpec LLC, 2002, Atmospheric CORrection Now (ACORN), InSpec, LLC.

Irvine, J. M., Evers, T. K., Smyre, J. L., Huff, D., King, A. L., Stahl, G., and J. Odenweller, 1997, “The Detection and Mapping of Buried Waste," International Journal of Remote Sensing, 18(7):1583-1595.

Jensen, J. R., 1996, Introductory Digital Image Processing: A Remote Sensing Perspective, Upper Saddle River: Prentice-Hall, Inc., 318 p.

Jensen, J. R., 2000, Remote Sensing of the Environment: An Earth Resource Perspective, Upper Saddle River: Prentice-Hall, Inc., 544 p.

Johnson, B. J., 1993, "Frequency of Plant Growth Regulator and Mowing Treatments: Effects on Injury and Suppression of Centipedegrass," Agronomy Journal, 85:276-280.

Kelch, D., Jensen, J. R., Filippi, T., and J. Gladden, 2001, "Hyperspectral Analysis of Hazardous Waste Sites," presented at the NASA Hyperspectral EOCAP Conference, MS: Stennis Space Center with MTL, Inc., $150 \mathrm{p}$.

Kruse, F. A., 1994, "Imaging Spectrometer Data Analysis — A Tutorial," Proceedings, International Symposium on Spectral Sensing Research, 1994, 11 pp.

Kruse, F. A., K. S. Kierein-Young, and J. W. Boardman, 1990, "Mineral Mapping at Cuprite, Nevada, with a 63-Channel Imaging Spectrometer," Photogrammetric Engineering \& Remote Sensing, 56(1):83-92.

Kruse, F. A., Lefkoff, A. B., Boardman, J. B., Heidebrecht, K. B., Shapiro, A. T., Barloon, P. J., and A. F. H. Goetz, 1993, "The Spectral Image Processing System (SIPS) - Interactive Visualization and Analysis of Imaging spectrometer Data," Remote Sensing of Environment, 44:145-163.

Li, Y., Demetriades-Shah, T. H., Kanemasu, E. T., Shultis, J. K., and K. B. Kirkham, 1993, "Use of Second Derivatives of Canopy Reflectance for Monitoring Prairie Vegetation over Different Soil Backgrounds," Remote Sensing of Environment, 44:81-87.

Malthus, T. J. and A. C. Madeira, 1993, "High Resolution Spectroradiometry: Spectral Reflectance of Field Bean Leaves Infected by Botrytis fabae," Remote Sensing of Environment, 45:107-116.

O’Haver, T. C., 1982, "Derivative Spectroscopy and its Applications in Analysis: Derivative Spectroscopy: Theoretical Aspects," Plenary lecture, Anal. Proc. 54:22-28.

Penuelas, J., Gamon, J. A., Griffin, K. L., and C. B. Field, 1993, “Assessing Community Type, Plant Biomass, Pigment Composition, and Photosynthetic Efficiency of Aquatic Vegetation from Spectral Reflectance," Remote Sensing of Environment, 46:110-118. 
WSRC-TR-2003-00275, REVISION 0

Philpot, W. D., 1991, “The Derivative Ratio Algorithm: Avoiding Atmospheric Effects in Remote Sensing," IEEE Transactions on Geoscience and Remote Sensing, 29(3):350-357.

Pendergast, M. M., 2002, An Analysis of SRTC Meteorological Data Relevant to Ground Truth Data Collected During the Over Flight of SRS Waste Sites on July 31, 2002, Report to Savannah River Technology Center, Aiken, SC, 3 p.

Research Systems Inc., 2000, ENVI Extension User's Guide, Boulder: Research Systems, Inc., 30 p.

Research Systems Inc., 2000, ENVI User's Guide, Boulder: Research Systems, Inc., 864 p.

Roberts, D. A., Yamagushi, Y., and Lyon, R. J. P., 1986, "Comparison of Various Techniques for Calibration of AIS Data, Proceedings, 2nd Airborne Imaging Spectrometer Data Analysis Workshop (G. Vane and A. F. H. Goetz, Eds.), JPL Publication 86-35, Jet Propulsion Laboratory, Pasadena, CA, pp. 21-30.

Rubin, T. D., 1993, "Spectral Mapping with Imaging Spectrometers," Photogrammetric Engineering \& Remote Sensing, 59(2):215-220.

Talsky, G., 1994, Derivative Spectrophotometry: Low and Higher Order, New York: VCH Publishers, Inc., $228 \mathrm{p}$.

Terry, S., 2002, Personal correspondence, SpectraTech, Inc.

Theseria, M. A., Thomas, G., and C. A. D. Sannier, 2002, “An Evaluation of Spectral Mixture Modelling Applied to A Semi-arid Environment," International Journal of Remote Sensing, 23(4):687-700.

Tsai, F., and Philpot, W., 1998, "Derivative Analysis of Hyperspectral Data," Remote Sensing of Environment, $66: 41-51$

Tucker, C. J., 1979, "Red and Photographic Infrared Linear Combinations for Monitoring Vegetation," Remote Sensing of Environment, 8:127-150.

Vane, G. and A. F. H. Goetz, 1993, “Terrestrial Imaging Spectrometry: Current Status, Future Trends," Remote Sensing of Environment, 44:117-126.

Vincent, R. K., 1994, "Remote Sensing for Solid Waste Landfills and Hazardous Waste Sites," Photogrammetric Engineering \& Remote Sensing, 60(8):979-982. 